Keywords: Gadolinium, CPC, neutron poison

Retention: Permanent

\title{
Partitioning of Gadolinium in the Chemical Processing Cell
}

\author{
S. H. Reboul \\ D. R. Best \\ M. E. Stone \\ D. R. Click
}

April 2011

Savannah River National Laboratory Savannah River Nuclear Solutions Aiken, SC 29808

Prepared for the U.S. Department of Energy under contract number DE-AC09-08SR22470.

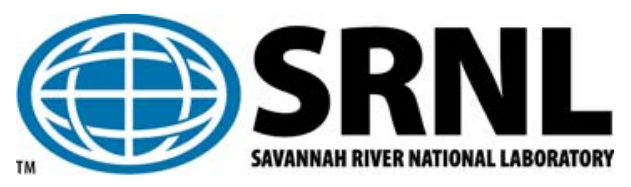


SRNL-STI-2010-00804

Revision 0

\section{DISCLAIMER}

This work was prepared under an agreement with and funded by the U.S. Government. Neither the U.S. Government or its employees, nor any of its contractors, subcontractors or their employees, makes any express or implied:

1. warranty or assumes any legal liability for the accuracy, completeness, or for the use or results of such use of any information, product, or process disclosed; or

2. representation that such use or results of such use would not infringe privately owned rights; or

3. endorsement or recommendation of any specifically identified commercial product, process, or service.

Any views and opinions of authors expressed in this work do not necessarily state or reflect those of the United States Government, or its contractors, or subcontractors.

\section{Printed in the United States of America}

Prepared for U.S. Department of Energy 


\section{REVIEWS AND APPROVALS}

\section{AUTHORS:}

S. H. Reboul, Process Technology Programs

Date

D. R. Best, Process Science Analytical Laboratory

Date

M. E. Stone, Process Technology Programs

Date

D. R. Click, Analytical Development

Date

TECHNICAL REVIEW:

J. M. Pareizs, Process Technology Programs

Date

D. P. Lambert, Process Technology Programs

Date

\section{APPROVAL:}

D. K. Peeler, WP-4/5 SRNL Representative

Date

Process Technology Programs

C. C. Herman, Manager

Date

Process Technology Programs

S. L. Marra, Manager

Date

Environmental \& Chemical Process Technology Research Programs 


\section{ACKNOWLEDGEMENTS}

The following individuals are acknowledged for contributing to this study: Whitney Riley and Pat Simmons, who provided the analytical support for the simulant testing; Vickie Williams, Irene Reamer, Jon DuVall, Tony Burckhalter, and Phyllis Workman, who performed the SRAT runs; David Koopman, who provided guidance during the SRAT runs; Brad Pickenheim, who provided applicable data from his alternative reductant SRAT testing; Dee Wheeler, Lucy Beasley, Mona Galloway, and Phyllis Burkhalter, who performed the real-waste beaker tests; Boyd Wiedenman and Mark Jones, who performed the ICP-AES analyses for the real-waste testing; and Curtis Johnson, who performed the ICP-MS analyses for the real-waste testing. The assistance of each of these individuals is appreciated. 


\section{EXECUTIVE SUMMARY}

A combination of short-term beaker tests and longer-duration Sludge Receipt and Adjustment Tank (SRAT) simulations were performed to investigate the relative partitioning behaviors of gadolinium and iron under conditions applicable to the Chemical Processing Cell (CPC). The testing was performed utilizing non-radioactive simple Fe-Gd slurries, non-radioactive Sludge Batch 6 simulant slurries, and a radioactive real-waste slurry representative of Sludge Batch 7 material. The testing focused on the following range of conditions: a) Fe:Gd ratios of 25-100; b) pH values of $2-6$; c) acidification via addition of nitric, formic, and glycolic acids; d) temperatures of $\sim 93{ }^{\circ} \mathrm{C}$ and $\sim 22^{\circ} \mathrm{C}$; and e) oxalate concentrations of $<100 \mathrm{mg} / \mathrm{kg}$ and $\sim 10,000 \mathrm{mg} / \mathrm{kg}$. The purpose of the testing was to provide data for assessing the potential use of gadolinium as a supplemental neutron poison when dispositioning excess plutonium. Understanding of the partitioning behavior of gadolinium in the CPC was the first step in assessing gadolinium's potential applicability.

Significant fractions of gadolinium partitioned to the liquid-phase at $\mathrm{pH}$ values of 4.0 and below, regardless of the Fe:Gd ratio. In SRAT simulations targeting nitric and formic acid additions of $150 \%$ acid stoichiometry, the $\mathrm{pH}$ dropped to a minimum of 3.5-4.0, and the maximum fractions of gadolinium and iron partitioning to solution were both $\sim 20 \%$. In contrast, in a SRAT simulation utilizing a nitric and formic acid addition under atypical conditions (due to an anomalously low insoluble solids content), the $\mathrm{pH}$ dropped to a minimum of 3.7 , and the maximum fractions of gadolinium and iron partitioning to solution were $\sim 60 \%$ and $\sim 70 \%$, respectively. When glycolic acid was used in combination with nitric and formic acids at $100 \%$ acid stoichiometry, the $\mathrm{pH}$ dropped to a minimum of 3.6-4.0, and the maximum fractions of gadolinium and iron partitioning to solution were $60-80 \%$ and $3-5 \%$, respectively. Thus, the presence of glycolic acid increased dissolution of gadolinium, but decreased dissolution of iron.

In beaker tests, the fractions of gadolinium partitioning to solution were all less than the minimum detection limits at $\mathrm{pH} 6$, on the order of a few percent at $\mathrm{pH} 4$, and ranging from $70-90 \%$ at $\mathrm{pH} 2$. In contrast, the fractions of iron partitioning to solution were all less than the minimum detection limits at $\mathrm{pH} 6, \leq 0.04 \%$ at $\mathrm{pH} 4$, and $\leq 0.9 \%$ at $\mathrm{pH} 2$. A possible explanation for the small magnitude of these fractions (as compared to the fractions observed in the SRAT simulations) was incomplete equilibrium, due to the short duration (30 minutes) of the beaker tests. As demonstrated by the SRAT simulations, the typical partitioning equilibration time was on the order of hours.

The Fe:Gd ratio appeared to impact the extent of liquid-phase conditions under certain conditions, although the exact relationship was not clear. Temperature impacts on the liquid-phase gadolinium concentrations were modest, with liquid phase concentrations typically increasing about $25 \%$ as temperatures rose from $\sim 2{ }^{\circ} \mathrm{C}$ to $\sim 93{ }^{\circ} \mathrm{C}$. The presence of high concentrations of oxalate did not appear to change the liquid-phase gadolinium concentrations - however, it did increase the liquid-phase iron concentrations (from being undetectable to being detectable but still minor). 
Additional gadolinium partitioning testing is recommended. Of greatest usefulness will be SRAT simulations focusing on a wider range of acid addition scenarios and alternate sludge compositions, particularly those specific to future sludge batches where addition of excess plutonium is being considered. 


\section{TABLE OF CONTENTS}

LIST OF TABLES AIST OF FIGURES .




\section{LIST OF TABLES}

Table 4-1. Reagents Used to Generate the Simple Fe-Gd Slurries............................................. 13

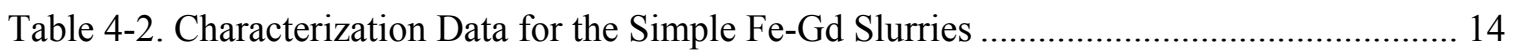

Table 4-3. Quantities of $\mathrm{Gd}\left(\mathrm{NO}_{3}\right)_{3} \cdot 6 \mathrm{H}_{2} \mathrm{O}$ Added to SB6 Simulants ......................................... 14

Table 4-4. Characterization Data for the SB6 Simulant Slurries.................................................. 15

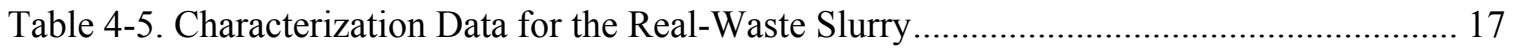

Table 4-6. Summary of SRAT Simulation Conditions.......................................................... 19

Table 5-1. Supernatant Constituent Concentrations in Simple Fe-Gd Slurries ............................ 22

Table 5-2. Soluble Portions of Gadolinium in the Simple Fe-Gd Slurries ................................... 22

Table 5-3. Soluble Portions of Iron in the Simple Fe-Gd Slurries .............................................. 22

Table 5-4. Supernatant Constituent Concentrations in the SB6-E Slurries ................................... 25

Table 5-5. Soluble Portions of Gadolinium in the SB6-E Slurries.............................................. 25

Table 5-6. Soluble Portions of Iron in the SB6-E Slurries ........................................................... 25

Table 5-7. Supernatant Constituent Concentrations in SB6-E Slurries with Added Oxalate........ 28

Table 5-8. Soluble Portions of Gadolinium in SB6-E Slurries with Added Oxalate..................... 28

Table 5-9. Soluble Portions of Iron in SB6-E Slurries with Added Oxalate ................................. 28

Table 5-10. Supernatant Constituent Concentrations in Real-Waste Slurry …............................. 30

Table 5-11. Soluble Portions of Constituents in Real-Waste Slurry ............................................ 30

Table 5-12. Liquid-Phase Concentrations, Partitioning, and pH during SB6-27 ........................ 33

Table 5-13. Liquid-Phase Concentrations, Partitioning, and pH during SB6-28 ….................... 36

Table 5-14. Liquid-Phase Concentrations, Partitioning, and pH during SB6-29 ........................ 39

Table 5-15. Liquid-Phase Concentrations, Partitioning, and pH during SB6-30 ........................ 42

Table 5-16. Liquid-Phase Concentrations, Partitioning, and pH during GF-13 .......................... 46

Table 5-17. Liquid-Phase Concentrations, Partitioning, and pH during GF-14 ......................... 49 


\section{LIST OF FIGURES}

Figure 5-1. Simple Fe-Gd Slurries: Supernatant Gd Concentrations at pH 2 and 4.................... 23

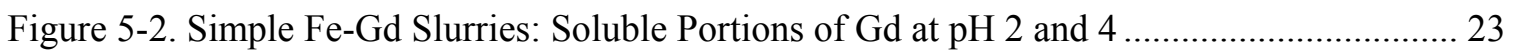

Figure 5-3. SB6-E Slurries: Supernatant Gd Concentrations at pH 2 and 4.............................. 26

Figure 5-4. SB6-E Slurries: Soluble Portions of Gd at pH 2 and 4 ........................................... 26

Figure 5-5. SB6-E Slurries w/ and w/o Added Oxalate: Soluble Portions of Gd......................... 28

Figure 5-6. Real-Waste Slurry: Supernatant Metal Concentrations at $\mathrm{pH} 2$ and 4...................... 30

Figure 5-7. Real-Waste Slurry: Soluble Portions of Metals at pH 2 and 4 ................................. 31

Figure 5-8. Summary of Beaker Test Gd Partitioning Data ...................................................... 32

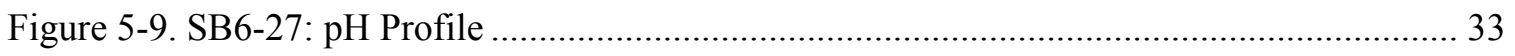

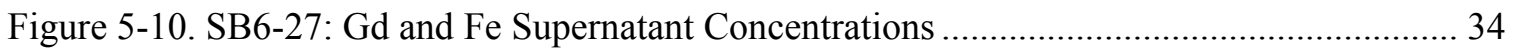

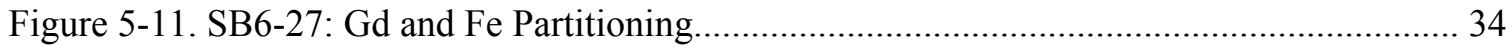

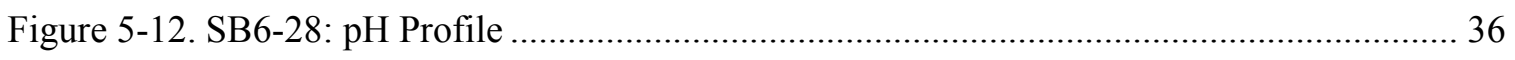

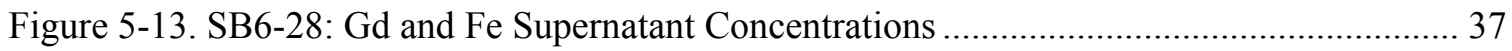

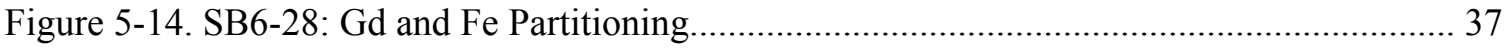

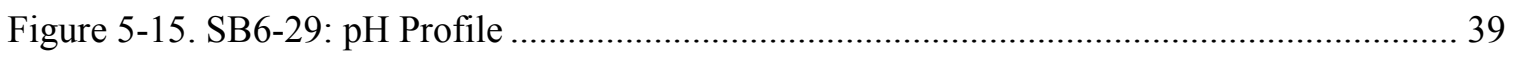

Figure 5-16. SB6-29: Gd and Fe Supernatant Concentrations .................................................. 40

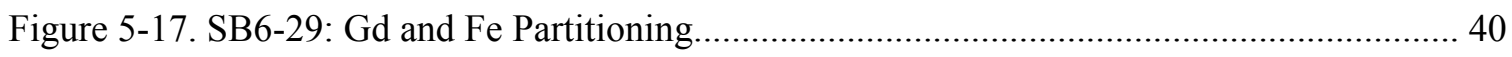

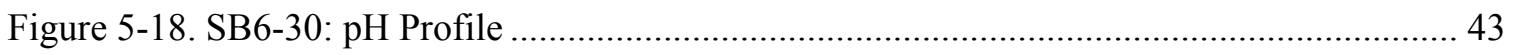

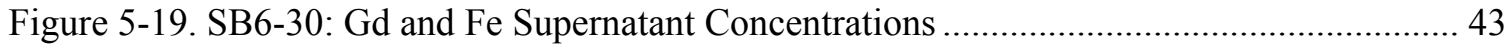

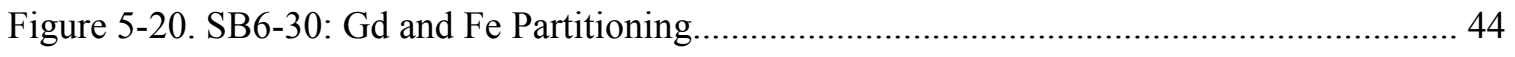

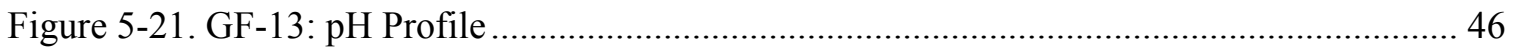

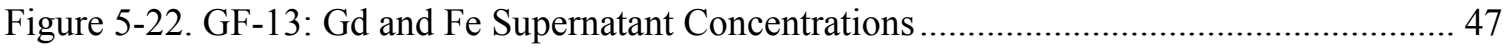

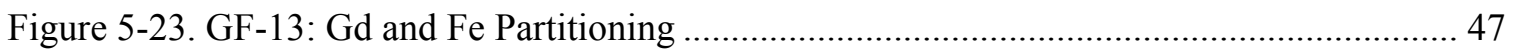

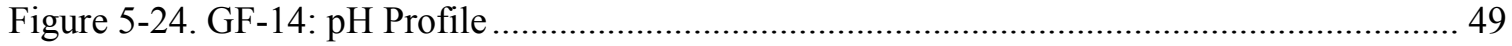

Figure 5-25. GF-14: Gd and Fe Supernatant Concentrations ................................................... 50

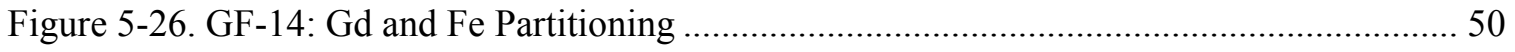




\section{LIST OF ABBREVIATIONS}

$\begin{array}{ll}\text { SRS } & \text { Savannah River Site } \\ \text { DWPF } & \text { Defense Waste Processing Facility } \\ \text { CPC } & \text { Chemical Processing Cell } \\ \text { DOE } & \text { Department of Energy } \\ \text { EM } & \text { Environmental Management } \\ \text { SRAT } & \text { Sludge Receipt \& Adjustment Tank } \\ \text { TTQAP } & \text { Task Technical and Quality Assurance Plan } \\ \text { PSAL } & \text { Process Science Analytical Laboratory } \\ \text { AD } & \text { Analytical Development } \\ \text { ICP-AES } & \text { Inductively coupled plasma-atomic emission spectroscopy } \\ \text { IC } & \text { Ion chromatography } \\ \text { ICP-MS } & \text { Inductively coupled plasma-mass spectrometry }\end{array}$




\subsection{INTRODUCTION}

Fissile material in the Savannah River Site (SRS) Tank Farm has historically been "neutron-poisoned" by the large quantity of iron inherent to the waste. As the sludge is transferred to the Defense Waste Processing Facility (DWPF), the same iron has provided criticality protection during treatment in the Chemical Processing Cell (CPC) and in the final glass waste form.

Potential disposition of excess plutonium via the Tank Farm and/or DWPF is currently being considered. Such disposition would require introduction of additional neutronpoisoning material to assure criticality safety. To minimize the impact on DWPF production, use of a poisoning material more efficient than iron will likely be necessary. One promising alternative is gadolinium, which absorbs neutrons so efficiently that the mass requirements for criticality safety are two orders of magnitude lower than for iron.

Based on a review of the pre-existing gadolinium solubility data, ${ }^{1}$ a conclusion was drawn that insufficient information was available to quantify gadolinium partitioning and subsequent poisoning applicability in the CPC. The pre-existing data suggested that gadolinium solubilities were relatively high in the absence of iron and relatively low when Fe:Gd mass ratios were exceedingly high $(\geq 300)$. However, no data were available for the typical conditions anticipated if excess plutonium were to be added to the waste - namely, if the Fe:Gd ratios were on the order of 25-100.

Gadolinium solubility and partitioning data applicable to the CPC is the subject of this report.

This study was performed at the request of the Department of Energy (DOE)/EM-31 Office of Waste Processing. The work was authorized through a Task Change Request. The project and task numbers are HQTD1004 and WP-4.1.4, respectively.

\subsection{OBJECTIVES}

The overall goal of this study was to determine the solid-liquid phase partitioning behavior of gadolinium under conditions applicable to the CPC. Understanding of such partitioning behavior is integral to assessing the practicality of using gadolinium as a supplemental neutron poison when dispositioning excess plutonium.

The specific objective of the study was to quantify the fraction of gadolinium partitioning to the liquid phase over the following ranges of conditions:

1) Sludge slurry matrices with Fe:Gd mass ratios of 25-100. (Included amongst the slurry matrices tested were: a) simple sludge simulant with a solid phase comprised primarily of iron hydroxide and gadolinium hydroxide; b) more complex sludge simulant 
with a solid phase containing numerous metal hydroxides and oxides; and c) real-waste sludge slurry doped with gadolinium).

2) Slurry $\mathrm{pH}$ from 2-6. ( $\mathrm{pH}$ adjustments were performed utilizing: a) nitric acid; $\mathrm{b}$ ) formic acid; and c) glycolic acid).

3) Temperatures of $\sim 93{ }^{\circ} \mathrm{C}$ and $\sim 22^{\circ} \mathrm{C}$. $\left(93^{\circ} \mathrm{C}\right.$ is the typical $\mathrm{CPC}$ temperature during acid addition).

4) Oxalate concentrations of $\sim 0 \mathrm{mg} / \mathrm{kg}$ and $\sim 10,000 \mathrm{mg} / \mathrm{kg}$. (Oxalate is a chelator used for tank cleaning purposes and can raise the solubility of metals).

5) Equilibration times of 30 minutes and several hours. (Short-term equilibration was tested in small-scale beaker tests, while longer-term equilibration was tested in largerscale Sludge Receipt and Adjustment Tank [SRAT] simulations).

\subsection{QUALITY ASSURANCE}

This study was conducted in accordance with the quality assurance protocols identified in the Task Technical and Quality Assurance Plan (TTQAP). ${ }^{2}$ All of the raw data and ancillary information related to this study have been recorded in laboratory notebook SRNL-NB-2010-00102. ${ }^{3}$

\subsection{METHODOLOGY}

\subsection{Generation of Test Slurry Matrices}

Three primary types of slurry matrices were utilized in the testing: 1) simple nonradioactive slurries with solid phases consisting primarily of $\mathrm{Fe}(\mathrm{OH})_{3}$ and $\mathrm{Gd}(\mathrm{OH})_{3}$; 2) more complex non-radioactive slurries with solid phases containing several metal hydroxides and oxides (SRS sludge simulant); and 3) a real-waste sludge slurry containing several stable and radioactive constituents (SRS tank waste). The methods for generating and/or preparing each type of slurry matrix are presented below.

\section{Simple Fe-Gd Slurries}

The simple slurries were generated utilizing the following steps:

- Dissolve $\mathrm{Fe}\left(\mathrm{NO}_{3}\right)_{3} \cdot 9 \mathrm{H}_{2} \mathrm{O}$ and $\mathrm{Gd}\left(\mathrm{NO}_{3}\right)_{3} \cdot 6 \mathrm{H}_{2} \mathrm{O}$ in de-ionized water

- Add $\mathrm{NaOH}$ to precipitate iron and gadolinium hydroxides

- Allow insoluble solids to settle

- Decant supernatant to concentrate insoluble solids

Three 1-L batches of the simple slurry were prepared - one with an Fe:Gd ratio of 25, one with an Fe:Gd ratio of 50, and one with an Fe:Gd ratio of 100. The masses of 
reagents used to prepare each batch are given in Table 4-1. The simple slurries were utilized solely in the beaker tests.

Table 4-1. Reagents Used to Generate the Simple Fe-Gd Slurries

\begin{tabular}{|l|c|c|c|}
\hline \multirow{2}{*}{ Reagent } & \multicolumn{3}{|c|}{ Reagent Mass, g } \\
\cline { 2 - 4 } & Fe:Gd = 25 & Fe:Gd = 50 & Fe:Gd = 100 \\
\hline \hline $\mathrm{Fe}\left(\mathrm{NO}_{3}\right)_{3} \cdot 9 \mathrm{H}_{2} \mathrm{O}$ & 269.33 & 269.34 & 269.33 \\
\hline $\mathrm{Gd}\left(\mathrm{NO}_{3}\right)_{3} \cdot 6 \mathrm{H}_{2} \mathrm{O}$ & 4.26 & 2.15 & 1.08 \\
\hline $\mathrm{NaOH}$ & 83.32 & 80.53 & 80.27 \\
\hline
\end{tabular}

Note: For each batch, the quantities of reagents were mixed with sufficient water to produce a two liter slurry volume. Then after a settling period, one liter of supernatant was decanted from each to produce a final batch volume of approximately one liter.

For each batch, the $\mathrm{Fe}\left(\mathrm{NO}_{3}\right)_{3} \cdot 9 \mathrm{H}_{2} \mathrm{O}$ and $\mathrm{Gd}\left(\mathrm{NO}_{3}\right)_{3} \cdot 6 \mathrm{H}_{2} \mathrm{O}$ were added to approximately one liter of de-ionized water in a two liter capacity beaker. The contents of the beaker were stirred during and after reagent additions. Following dissolution of the iron and gadolinium salts, the $\mathrm{NaOH}$ was added. (Note that the $\mathrm{NaOH}$ was dissolved in about 500 $\mathrm{mL}$ de-ionized water prior to its addition - thus, it was added in the form of a solution with approximate concentration of $4 \mathrm{M}$ ).

As the $\mathrm{NaOH}$ was added, the metal salts precipitated out of solution, leaving $\mathrm{NaNO}_{3}$ as the predominant constituent dissolved in the liquid phase. Additional de-ionized water was mixed with the slurry to bring the total volume to approximately two liters. This produced a supernatant $\mathrm{NaNO}_{3}$ concentration of $\sim 1 \mathrm{M}$.

Following a settling period of 5-7 days (dependent on batch), approximately one liter of free supernatant was removed, via decanting. The remaining material (supernatant and insoluble solids) had a volume of approximately one liter, with an insoluble solids concentration of 6-7 weight percent (dependent on batch).

Characterization information for the three batches, based on sample analyses performed by the Process Science Analytical Laboratory (PSAL), is given in Table 4-2.

\section{SRS Sludge Simulant Slurries}

Two different batches of SRS Sludge Batch 6 (SB6) simulant were utilized in the testing, SB6-E and SB6-H. These simulants had been generated previously, in accordance with the prescribed procedure, ${ }^{4}$ for use in SB6 flowsheet test studies.

Prior to the gadolinium partitioning tests, the SB6 simulant slurries were spiked with $\mathrm{Gd}\left(\mathrm{NO}_{3}\right)_{3} \cdot 6 \mathrm{H}_{2} \mathrm{O}$, to attain the desired Fe:Gd ratios. The amounts of $\mathrm{Gd}\left(\mathrm{NO}_{3}\right)_{3} \cdot 6 \mathrm{H}_{2} \mathrm{O}$ spiked into the various slurries are given in Table 4-3. Note that two Fe:Gd ratios (25 and 50) were investigated with SB6-E, while only one Fe:Gd ratio (50) was investigated with SB6-H. 
Table 4-2. Characterization Data for the Simple Fe-Gd Slurries

\begin{tabular}{|l|c|c|c|}
\hline \multirow{2}{*}{ Parameters } & \multicolumn{3}{|c|}{ Mean Result } \\
\cline { 2 - 4 } & Fe:Gd = 25 & Fe:Gd = 50 & Fe:Gd = 100 \\
\hline \hline Density, g/mL & & & \\
\hline Slurry & 1.10 & 1.09 & 1.09 \\
\hline Supernatant & 1.05 & 1.05 & 1.05 \\
\hline Solids distribution & & & \\
\hline Total solids, wt\% of slurry & 14.5 & 14.1 & 13.8 \\
\hline Insoluble solids, wt\% of slurry & 7.1 & 6.7 & 6.0 \\
\hline Soluble solids, wt\% of slurry & 7.4 & 7.4 & 7.8 \\
\hline Dissolved solids, wt\% of supernatant & 8.0 & 7.9 & 8.3 \\
\hline Metals in slurry, wt\% of total solids & & & \\
\hline Iron & 24.5 & 25.9 & 24.1 \\
\hline Gadolinium & 0.951 & 0.521 & 0.242 \\
\hline Sodium & 16.0 & 12.3 & 13.2 \\
\hline Calculated ratio based on measurements & & & \\
\hline Fe:Gd in total solids & 26 & 50 & 100 \\
\hline Metals in supernatant, mg/L & & & \\
\hline Iron & $<1.0$ & $<1.0$ & $<1.0$ \\
\hline Gadolinium & $<0.10$ & $<0.10$ & $<0.10$ \\
\hline Sodium & $2.38 \mathrm{E}+4$ & $2.31 \mathrm{E}+4$ & $2.15 \mathrm{E}+4$ \\
\hline Primary ions in supernatant, M & & & \\
\hline Sodium & 1.03 & 1.01 & 0.93 \\
\hline Nitrate & 1.03 & 0.97 & 1.03 \\
\hline
\end{tabular}

Note: These data were based on analyses performed by the PSAL

Table 4-3. Quantities of $\mathrm{Gd}\left(\mathrm{NO}_{3}\right)_{3} \cdot \mathbf{6} \mathrm{H}_{2} \mathrm{O}$ Added to SB6 Simulants

\begin{tabular}{|c|c|c|}
\hline \multirow{2}{*}{$\begin{array}{c}\text { Fe:Gd } \\
\text { Ratio }\end{array}$} & Grams Gd(NO $\left.\mathbf{N}_{\mathbf{3}}\right)_{\mathbf{3}} \cdot \mathbf{6 H}_{\mathbf{2}} \mathbf{O}$ Per Kilogram of Slurry \\
\cline { 2 - 3 } & SB6-E & SB6-H \\
\hline 25 & 2.15 & 2.63 \\
\hline 50 & 1.07 & N/A \\
\hline
\end{tabular}

Characterization data for the SB6 simulant batches, based on sample analyses performed by the PSAL, are given in Table 4-4.

Note that the SB6-E simulant slurry was utilized in a combination of beaker tests and SRAT simulations, while the SB6-H simulant slurry was utilized solely in SRAT simulations. 
Table 4-4. Characterization Data for the SB6 Simulant Slurries

\begin{tabular}{|c|c|c|}
\hline \multirow[t]{2}{*}{ Parameters } & \multicolumn{2}{|c|}{ Mean Result } \\
\hline & SB6-E & SB6-H \\
\hline \multicolumn{3}{|l|}{ Density, g/mL } \\
\hline Slurry & 1.11 & 1.11 \\
\hline Supernatant & 1.04 & 1.07 \\
\hline \multicolumn{3}{|l|}{ Solids distribution } \\
\hline Total solids, wt $\%$ of slurry & 14.5 & 16.5 \\
\hline Insoluble solids, $w \mathrm{t} \%$ of slurry & 9.4 & 8.5 \\
\hline Soluble solids, $\mathrm{wt} \%$ of slurry & 5.1 & 8.0 \\
\hline Dissolved solids, wt $\%$ of supernatant & 5.6 & 8.7 \\
\hline \multicolumn{3}{|l|}{ Metals in slurry, wt \% of total solids } \\
\hline Iron & 12.9 & 13.4 \\
\hline Gadolinium (for Fe:Gd = 25) & 0.50 & 0.56 \\
\hline Gadolinium (for $\mathrm{Fe}: \mathrm{Gd}=50$ ) & 0.25 & N/A \\
\hline Sodium & 11.6 & 14.7 \\
\hline Aluminum & 13.3 & 11.3 \\
\hline Manganese & 6.2 & 4.7 \\
\hline Nickel & 1.7 & 1.9 \\
\hline Chromium & 0.21 & 0.012 \\
\hline Zirconium & 0.22 & 0.17 \\
\hline Silicon & 1.0 & 0.065 \\
\hline Calcium & 0.18 & 0.44 \\
\hline Magnesium & 0.29 & 0.29 \\
\hline Sulfur & 0.21 & 0.35 \\
\hline \multicolumn{3}{|l|}{ Chelator in slurry, $\mathrm{mg} / \mathrm{kg}$} \\
\hline Oxalate & $<100$ & 815 \\
\hline \multicolumn{3}{|l|}{ Metals in supernatant, $\mathrm{mg} / \mathrm{L}$} \\
\hline Iron & $<0.10$ & $<0.10$ \\
\hline Gadolinium & $<0.10$ & Not quantified \\
\hline Sodium & $2.0 \mathrm{E}+4$ & Not quantified \\
\hline Aluminum & $3.5 \mathrm{E}+3$ & $3.9 \mathrm{E}+3$ \\
\hline Potassium & $1.8 \mathrm{E}+2$ & $3.0 \mathrm{E}+2$ \\
\hline Sulfur & $5.2 \mathrm{E}+2$ & $1.0 \mathrm{E}+3$ \\
\hline Chromium & $1.1 \mathrm{E}+1$ & $1.8 \mathrm{E}+1$ \\
\hline Phosphorus & $6.5 \mathrm{E} 0$ & $1.6 \mathrm{E} 0$ \\
\hline \multicolumn{3}{|l|}{ Primary ions in supernatant, $M$} \\
\hline Sodium & 0.85 & Not quantified \\
\hline Nitrite & 0.23 & 0.43 \\
\hline Nitrate & 0.10 & 0.12 \\
\hline Carbonate & Not quantified & 0.092 \\
\hline Oxalate & $<0.0013$ & Not quantified \\
\hline Aluminate & 0.13 & 0.14 \\
\hline Sulfate & 0.014 & 0.028 \\
\hline
\end{tabular}

Note: These data were based on analyses performed by the PSAL 
A washed Sludge Batch 7 (SB7) test slurry, generated during a previous real-waste washing and settling demonstration, ${ }^{5}$ was utilized in the beaker tests. Prior to the beaker tests, the real-waste slurry was spiked with $\mathrm{Gd}\left(\mathrm{NO}_{3}\right)_{3} \cdot 6 \mathrm{H}_{2} \mathrm{O}$, to attain an Fe:Gd ratio of 25 , and diluted with a combination of de-ionized water and previously-decanted supernatant solution, to reduce the insoluble solids concentration from $\sim 18 \mathrm{wt} \%$ to $\sim 14$ $\mathrm{wt} \%$. (This reduction in the insoluble solids concentration was done to decrease the yield stress of the slurry to a manageable level). ${ }^{5}$ Specifically, $1.21 \mathrm{~g} \mathrm{Gd}\left(\mathrm{NO}_{3}\right)_{3} \cdot 6 \mathrm{H}_{2} \mathrm{O}, 46.2 \mathrm{~g}$ de-ionized water, and $90.1 \mathrm{~g}$ supernatant solution were mixed with $390 \mathrm{~g}$ of the washed SB7 test slurry.

Characterization data for the real-waste slurry after adding the gadolinium, water, and supernatant are given in Table 4-5. This information is based on sample analyses performed by Analytical Development (AD). Note that: a) the oxalate content of the real-waste slurry was substantial $(9100 \mathrm{mg} / \mathrm{kg})$; and b) the uranium and $\mathrm{Pu}-239$ concentrations of the real-waste slurry were identified for purposes of quantifying partitioning of fissile constituents.

\subsection{Beaker Tests}

The slurry types and experimental conditions of the beaker tests are summarized below. Note that four slurry types were utilized in the beaker tests: 1) simple Fe-Gd slurries; 2) SB6-E sludge simulant slurries; 3) SB6-E sludge simulant slurries spiked with 10,000 mg oxalate per kg slurry; and 4) real-waste sludge slurries.

Simple Fe-Gd slurries:

- Fe:Gd ratios of 25, 50, and 100

- $\mathrm{pH}$ values of 2,4 , and 6

- $\quad$ Temperatures of $\sim 93{ }^{\circ} \mathrm{C}$ and $\sim 22^{\circ} \mathrm{C}$

SB6-E sludge simulant slurries:

- Fe:Gd ratios of 25 and 50

- $\mathrm{pH}$ values of 2 and 4

- Temperatures of $\sim 93{ }^{\circ} \mathrm{C}$ and $\sim 22^{\circ} \mathrm{C}$

SB6-E sludge simulant slurries with added oxalate $(10,000 \mathrm{mg} / \mathrm{kg}$ slurry):

- Fe:Gd ratios of 25 and 50

- $\mathrm{pH} 4$

- Temperatures of $\sim 93{ }^{\circ} \mathrm{C}$ and $\sim 22^{\circ} \mathrm{C}$

Real-waste sludge slurries:

- Fe:Gd ratio of 25

- $\mathrm{pH} 2$ and 4

- Temperatures of $\sim 93^{\circ} \mathrm{C}$ and $\sim 22^{\circ} \mathrm{C}$ 
Table 4-5. Characterization Data for the Real-Waste Slurry

\begin{tabular}{|c|c|}
\hline Parameters & Mean Result \\
\hline \multicolumn{2}{|l|}{ Density, g/mL } \\
\hline Slurry & 1.17 \\
\hline Supernatant & 1.05 \\
\hline \multicolumn{2}{|l|}{ Solids distribution } \\
\hline Total solids, wt $\%$ of slurry & 19.4 \\
\hline Insoluble solids, $\mathrm{wt} \%$ of slurry & 13.5 \\
\hline Soluble solids, wt $\%$ of slurry & 5.9 \\
\hline Dissolved solids, wt $\%$ of supernatant & 6.8 \\
\hline \multicolumn{2}{|l|}{ Metals in slurry, wt \% of total solids } \\
\hline Iron & 10.8 \\
\hline Gadolinium & 0.418 \\
\hline Sodium & 13.7 \\
\hline Aluminum & 12.9 \\
\hline Manganese & 2.2 \\
\hline Nickel & 2.0 \\
\hline Mercury & 0.89 \\
\hline Silicon & 1.0 \\
\hline Calcium & 0.49 \\
\hline Magnesium & 0.22 \\
\hline Sulfur & 0.58 \\
\hline Uranium & 3.8 \\
\hline Plutonium-239 & 0.016 \\
\hline \multicolumn{2}{|l|}{ Chelator in slurry, mg/kg } \\
\hline Oxalate & 9100 \\
\hline \multicolumn{2}{|l|}{ Metals in supernatant, $\mathrm{mg} / \mathrm{L}$} \\
\hline Iron & 6.3 \\
\hline Sodium & $2.0 \mathrm{E}+4$ \\
\hline Aluminum & 737 \\
\hline Potassium & 75 \\
\hline Sulfur & 852 \\
\hline Chromium & 37 \\
\hline Phosphorus & 16 \\
\hline Molybdenum & 6.3 \\
\hline \multicolumn{2}{|l|}{ Primary ions in supernatant, $M$} \\
\hline Sodium & 0.89 \\
\hline Nitrite & 0.27 \\
\hline Nitrate & 0.14 \\
\hline Free hydroxide & 0.16 \\
\hline Carbonate & 0.076 \\
\hline Oxalate & 0.073 \\
\hline Aluminate & 0.027 \\
\hline Sulfate & 0.028 \\
\hline
\end{tabular}

Note: These data were based on analyses performed by Environmental \& Chemical Process Technology and AD 
In each test, $100 \mathrm{~mL}$ of slurry was transferred to a $250 \mathrm{~mL}$ capacity beaker. A magnetic stirring bar was added to the slurry and a watchglass was placed atop the beaker. The slurry was then mixed and heated using a hot plate with magnetic stirring capability. The mixing speed was adjusted to produce a small vortex that would maintain suspension of insolubles, without causing significant splashing. The temperature of the slurry was raised to $\sim 93{ }^{\circ} \mathrm{C}$, with frequent monitoring via thermometer and hotplate temperature adjustments, as necessary. (The watchglass was removed during the temperature measurements, and then replaced once each temperature measurement was complete).

Upon reaching a slurry temperature between 91 and $95^{\circ} \mathrm{C}$, aliquots of concentrated nitric acid solution were added to the slurry to reduce the $\mathrm{pH}$ of the slurry to the targeted test condition. The nitric acid was added dropwise, using a disposable slurry pipette, at a rate conducive to maintaining control of the $\mathrm{pH}$ and avoiding overheating associated with acidification reactions. A pre-calibrated portable $\mathrm{pH}$ meter was used to monitor the $\mathrm{pH}$ during and after the nitric acid additions. (The watchglass was removed during the $\mathrm{pH}$ measurements, and then replaced once each $\mathrm{pH}$ measurement was complete).

The temperature of the slurry was maintained at $\sim 93{ }^{\circ} \mathrm{C}$ for a period of 30 minutes. During this time, temperature and $\mathrm{pH}$ were monitored every 5 minutes, and as necessary, temperature adjustments were made and/or more nitric acid was added to maintain the targeted conditions.

Upon completion of the 30 minute equilibration period, the beaker was removed from the hotplate, and two 12-15 mL aliquots of the hot slurry were removed from the beaker and transferred to centrifuge tubes. While still hot, these aliquots were centrifuged at $\sim 3000$ rpm for 8-10 minutes. Immediately after completing the centrifuge cycle, free supernatant was withdrawn from the top of the centrifuge tubes and prepared for analysis.

The slurry remaining in the beaker was allowed to cool to room temperature, with the watchglass in place to minimize evaporation of water. The cooling period was typically 1-2 hours. Following the cooling period, two $12-15 \mathrm{~mL}$ aliquots of the slurry were removed from the beaker and transferred to centrifuge tubes. As in the case of the hot aliquots, the cooled aliquots were centrifuged at $\sim 3000 \mathrm{rpm}$ for 8-10 minutes, and free supernatant was subsequently withdrawn and prepared for analysis.

Supernatant aliquots from all beaker tests were acidified with nitric acid, diluted with deionized water, and then submitted for gadolinium, iron, and sodium analyses by inductively coupled plasma-atomic emission spectroscopy (ICP-AES). Duplicate supernatant aliquots were prepared and submitted for each analysis. Note that the acidification and dilution steps were necessary to maintain dissolution of the analytes and to meet sample analysis volume requirements.

In the case of the oxalate-spiked SB6-E slurry tests, additional supernatant aliquots were diluted with de-ionized water only (no acidification) and submitted for oxalate analyses by ion chromatography (IC). In the case of the real-waste slurry tests, the acidified and diluted supernatant aliquots (the ones prepared for ICP-AES analyses) were also 
submitted for $\mathrm{Pu}-239$ analyses by inductively coupled plasma-mass spectrometry (ICPMS).

Beaker tests with the non-radioactive slurry matrices (simple Fe-Gd slurries and SB6 simulant slurries) were performed in standard "non-rad" laboratories, and the associated analyses were performed at the PSAL. In contrast, the real-waste beaker tests were performed remotely in the Shielded Cells facility, and the associated analyses were performed by AD.

\subsection{SRAT Simulation Testing}

Six SRAT simulations were performed using the SB6-E and SB6-H simulant slurry matrices. Each SRAT simulation was conducted in accordance with the prescribed procedure. $^{6}$ A detailed description of the laboratory equipment used in the SRAT simulations and a series of schematics illustrating the laboratory set-up are documented in a 2010 SRNL memorandum. ${ }^{7}$ The slurry volume associated with each simulation was approximately three liters. The typical cycle time was approximately twenty hours.

The experimental conditions of the SRAT simulations are summarized in Table 4-6. The first four simulations were performed using the SB6-E slurry matrix, and a combination of nitric and formic acids. The fifth and sixth simulations were performed using the SB6$\mathrm{H}$ slurry matrix, and a combination of nitric, formic, and glycolic acids. Detailed run parameters for the simulations are given in Appendices A-F.

Table 4-6. Summary of SRAT Simulation Conditions

\begin{tabular}{|l|c|c|c|c|c|c|c|}
\hline SRAT & Simulant & Fe:Gd & Moles Acid Added & Targeted Acid & \multicolumn{3}{|c|}{ Mole \% } \\
\cline { 6 - 8 } Run \# & Batch & Ratio & Per Liter of Slurry & Stoichiometry & Nitric & Formic & Glycolic \\
\hline \hline SB6-27 & SB6-E & 25 & 1.8 & $150 \%$ & 30 & 70 & 0 \\
\hline SB6-28 & SB6-E & 25 & 1.8 & $150 \%$ & 10 & 90 & 0 \\
\hline SB6-29 & SB6-E & 50 & 1.8 & $150 \%$ & 30 & 70 & 0 \\
\hline SB6-30 & SB6-E & 50 & 1.8 & $150 \%$ & 10 & 90 & 0 \\
\hline GF-13 & SB6-H & 24 & 1.4 & $100 \%$ & 49 & 10 & 41 \\
\hline GF-14 & SB6-H & 24 & 1.4 & $100 \%$ & 41 & 12 & 47 \\
\hline
\end{tabular}

Notes: a) Fe:Gd ratios in the table are based upon original batch characterization of simulant materials and the masses of gadolinium added for each of the SRAT runs; and b) percent acid stoichiometries were calculated based on Equation 2 given in SRNL-L3100-2009-00146 (Koopman, D. C., A. I. Fernandez, and B. R. Pickenheim; Preliminary Evaluation of Two Proposed Stoichiometric Acid Equations; June 15, 2009).

Fourteen milliliter slurry sample aliquots were collected at various times during the simulations (during and after acid addition), and then centrifuged while hot at 3000-4000 rpm for 10 minutes. Immediately following centrifugation, the free supernatant was removed from the centrifuge tube and submitted to the PSAL for ICP-AES analysis. At the end of the simulation, a $120 \mathrm{~mL}$ sample of the SRAT product was collected and submitted to the PSAL for a series of analyses, including: a) slurry and supernatant elementals by ICP-AES; b) supernatant anions by IC; c) slurry and supernatant densities; d) solids distribution; and e) $\mathrm{pH}$. Two measurements were performed on each sample. 


\subsection{Test Data Analysis}

Analytical results for the replicate supernatant measurements were averaged after adjusting the raw data for dilution. The average concentrations of gadolinium, iron, and sodium were reported for every test case except the GF-13 and GF-14 SRAT simulations. In the GF-13 and GF-14 cases, only the supernatant gadolinium and iron concentrations were reported, as sodium measurements had not been performed. (Note that GF-13 and GF-14 simulations were conducted as part of a different project, with different sampling and analysis protocols).

The supernatant sodium concentrations provided a measure of the extent of water gain or loss during the addition of the acid solutions and the subsequent evaporation occurring while boiling. Under the assumption that all of the sodium was soluble (all in the liquid phase), the estimated fraction of net water gained or lost was $\left(C_{i}-C_{f}\right) / C_{f}$, where $C_{i}$ was the initial supernatant sodium concentration (prior to testing) and $\mathrm{C}_{\mathrm{f}}$ was the final supernatant sodium concentration (at conclusion of testing). Note that a positive fraction indicated a net water gain, while a negative fraction indicated a net water loss.

For all tests except those of GF-13 and GF-14, the estimated portions of gadolinium and iron partitioning to the liquid phase were calculated using the following quantities:

- The liquid-phase gadolinium and iron concentrations observed for the test samples

- The gadolinium and iron concentrations in the total solids of the original slurries

- The solids distributions of the original slurries

- The original supernatant density

- The net volumes of water gained or lost during the tests

The initial quantities of gadolinium and iron in a unit mass of slurry were calculated based on the concentrations in the total solids and the total solids content of the slurry. The volume of supernatant associated with the initial slurry was calculated by multiplying the unit slurry mass by the supernatant mass fraction (one minus the insoluble solids mass fraction) and dividing the product by the supernatant density. The final volume of supernatant (at the time of sampling) was determined by applying the net water gain or loss. The final liquid-phase constituent mass was the product of the final liquid-phase concentration and the supernatant volume adjusted for water gain or loss. The estimated portion of the constituent in the liquid phase was the final liquid-phase constituent mass divided by the total constituent mass associated with the initial slurry.

For the GF-13 and GF-14 tests, the liquid-phase partitioning values were estimated using the same calculation approach described above - however, the supernatant volumes were not adjusted for water gains or losses, due to the lack of sodium concentration data. The net effect was that the reported partitioning values for these tests were expected to be underestimates during the period when $\mathrm{pH}$ was declining (during the acid additions) and overestimates for the period following the acid additions (when water was boiled off). The maximum extent of underestimation or overestimation in these cases was thought to be $\sim 25 \%$ (on a relative basis). 


\subsection{RESULTS AND DISCUSSION}

\subsection{Beaker Tests}

\section{Simple Fe-Gd Slurries}

Gadolinium, iron, and sodium concentrations in the supernatants of the "simple Fe-Gd" slurries are given in Table 5-1. The estimated portions of gadolinium and iron that partitioned to the liquid phase are given in Tables 5-2 and 5-3, respectively. Plots of the supernatant gadolinium concentrations and estimated liquid-phase partitioning under the hot temperature conditions are given as functions of the $\mathrm{pH}$ in Figures 5-1 and 5-2, respectively. Note that the gadolinium data from the $\mathrm{pH} 6$ tests were not included in plots, since the measured gadolinium concentrations at $\mathrm{pH} 6$ were all less than the minimum detection limits. Also note that the iron data were not plotted, since the iron concentrations at $\mathrm{pH} 4$ and 6 were all less than the minimum detection limits.

At $\mathrm{pH}$ 6, the liquid-phase concentrations of gadolinium were less than the minimum detection limit ( $1 \mathrm{mg} / \mathrm{L})$, regardless of the Fe:Gd ratio. The corresponding portions of gadolinium partitioning to the liquid-phase at $\mathrm{pH} 6$ were exceedingly small, less than $0.2 \%$ of the total gadolinium. At $\mathrm{pH} 4$, the liquid-phase gadolinium concentrations were detectable, ranging from approximately $6 \mathrm{mg} / \mathrm{L}$ for the hot $100: 1 \mathrm{Fe}: \mathrm{Gd}$ slurry to approximately $100 \mathrm{mg} / \mathrm{L}$ for the hot 25:1 Fe:Gd slurry. Still, the estimated portions of gadolinium partitioning to the liquid phase were small, from about $1 \%$ for the $100: 1$ Fe:Gd slurry to about 4\% for the 25:1 Fe:Gd slurry.

In contrast, at $\mathrm{pH} 2$, the liquid-phase concentrations of gadolinium were substantial. Specifically, the supernatant gadolinium concentrations for the 25:1, 50:1, and 100:1 Fe:Gd slurries were approximately 2000, 1000, and $500 \mathrm{mg} / \mathrm{L}$, respectively. Correspondingly, the estimated portions of the gadolinium partitioning to the liquid phase were on the order of $80-90 \%$, regardless of the Fe:Gd ratio. Given that the liquid-phase concentrations doubled with the amounts of gadolinium present (twice as much gadolinium in the 25:1 Fe:Gd slurry as in the 50:1 Fe:Gd slurry, and twice as much gadolinium in the 50:1 Fe:Gd slurry as in the 100:1 Fe:Gd slurry), it is conjectured that all of the available gadolinium may have been partitioning into solution in each case.

A comparison of the "hot" and "cold" gadolinium concentrations provides additional support that essentially $100 \%$ of the gadolinium partitioned to the liquid-phase at $\mathrm{pH} 2$. Whereas at $\mathrm{pH} 4$, the gadolinium concentrations at elevated temperature conditions were as much as $40-70 \%$ higher than those at the cooler temperature, at $\mathrm{pH} 2$, the gadolinium concentrations at elevated temperature were a mere $2-5 \%$ higher than those at the cooler temperature. Given the expected increase in solubility at higher temperatures (consistent with the $\mathrm{pH} 4$ results), the similarities between the "cold" and "hot" $\mathrm{pH} 2$ results suggest that the vast majority of the available gadolinium was soluble at the lower temperature. 
Table 5-1. Supernatant Constituent Concentrations in Simple Fe-Gd Slurries

\begin{tabular}{|c|c|c|c|c|c|}
\hline \multirow{2}{*}{$\begin{array}{l}\text { Fe:Gd } \\
\text { Ratio }\end{array}$} & \multirow{2}{*}{$\mathbf{p H}$} & \multirow{2}{*}{ Temp } & \multicolumn{3}{|c|}{ Supernatant Concentration, mg/L } \\
\hline & & & Gd & Fe & $\mathrm{Na}$ \\
\hline \multirow{6}{*}{25} & \multirow{2}{*}{6} & $\mathrm{H}$ & $<1$ & $<12$ & $4.0 \mathrm{E}+4$ \\
\hline & & $\mathrm{C}$ & $<1$ & $<12$ & $4.2 \mathrm{E}+4$ \\
\hline & \multirow{2}{*}{4} & $\mathrm{H}$ & $1.0 \mathrm{E}+2$ & $<13$ & $3.5 \mathrm{E}+4$ \\
\hline & & $\mathrm{C}$ & 71 & $<8$ & $3.8 \mathrm{E}+4$ \\
\hline & \multirow{2}{*}{2} & $\mathrm{H}$ & $1.9 \mathrm{E}+3$ & 17 & $3.4 \mathrm{E}+4$ \\
\hline & & $\mathrm{C}$ & $2.0 \mathrm{E}+3$ & 19 & $3.5 \mathrm{E}+4$ \\
\hline \multirow{6}{*}{50} & \multirow{2}{*}{6} & $\mathrm{H}$ & $<1$ & $<8$ & $3.2 \mathrm{E}+4$ \\
\hline & & $\mathrm{C}$ & $<1$ & $<9$ & $3.4 \mathrm{E}+4$ \\
\hline & \multirow{2}{*}{4} & $\mathrm{H}$ & 8.7 & $<9$ & $4.0 \mathrm{E}+4$ \\
\hline & & $\mathrm{C}$ & 5.0 & $<11$ & $3.9 \mathrm{E}+4$ \\
\hline & \multirow{2}{*}{2} & $\mathrm{H}$ & $9.4 \mathrm{E}+2$ & $1.8 \mathrm{E}+2$ & $3.3 \mathrm{E}+4$ \\
\hline & & $\mathrm{C}$ & $9.1 \mathrm{E}+2$ & $2.4 \mathrm{E}+2$ & $3.4 \mathrm{E}+4$ \\
\hline \multirow{6}{*}{100} & \multirow{2}{*}{6} & $\mathrm{H}$ & $<1$ & $<9$ & $3.1 \mathrm{E}+4$ \\
\hline & & $\mathrm{C}$ & $<1$ & $<9$ & $3.3 \mathrm{E}+4$ \\
\hline & \multirow{2}{*}{4} & $\mathrm{H}$ & 5.6 & $<10$ & $3.4 \mathrm{E}+4$ \\
\hline & & $\mathrm{C}$ & 3.3 & $<10$ & $3.5 \mathrm{E}+4$ \\
\hline & \multirow{2}{*}{2} & $\mathrm{H}$ & $5.1 \mathrm{E}+2$ & $5.4 \mathrm{E}+2$ & $3.5 \mathrm{E}+4$ \\
\hline & & $\mathrm{C}$ & $5.0 \mathrm{E}+2$ & $3.2 \mathrm{E}+2$ & $3.6 \mathrm{E}+4$ \\
\hline
\end{tabular}

$\mathrm{H}=\operatorname{hot}\left(\sim 93{ }^{\circ} \mathrm{C}\right.$ when sampled $) ; \mathrm{C}=$ cooled to $\sim 22^{\circ} \mathrm{C}$

Table 5-2. Soluble Portions of Gadolinium in the Simple Fe-Gd Slurries

\begin{tabular}{|c|c|c|c|c|c|c|}
\hline \multirow{2}{*}{$\begin{array}{c}\text { Fe:Gd } \\
\text { Ratio }\end{array}$} & \multicolumn{6}{|c|}{ Soluble Portion of Gadolinium, \% } \\
\cline { 2 - 7 } & $\begin{array}{c}\text { pH 6, } \\
\text { HOT }\end{array}$ & $\begin{array}{c}\text { pH 6, } \\
\text { COLD }\end{array}$ & $\begin{array}{c}\text { pH 4, } \\
\text { HOT }\end{array}$ & $\begin{array}{c}\text { pH 4, } \\
\text { COLD }\end{array}$ & $\begin{array}{c}\text { pH 2, } \\
\text { HOT }\end{array}$ & $\begin{array}{c}\text { pH 2, } \\
\text { COLD }\end{array}$ \\
\hline \hline 25 & $<0.04$ & $<0.04$ & 4.4 & 2.9 & 86 & 88 \\
\hline 50 & $<0.07$ & $<0.08$ & 0.62 & 0.35 & 79 & 74 \\
\hline 100 & $<0.17$ & $<0.17$ & 0.96 & 0.54 & 84 & 80 \\
\hline
\end{tabular}

Table 5-3. Soluble Portions of Iron in the Simple Fe-Gd Slurries

\begin{tabular}{|c|c|c|c|c|c|c|}
\hline \multirow{2}{*}{$\begin{array}{c}\text { Fe:Gd } \\
\text { Ratio }\end{array}$} & \multicolumn{7}{|c|}{ Soluble Portion of Iron, \% } \\
\cline { 2 - 7 } & $\begin{array}{c}\text { pH 6, } \\
\text { HOT }\end{array}$ & $\begin{array}{c}\text { pH 6, } \\
\text { COLD }\end{array}$ & $\begin{array}{c}\text { pH 4, } \\
\text { HOT }\end{array}$ & $\begin{array}{c}\text { pH 4, } \\
\text { COLD }\end{array}$ & $\begin{array}{c}\text { pH 2, } \\
\text { HOT }\end{array}$ & $\begin{array}{c}\text { pH 2, } \\
\text { COLD }\end{array}$ \\
\hline \hline 25 & $<0.02$ & $<0.02$ & $<0.02$ & $<0.02$ & 0.03 & 0.03 \\
\hline 50 & $<0.02$ & $<0.02$ & $<0.02$ & $<0.02$ & 0.30 & 0.39 \\
\hline 100 & $<0.02$ & $<0.02$ & $<0.02$ & $<0.02$ & 0.89 & 0.80 \\
\hline
\end{tabular}




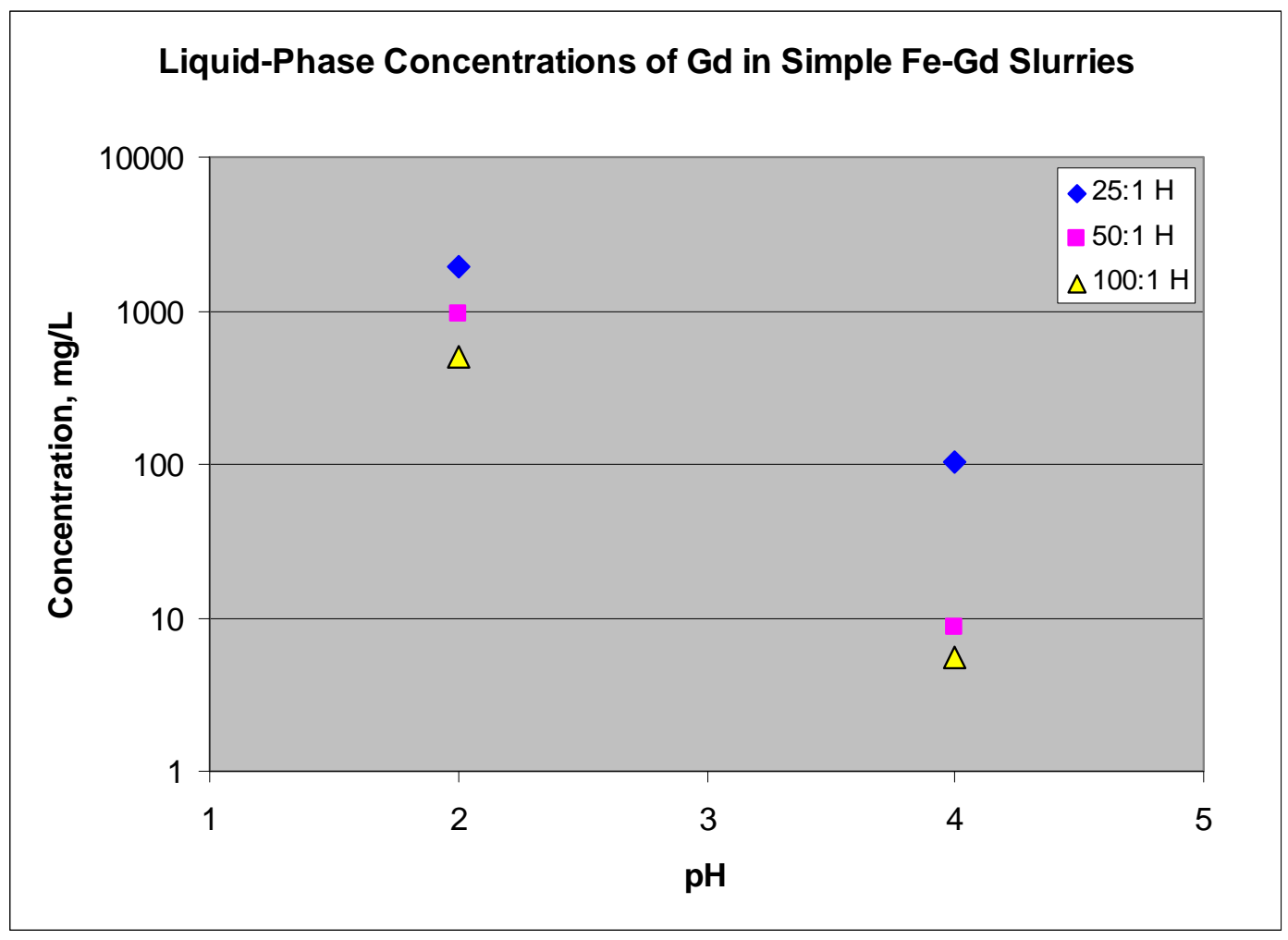

Figure 5-1. Simple Fe-Gd Slurries: Supernatant Gd Concentrations at pH 2 and 4

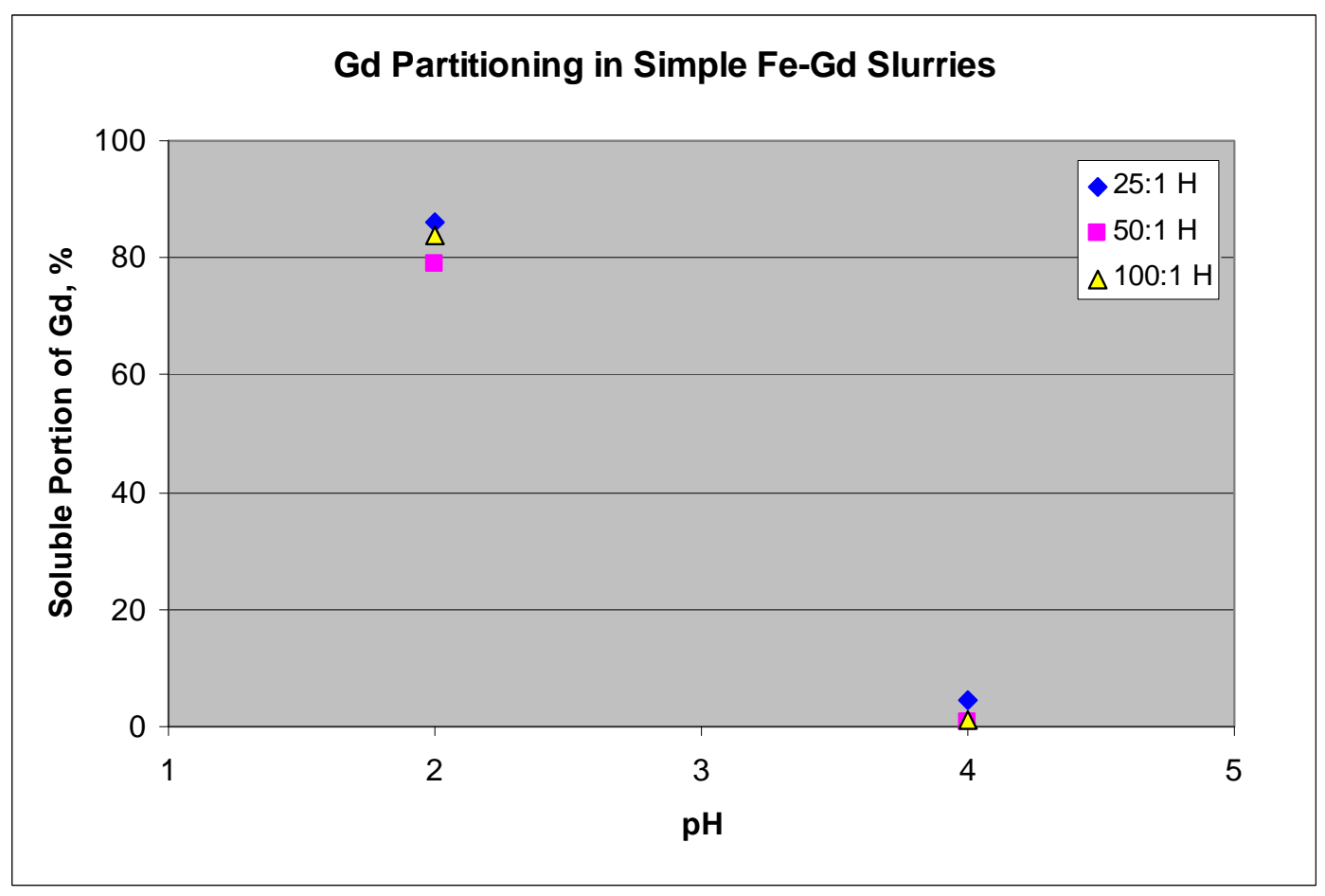

Figure 5-2. Simple Fe-Gd Slurries: Soluble Portions of Gd at pH 2 and 4 
At pH 6 and 4, the liquid-phase concentrations of iron were less than the minimum detection limits $(\sim 10 \mathrm{mg} / \mathrm{L})$, regardless of the Fe:Gd ratio. Because of the large quantities of iron in the slurries, the corresponding portions of iron partitioning to the liquid phase were minute, less than $0.02 \%$ of the total iron. At $\mathrm{pH} 2$, the liquid-phase concentrations of iron were detectable, ranging from approximately $20 \mathrm{mg} / \mathrm{L}$ for the hot 25:1 Fe:Gd slurry to approximately $500 \mathrm{mg} / \mathrm{L}$ for the hot 100:1 Fe:Gd slurry. The lower iron concentration for the 25:1 Fe:Gd slurry (where the gadolinium content was higher) suggests that the greater presence of gadolinium may suppress the iron solubility.

The impact of temperature on the supernatant iron concentrations at $\mathrm{pH} 2$ is not clear. For the 25:1 Fe:Gd slurry, the "hot" and "cold" iron concentrations were approximately the same, 17 and $19 \mathrm{mg} / \mathrm{L}$, respectively. The difference between these two concentrations is approximately $10 \%$ and not considered significant, as it is less than the expected propagated experimental uncertainty. For the 50:1 Fe:Gd slurry, the "hot" iron concentration $(180 \mathrm{mg} / \mathrm{L})$ was $25 \%$ lower than the "cold" concentration $(240 \mathrm{mg} / \mathrm{L})$. This difference may not be significant either, as it is on the order of the expected uncertainty. In contrast, for the 100:1 Fe:Gd slurry, the "hot" iron concentration (540 $\mathrm{mg} / \mathrm{L}$ ) was about $70 \%$ higher than the "cold" concentration. The $70 \%$ difference is considered significant, since it is clearly higher than the expected uncertainty $(\sim 25 \%)$.

The liquid-phase sodium concentrations ranged from $3.3 \mathrm{E}+4$ to $4.2 \mathrm{E}+4 \mathrm{mg} / \mathrm{L}$. These concentrations were $40-70 \%$ higher than the supernatant sodium concentrations of the original slurries prior to the acid additions and evaporative losses that occurred during boiling (see Table 4-2 for the original supernatant sodium concentration). Note that the sodium concentration increases were reflective of the net water losses that occurred during boiling. (Quantification of these losses was needed to estimate the portions of gadolinium and iron partitioning to the liquid phase).

\section{SB6-E Simulant Slurries (Without Extra Oxalate)}

Gadolinium, iron, and sodium concentrations in the supernatants of the various "SB6-E simulant" slurries are given in Table 5-4. The estimated portions of gadolinium and iron that partitioned to the liquid phase are given in Tables 5-5 and 5-6, respectively. Plots of the supernatant gadolinium concentrations and estimated liquid-phase partitioning under the hot temperature conditions are given as a function of the $\mathrm{pH}$ in Figures 5-3 and 5-4, respectively.

As was the case for the simple Fe-Gd slurries, the liquid-phase concentrations of gadolinium in the SB6-E slurries were detectable at both the $\mathrm{pH} 4$ and $\mathrm{pH} 2$ conditions. At $\mathrm{pH} 4$, the concentrations were $\sim 20 \mathrm{mg} / \mathrm{L}$, regardless of the Fe:Gd ratio and the slurry temperature. The corresponding portions of gadolinium partitioned to the liquid phase were $2-3 \%$. In contrast, at $\mathrm{pH} 2$, the concentrations were significantly higher, $\sim 800 \mathrm{mg} / \mathrm{L}$ for the 25:1 Fe:Gd slurry and $\sim 400 \mathrm{mg} / \mathrm{L}$ for the 50:1 Fe:Gd slurry. The corresponding portions of gadolinium partitioned to the liquid phase were estimated to be $\sim 70 \%$. However, as was the case for the simple slurries, the concentration trends suggest that at $\mathrm{pH} 2$, the portions of gadolinium in the liquid phase may have been closer to $100 \%$. 
Table 5-4. Supernatant Constituent Concentrations in the SB6-E Slurries

\begin{tabular}{|c|c|c|c|c|c|}
\hline $\begin{array}{c}\text { Fe:Gd } \\
\text { Ratio }\end{array}$ & \multirow{2}{*}{ pH } & \multirow{2}{*}{ Temp } & \multicolumn{3}{|c|}{ Supernatant Concentration, mg/L } \\
\cline { 3 - 6 } & & & Gd & Fe & Na \\
\hline \hline \multirow{3}{*}{25} & \multirow{2}{*}{4} & $\mathrm{H}$ & 19 & $<0.6$ & $2.4 \mathrm{E}+4$ \\
\cline { 3 - 6 } & & $\mathrm{C}$ & 18 & $<0.6$ & $2.5 \mathrm{E}+4$ \\
\cline { 2 - 6 } & \multirow{2}{*}{2} & $\mathrm{H}$ & $8.2 \mathrm{E}+2$ & $1.1 \mathrm{E}+2$ & $2.6 \mathrm{E}+4$ \\
\cline { 3 - 6 } & & $\mathrm{C}$ & $8.3 \mathrm{E}+2$ & 39 & $2.5 \mathrm{E}+4$ \\
\hline \multirow{3}{*}{50} & \multirow{2}{*}{4} & $\mathrm{H}$ & 18 & $<0.5$ & $2.5 \mathrm{E}+4$ \\
\cline { 3 - 6 } & \multirow{2}{*}{2} & $\mathrm{C}$ & 16 & $<0.5$ & $2.6 \mathrm{E}+4$ \\
\hline & & $\mathrm{H}$ & $4.2 \mathrm{E}+2$ & $1.6 \mathrm{E}+2$ & $2.5 \mathrm{E}+4$ \\
\hline
\end{tabular}

Table 5-5. Soluble Portions of Gadolinium in the SB6-E Slurries

\begin{tabular}{|c|c|c|c|c|}
\hline \multirow{2}{*}{$\begin{array}{c}\text { Fe:Gd } \\
\text { Ratio }\end{array}$} & \multicolumn{4}{|c|}{ Soluble Portion of Gadolinium, \% } \\
\cline { 2 - 5 } & $\begin{array}{c}\text { pH 4, } \\
\text { HOT }\end{array}$ & $\begin{array}{c}\text { pH 4, } \\
\text { COLD }\end{array}$ & $\begin{array}{c}\text { pH 2, } \\
\text { HOT }\end{array}$ & $\begin{array}{c}\text { pH 2, } \\
\text { COLD }\end{array}$ \\
\hline \hline 25 & 1.8 & 1.7 & 73 & 74 \\
\hline 50 & 3.0 & 2.5 & 70 & 69 \\
\hline
\end{tabular}

Table 5-6. Soluble Portions of Iron in the SB6-E Slurries

\begin{tabular}{|c|c|c|c|c|}
\hline \multirow{2}{*}{$\begin{array}{c}\text { Fe:Gd } \\
\text { Ratio }\end{array}$} & \multicolumn{4}{|c|}{ Soluble Portion of Iron, \% } \\
\cline { 2 - 5 } & $\begin{array}{c}\text { pH 4, } \\
\text { HOT }\end{array}$ & $\begin{array}{c}\text { pH 4, } \\
\text { COLD }\end{array}$ & $\begin{array}{c}\text { pH 2, } \\
\text { HOT }\end{array}$ & $\begin{array}{c}\text { pH 2, } \\
\text { COLD }\end{array}$ \\
\hline \hline 25 & $<0.002$ & $<0.002$ & 0.37 & 0.13 \\
\hline 50 & $<0.002$ & $<0.002$ & 0.55 & 0.55 \\
\hline
\end{tabular}




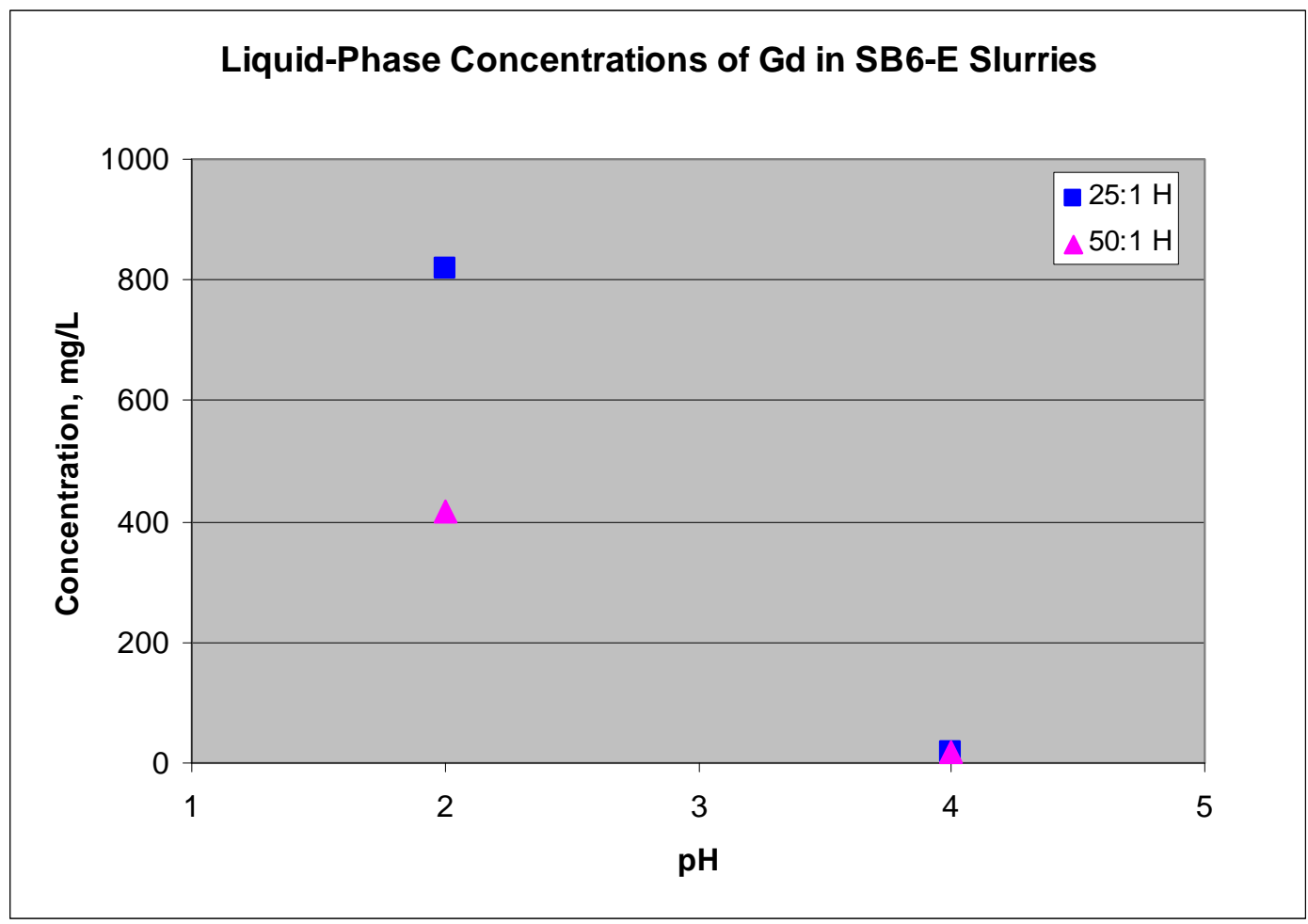

Figure 5-3. SB6-E Slurries: Supernatant Gd Concentrations at pH 2 and 4

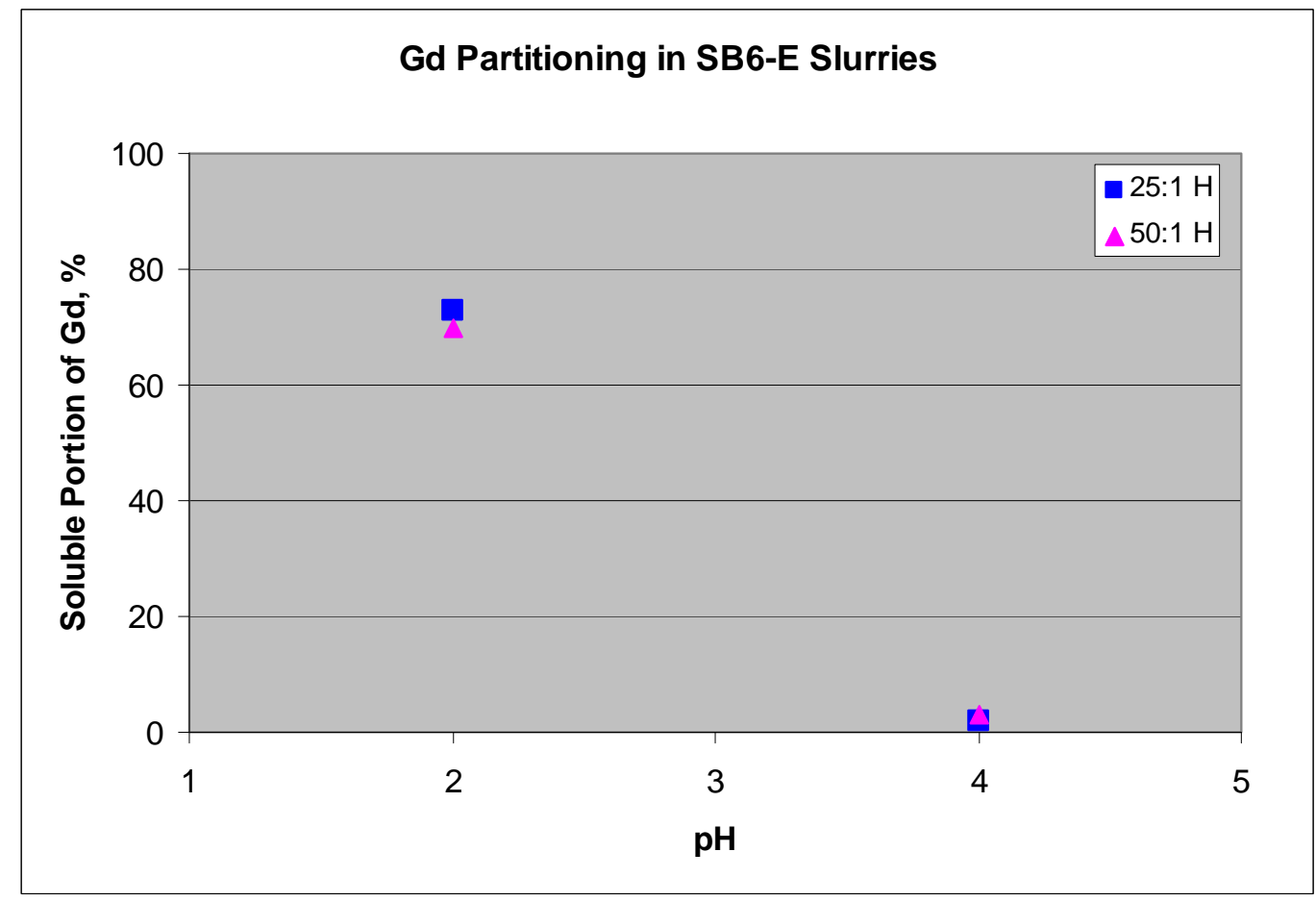

Figure 5-4. SB6-E Slurries: Soluble Portions of Gd at pH 2 and 4 
At $\mathrm{pH} 4$, the liquid-phase concentrations of iron in the SB6-E slurries were less than the minimum detection limits $(0.5-0.6 \mathrm{mg} / \mathrm{L})$. The corresponding portions of iron partitioning to the liquid phase were minute, less than $0.002 \%$ of the total iron. In contrast, at $\mathrm{pH} 2$, the liquid-phase concentrations of iron were detectable, although insignificant from the perspective of total iron. Specifically, the "hot" and "cold" iron concentrations were around 110 and $40 \mathrm{mg} / \mathrm{L}$ for the $25: 1 \mathrm{Fe}: \mathrm{Gd}$ ratio slurry (respectively), and around 160 and $60 \mathrm{mg} / \mathrm{L}$ for the $50: 1 \mathrm{Fe}$ Gd ratio slurry. The corresponding portions of iron in the liquid phase ranged from $\sim 0.1$ to $\sim 0.6 \%$.

Comparison of the "hot" and "cold" gadolinium concentrations at $\mathrm{pH} 4$ showed little or no temperature impact (the differences were smaller than the expected experimental uncertainties of $\sim 25 \%$ ). In contrast, the "hot" iron concentrations at $\mathrm{pH} 2$ were typically three times the "cold" iron concentrations under the same Fe:Gd ratio conditions.

The liquid-phase sodium concentrations ranged from $2.4 \mathrm{E}+4$ to $2.6 \mathrm{E}+4 \mathrm{mg} / \mathrm{L}$. These concentrations were $20-30 \%$ higher than the supernatant concentrations of the original slurries prior to the acid additions and evaporative losses that occurred during boiling (see Table 4-4 for the original sodium concentration).

\section{SB6-E Simulant Slurries with Added Oxalate (10,000 mg/kg slurry)}

Gadolinium, iron, sodium, and oxalate concentrations in the supernatants of the "oxalatespiked SB6-E simulant" slurries are given in Table 5-7. The estimated portions of gadolinium and iron that partitioned to the liquid phase are given in Tables 5-8 and 5-9, respectively. A plot showing a comparison of the gadolinium partitioning in the presence and absence of added oxalate is given in Figure 5-5. Note that a plot comparing iron partitioning in the presence and absence of added oxalate was not presented, since the $\mathrm{pH}$ 4 supernatant iron concentrations in the absence of added oxalate were less than the minimum detection limits (see Table 5-6).

The liquid-phase concentrations of gadolinium in the oxalate-spiked SB6-E slurries ranged from $\sim 8$ to $24 \mathrm{mg} / \mathrm{L}$. In comparison, the liquid-phase gadolinium concentrations for the unspiked SB6-E slurries at $\mathrm{pH} 4$ were all approximately $20 \mathrm{mg} / \mathrm{L}$ (Table 5-4). The fact that the gadolinium concentrations in the oxalate-spiked slurries were the same order of magnitude as those in the unspiked slurries suggests that the added oxalate had little or no significant impact on the gadolinium solubility. Of course, since the test was performed at $\mathrm{pH} 4$, additional testing would be necessary to determine potential impacts under alternate $\mathrm{pH}$ conditions, particularly at lower $\mathrm{pH}$.

In contrast, the liquid-phase concentrations of iron in the oxalate-spiked SB6-E slurries were one or more orders of magnitude higher than the concentrations in the unspiked slurries. Specifically, the iron concentrations in the presence of the oxalate ranged from $\sim 10-15 \mathrm{mg} / \mathrm{L}$, while the concentrations in the absence of the oxalate (at $\mathrm{pH} 4$ ) were all less than $0.6 \mathrm{mg} / \mathrm{L}$ (Table 5-4). Nonetheless, the portions of iron partitioning to liquid phase in the presence of the oxalate were still small, ranging from $\sim 0.1$ to $0.6 \%$. 
Table 5-7. Supernatant Constituent Concentrations in SB6-E Slurries with Added Oxalate

\begin{tabular}{|c|c|c|c|c|c|c|}
\hline Fe:Gd & \multirow{2}{*}{ Ratio } & \multirow{2}{*}{$\mathbf{p H}$} & \multirow{2}{*}{ Temp } & \multicolumn{4}{|c|}{ Supernatant Concentration, mg/L } \\
\cline { 4 - 7 } & & & Gd & Fe & Na & Oxalate \\
\hline \multirow{2}{*}{25} & \multirow{2}{*}{4} & Hot & 24 & 13 & $3.8 \mathrm{E}+4$ & $1.7 \mathrm{E}+3$ \\
\cline { 3 - 7 } & & Cold & 7.7 & 8.6 & $4.1 \mathrm{E}+4$ & $1.6 \mathrm{E}+3$ \\
\hline \multirow{2}{*}{50} & \multirow{2}{*}{4} & Hot & 14 & 15 & $3.7 \mathrm{E}+4$ & $2.2 \mathrm{E}+3$ \\
\cline { 3 - 7 } & & Cold & 12 & 13 & $3.5 \mathrm{E}+4$ & $2.3 \mathrm{E}+3$ \\
\hline
\end{tabular}

Table 5-8. Soluble Portions of Gadolinium in SB6-E Slurries with Added Oxalate

\begin{tabular}{|c|c|c|}
\hline \multirow[b]{2}{*}{$\begin{array}{c}\text { Fe:Gd } \\
\text { Ratio }\end{array}$} & \multicolumn{2}{|c|}{ Soluble Portion of Gadolinium, \% } \\
\hline & $\begin{array}{r}\text { pH 4, } \\
\text { HOT } \\
\end{array}$ & $\begin{array}{l}\text { pH 4, } \\
\text { COLD }\end{array}$ \\
\hline 25 & 1.5 & 0.44 \\
\hline 50 & 1.6 & 1.5 \\
\hline
\end{tabular}

Table 5-9. Soluble Portions of Iron in SB6-E Slurries with Added Oxalate

\begin{tabular}{|c|c|c|}
\hline \multirow{2}{*}{$\begin{array}{c}\text { Fe:Gd } \\
\text { Ratio }\end{array}$} & \multicolumn{2}{|c|}{ Soluble Portion of Iron, \% } \\
\cline { 2 - 3 } & $\begin{array}{c}\text { pH 4, } \\
\text { HOT }\end{array}$ & $\begin{array}{c}\text { pH 4, } \\
\text { COLD }\end{array}$ \\
\hline \hline 25 & 0.028 & 0.018 \\
\hline 50 & 0.038 & 0.036 \\
\hline
\end{tabular}

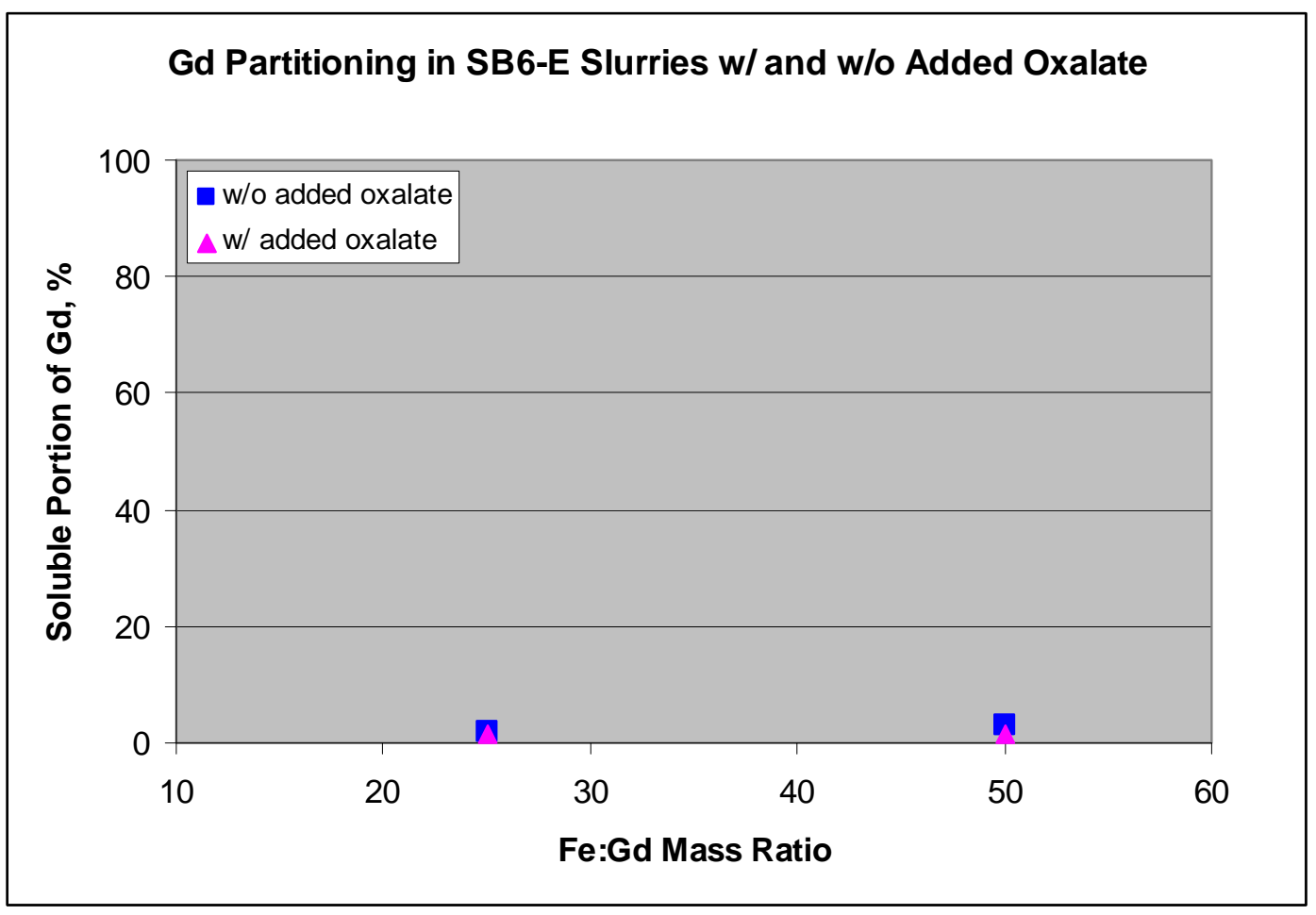

Figure 5-5. SB6-E Slurries w/ and w/o Added Oxalate: Soluble Portions of Gd 
The liquid-phase sodium concentrations ranged from $3.5 \mathrm{E}+4$ to $4.1 \mathrm{E}+4 \mathrm{mg} / \mathrm{L}$. These concentrations were $75-105 \%$ higher than the original sodium concentration prior to sodium oxalate and acid additions, and prior to evaporative losses that occurred during boiling. The relatively large increases in the sodium concentration were attributed to two primary impacts. First was the relatively large evaporative loss that occurred during acidification and boiling of the oxalate-spiked slurries. As opposed to the slurries without the added oxalate, the oxalate-spiked slurries tended to boil more intensely, especially during the periods of acid addition. Second was the additional sodium that was introduced with the oxalate (in the form of sodium oxalate). Assuming complete dissolution of sodium oxalate, the liquid-phase sodium contribution due to the added sodium oxalate would have been $\sim 6 \mathrm{E}+3 \mathrm{mg} / \mathrm{L}$.

The liquid-phase oxalate concentrations were on the order of $2 \mathrm{E}+3 \mathrm{mg} / \mathrm{L}$. This suggests that: a) only about one-third of the sodium oxalate partitioned to the liquid phase; and/or b) a portion of the oxalate was destroyed (decomposed to by-products) during acidification.

\section{SRS Real-Waste Sludge Slurry}

Gadolinium, iron, and sodium concentrations in the supernatants of the "real-waste" slurries are given in Table 5-10. Also given in Table 5-10 are the supernatant concentrations of plutonium-239, a constituent important from the standpoint of being fissile. The corresponding estimated portions of $\mathrm{Gd}, \mathrm{Fe}$, and $\mathrm{Pu}-239$ that partitioned to the liquid phase are given in Table 5-11. Plots of the supernatant constituent concentrations and estimated partitioning under the hot temperature conditions are given as functions of the $\mathrm{pH}$ in Figures 5-6 and 5-7, respectively.

Liquid-phase concentrations of the $\mathrm{Gd}, \mathrm{Fe}$, and $\mathrm{Pu}-239$ were detectable at both of the $\mathrm{pH}$ conditions tested ( $\mathrm{pH} 4$ and 2). As expected, the liquid-phase concentration of each constituent at $\mathrm{pH} 2$ was higher than the corresponding concentration at $\mathrm{pH} 4$. The liquidphase concentrations were highest for gadolinium ( $\sim 20$ to $\sim 900 \mathrm{mg} / \mathrm{L})$, second highest for iron $(\sim 10$ to $\sim 50 \mathrm{mg} / \mathrm{L})$, and lowest for Pu-239 ( 0.2 to $\sim 0.3 \mathrm{mg} / \mathrm{L})$.

Note that at $\mathrm{pH} 4$, the liquid-phase iron concentrations $(\sim 10 \mathrm{mg} / \mathrm{L})$ were: a) similar to those observed for the oxalate-spiked SB6-E slurry; and b) significantly higher than those observed for the simple Fe-Gd slurries and unspiked SB6-E slurries. Given that the realwaste slurry contained significant oxalate (see Table 4-5), the results are consistent with the assumption that high oxalate concentrations can raise the iron solubility.

The corresponding portions of constituents that partitioned to the liquid phase ranged from $\sim 2$ to $\sim 75 \%$ for gadolinium, $\sim 0.50$ to $\sim 0.75 \%$ for $\mathrm{Pu}-239$, and $\sim 0.03$ to $\sim 0.15 \%$ for iron. In each case, the lower value applied to the $\mathrm{pH} 4$ case and the higher value applied to the $\mathrm{pH} 2$ case. Based on these results, it is clear that the vast majority of the gadolinium, iron, and plutonium stayed together in the solid phase at $\mathrm{pH} 4$. However, at $\mathrm{pH} 2$, the majority of the gadolinium partitioned to the liquid phase, while most of the iron and plutonium remained together in the solid phase. 
Table 5-10. Supernatant Constituent Concentrations in Real-Waste Slurry

\begin{tabular}{|c|c|c|c|c|c|c|}
\hline $\begin{array}{c}\text { Fe:Gd } \\
\text { Ratio }\end{array}$ & \multirow{2}{*}{$\mathbf{p H}$} & \multirow{2}{*}{ Temp } & \multicolumn{4}{|c|}{ Supernatant Concentration, mg/L } \\
\cline { 4 - 7 } & & & Gd & Fe & Pu-239 & Na \\
\hline \multirow{3}{*}{25} & \multirow{2}{*}{4} & $\mathrm{H}$ & 25 & 9.3 & 0.22 & $3.7 \mathrm{E}+4$ \\
\cline { 3 - 7 } & & $\mathrm{C}$ & 19 & 8.8 & 0.22 & $3.8 \mathrm{E}+4$ \\
\cline { 3 - 7 } & \multirow{2}{*}{2} & $\mathrm{H}$ & $8.7 \mathrm{E}+2$ & 49 & 0.33 & $3.8 \mathrm{E}+4$ \\
\cline { 3 - 7 } & & $\mathrm{C}$ & $8.8 \mathrm{E}+2$ & 43 & 0.33 & $3.8 \mathrm{E}+4$ \\
\hline
\end{tabular}

Table 5-11. Soluble Portions of Constituents in Real-Waste Slurry

\begin{tabular}{|l|c|c|c|c|}
\hline \multirow{2}{*}{ Constituent } & \multicolumn{4}{|c|}{ Soluble Portion of Constituent, \% } \\
\cline { 2 - 5 } & pH 4, HOT & pH 4, COLD & pH 2, HOT & pH 2, COLD \\
\hline \hline Gadolinium & 2.3 & 1.7 & 75 & 74 \\
\hline Iron & 0.032 & 0.030 & 0.16 & 0.14 \\
\hline Pu-239 & 0.53 & 0.50 & 0.75 & 0.73 \\
\hline
\end{tabular}

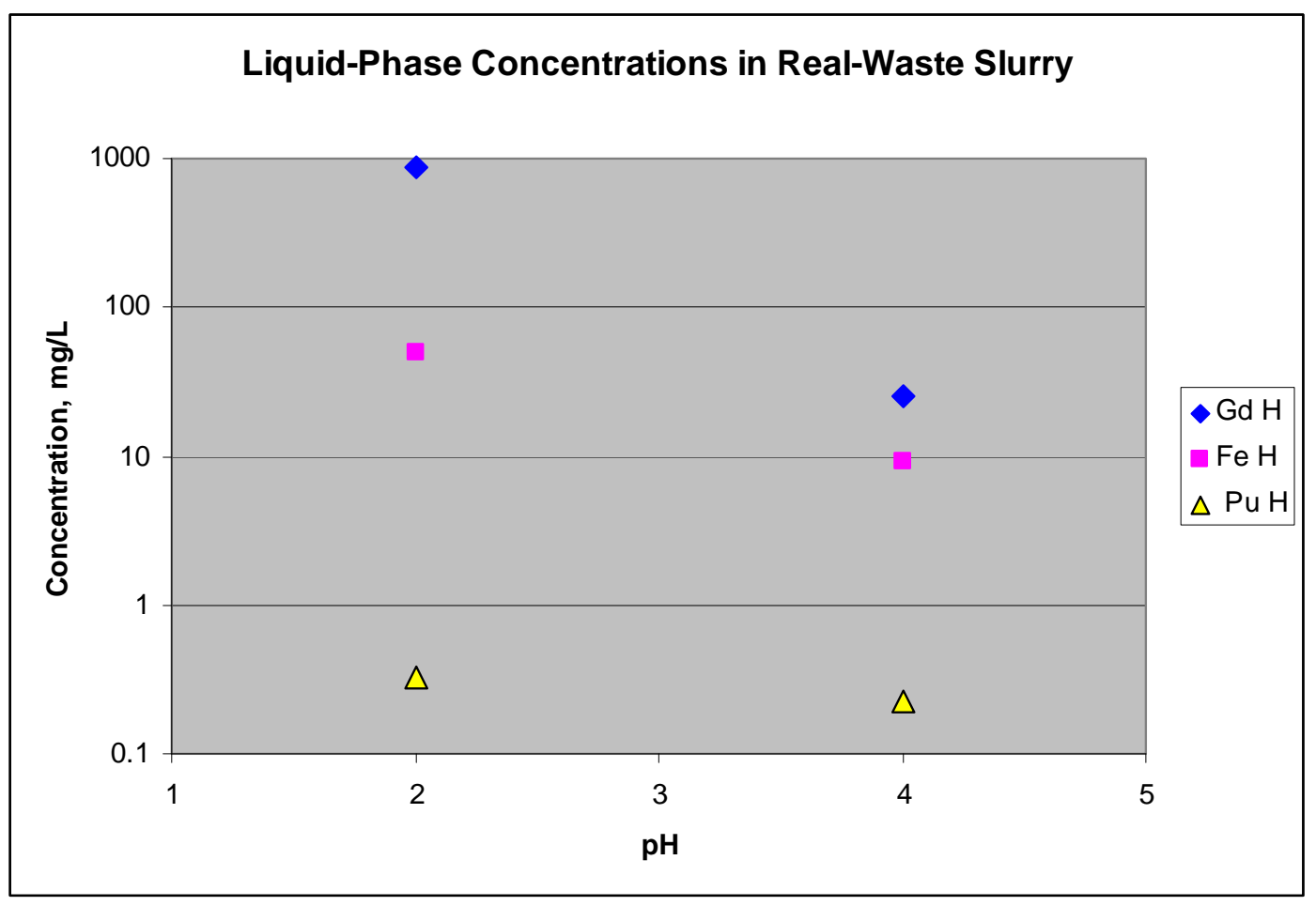

Figure 5-6. Real-Waste Slurry: Supernatant Metal Concentrations at pH 2 and 4 


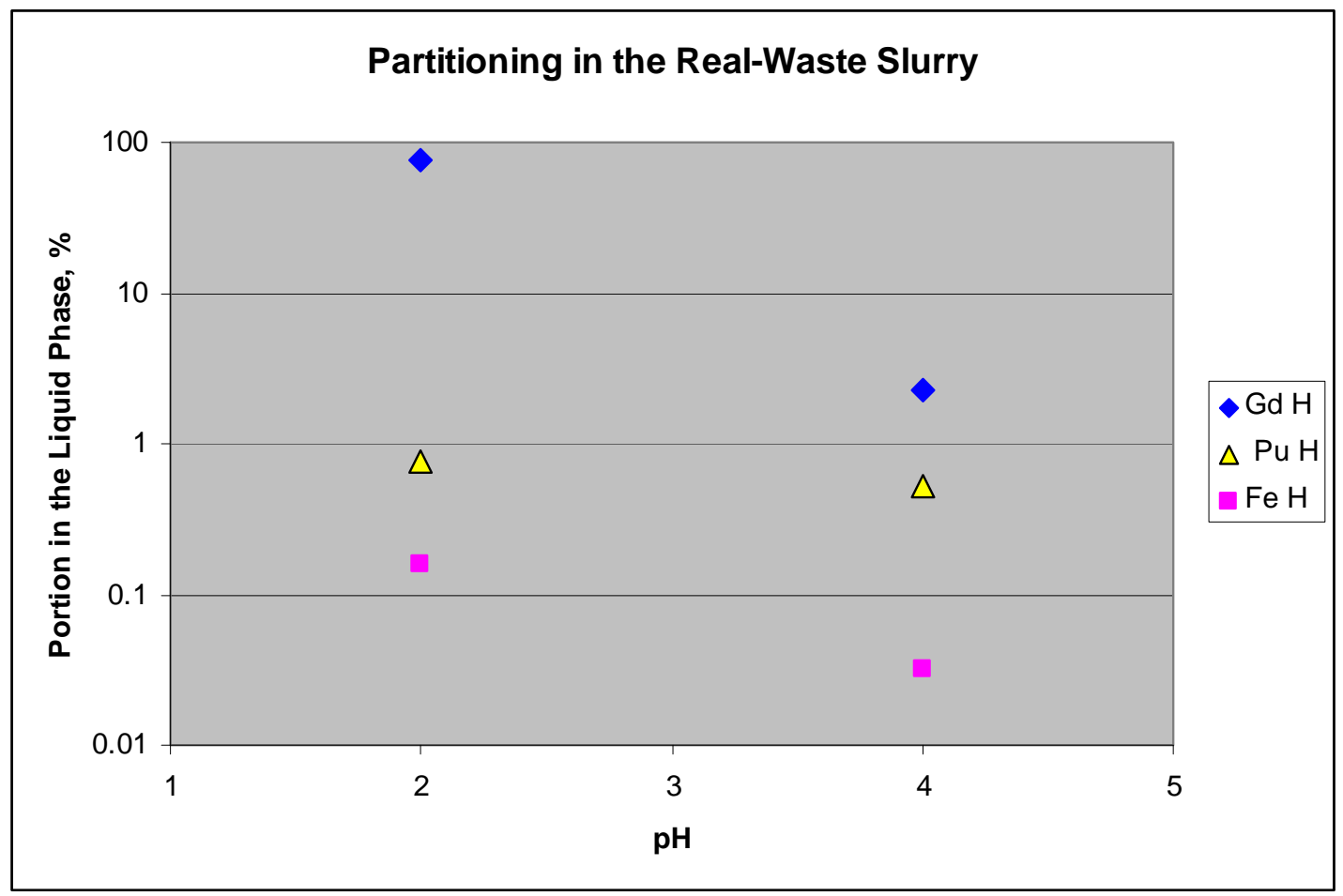

Figure 5-7. Real-Waste Slurry: Soluble Portions of Metals at pH 2 and 4

Comparison of the "hot" and "cold" constituent concentrations showed little or no clear temperature impact (the differences were typically the same magnitude as the expected experimental uncertainties, $\sim 25 \%$, or smaller).

The liquid-phase sodium concentrations were all $\sim 3.8 \mathrm{E}+4 \mathrm{mg} / \mathrm{L}$. These concentrations were $\sim 90 \%$ higher than the supernatant concentrations of the original slurry (see Table 45). The relatively large increases in the liquid-phase sodium concentration were attributed to the same impacts identified for the oxalate-spiked SB6-E slurry: 1) large evaporative losses due to heightened boiling intensities; and 2) additional supernatant sodium due to dissolution of solid-phase sodium oxalate. 
A plot summarizing all of the estimated gadolinium partitioning data for the beaker tests is given as a function of $\mathrm{pH}$ in Figure 5-8. Note that a similar plot for the iron partitioning data has not been presented, since in all tests the soluble portion of iron was trivial $(<1.0 \%)$.

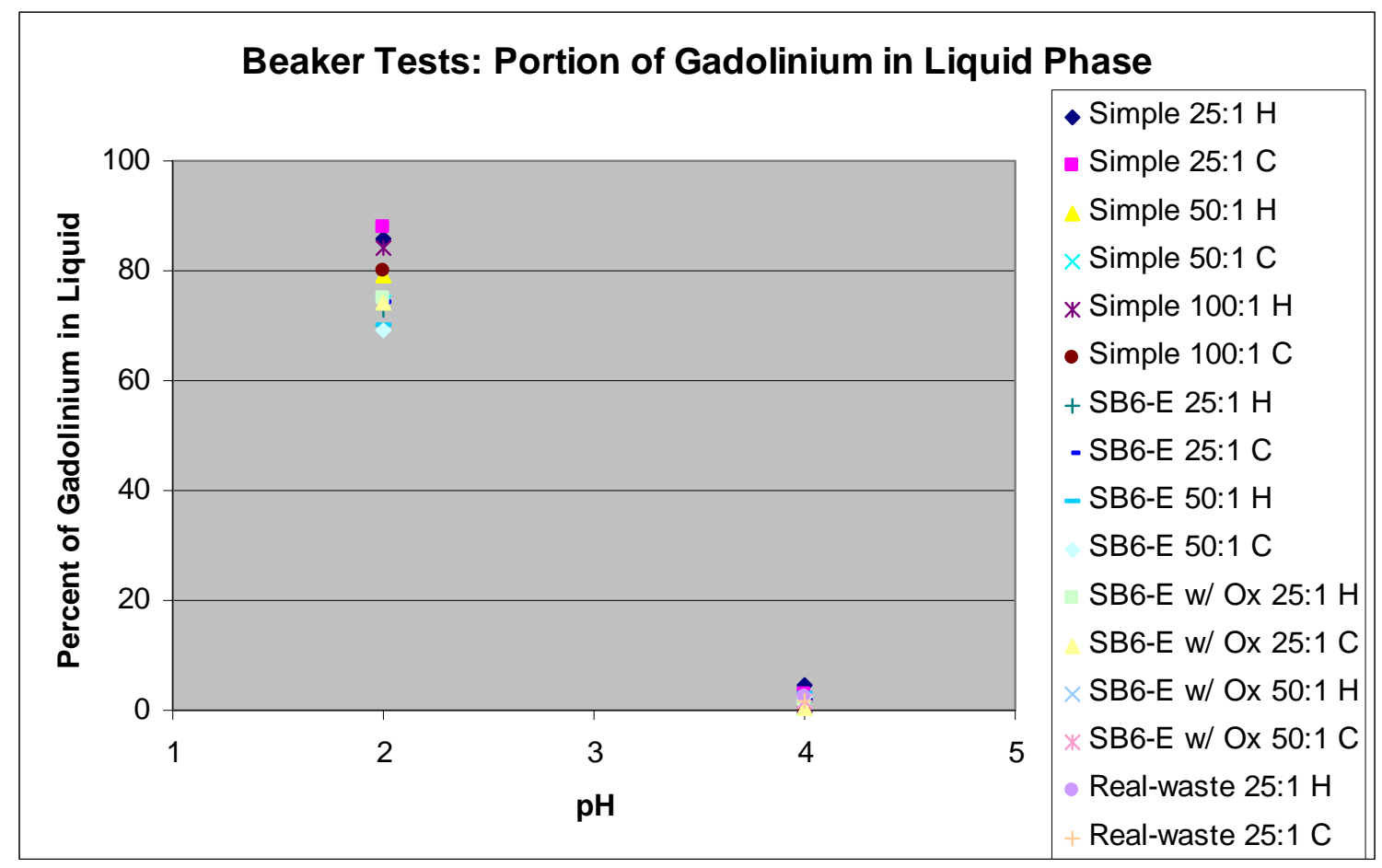

Figure 5-8. Summary of Beaker Test Gd Partitioning Data

Regardless of the slurry matrix, Fe:Gd ratio, and temperature, the portions of gadolinium partitioning to the liquid-phase were major at $\mathrm{pH} 2$ (70-90\%), minor at $\mathrm{pH} 4$ (a few percent or less), and below the minimum detection limits at $\mathrm{pH} 6$. In contrast, the portions of iron partitioning to the liquid-phase over the $\mathrm{pH} 2-6$ range were all very minor $(0.02-0.9 \%)$ or below the minimum detection limits. 


\section{2 $\underline{\text { SRAT Simulations }}$}

SB6-27 (Fe:Gd target of 25; 30\% nitric acid, 70\% formic acid)

Liquid-phase constituent and $\mathrm{pH}$ data for SB6-27 are given in Table 5-12. Plots of the $\mathrm{pH}$ profile, $\mathrm{Gd}$ and $\mathrm{Fe}$ concentrations, and $\mathrm{Gd}$ and $\mathrm{Fe}$ partitioning behavior are given as functions of time in Figures 5-9, 5-10, and 5-11, respectively. SRAT product analyses indicated that the final total solids content was $22.8 \mathrm{wt} \%$ and the Fe:Gd ratio was 28.

Table 5-12. Liquid-Phase Concentrations, Partitioning, and pH during SB6-27

\begin{tabular}{|c|c|c|c|c|c|c|}
\hline \multirow{2}{*}{$\begin{array}{c}\text { Time, } \\
\text { hrs }\end{array}$} & \multirow{2}{*}{$\mathbf{p H}$} & \multicolumn{2}{|c|}{ Liquid-Phase Concentration, mg/L } & \multicolumn{2}{c|}{ Soluble Portion of Constituent, \% } \\
\cline { 3 - 7 } & & Gadolinium & Iron & Sodium & Gadolinium & Iron \\
\hline \hline 4.4 & 6.0 & $2.7 \mathrm{E}-1$ & $4.9 \mathrm{E} 0$ & $1.9 \mathrm{E}+4$ & 0.036 & 0.026 \\
\hline 5.0 & 5.0 & $2.5 \mathrm{E} 0$ & $5.2 \mathrm{E} 0$ & $1.8 \mathrm{E}+4$ & 0.35 & 0.029 \\
\hline 6.1 & 4.0 & $7.9 \mathrm{E}+1$ & $2.5 \mathrm{E}+1$ & $1.8 \mathrm{E}+4$ & 11 & 0.13 \\
\hline 6.9 & 3.6 & $1.6 \mathrm{E}+2$ & $5.0 \mathrm{E}+1$ & $1.9 \mathrm{E}+4$ & 21 & 0.27 \\
\hline 10.3 & 4.2 & $1.8 \mathrm{E}+2$ & $4.2 \mathrm{E}+3$ & $2.4 \mathrm{E}+4$ & 19 & 18 \\
\hline 13.3 & 4.4 & $1.5 \mathrm{E}+2$ & $5.0 \mathrm{E}+3$ & $2.7 \mathrm{E}+4$ & 14 & 18 \\
\hline 16.3 & 4.6 & $9.7 \mathrm{E}+1$ & $4.6 \mathrm{E}+3$ & $2.4 \mathrm{E}+4$ & 10 & 19 \\
\hline 19.3 & 5.0 & $4.2 \mathrm{E}+1$ & $3.6 \mathrm{E}+3$ & $2.5 \mathrm{E}+4$ & 4.1 & 14 \\
\hline 20.0 & 5.2 & $4.0 \mathrm{E}+1$ & $1.7 \mathrm{E}+3$ & $2.7 \mathrm{E}+4$ & 3.8 & 6.4 \\
\hline
\end{tabular}

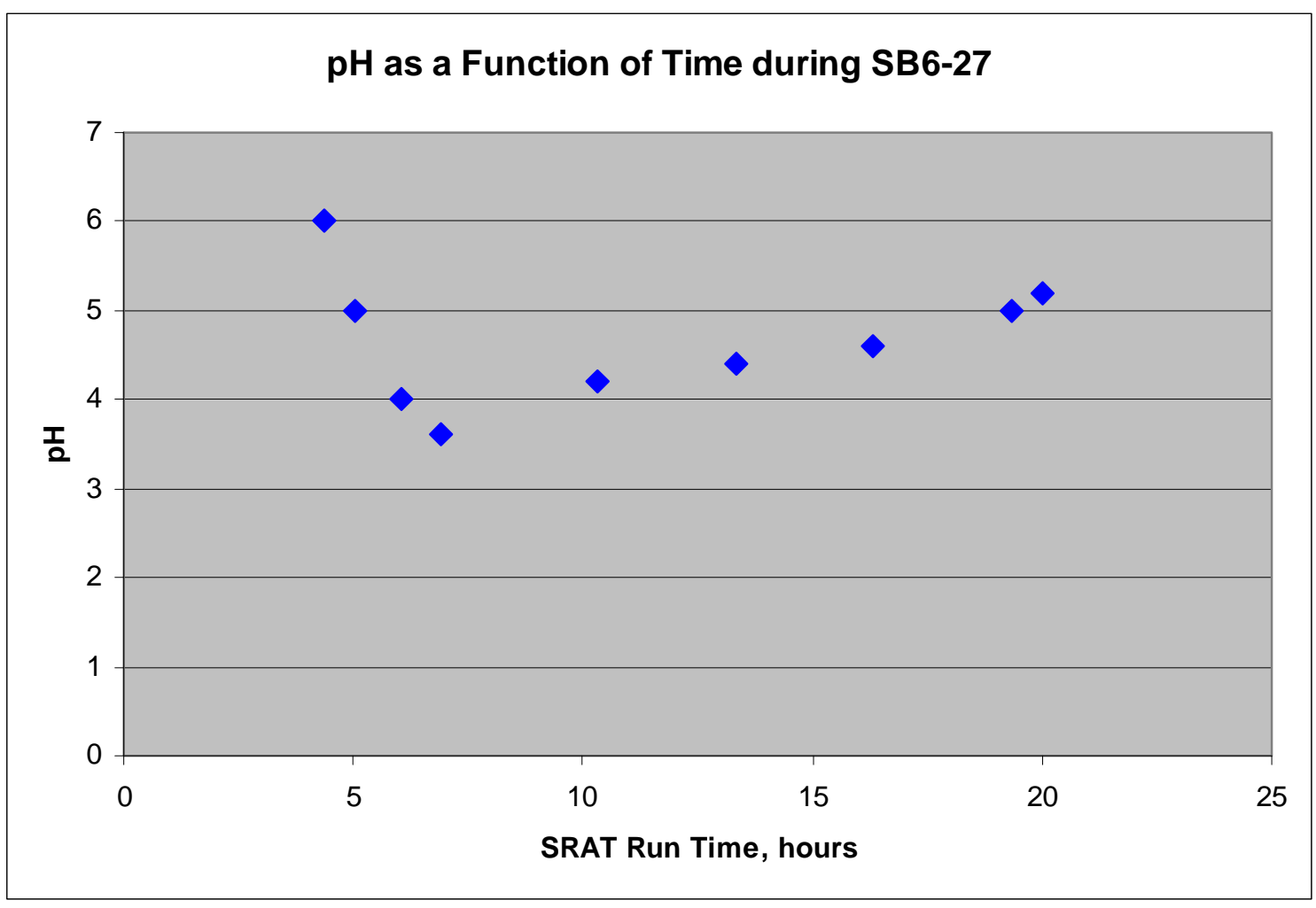

Figure 5-9. SB6-27: pH Profile 


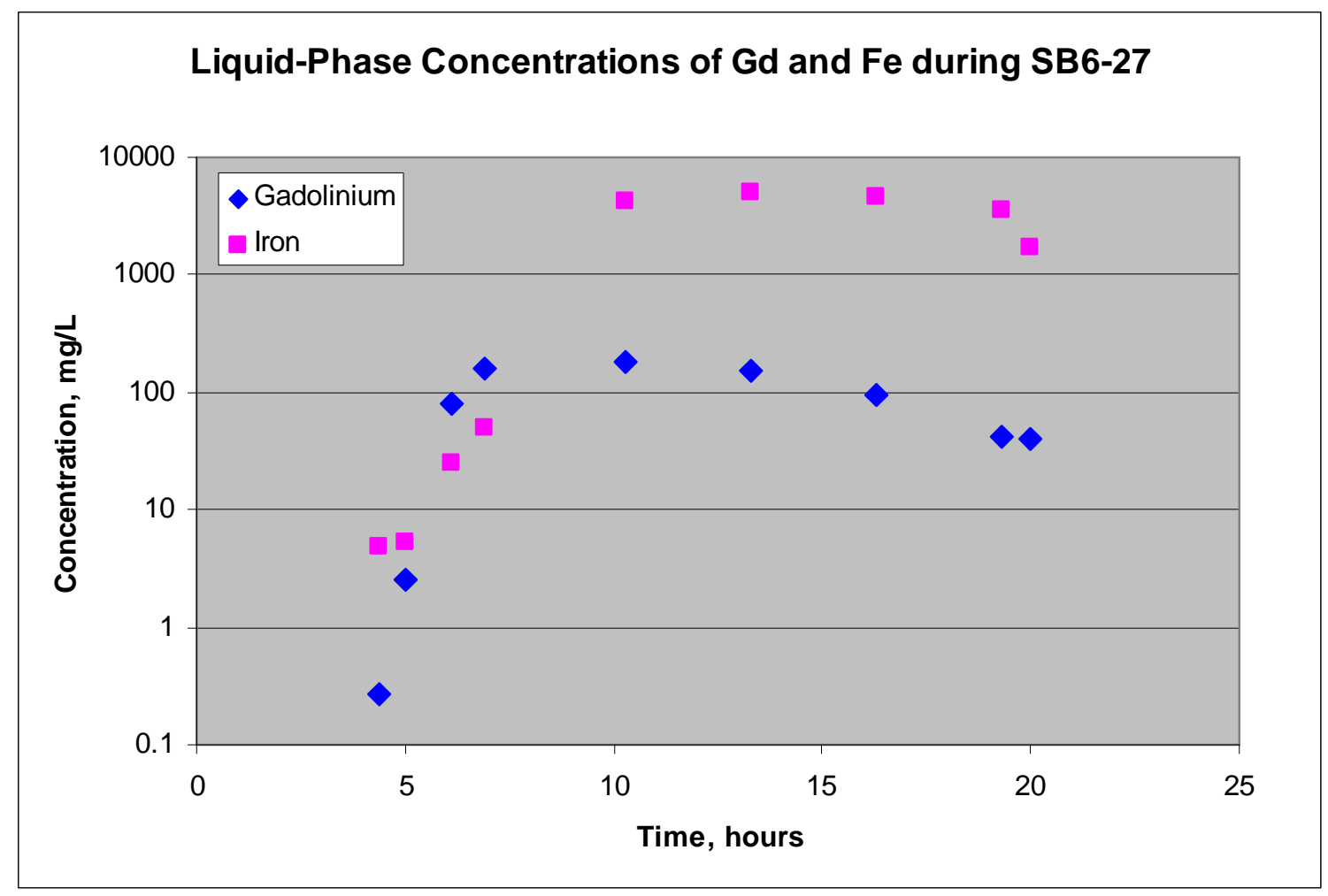

Figure 5-10. SB6-27: Gd and Fe Supernatant Concentrations

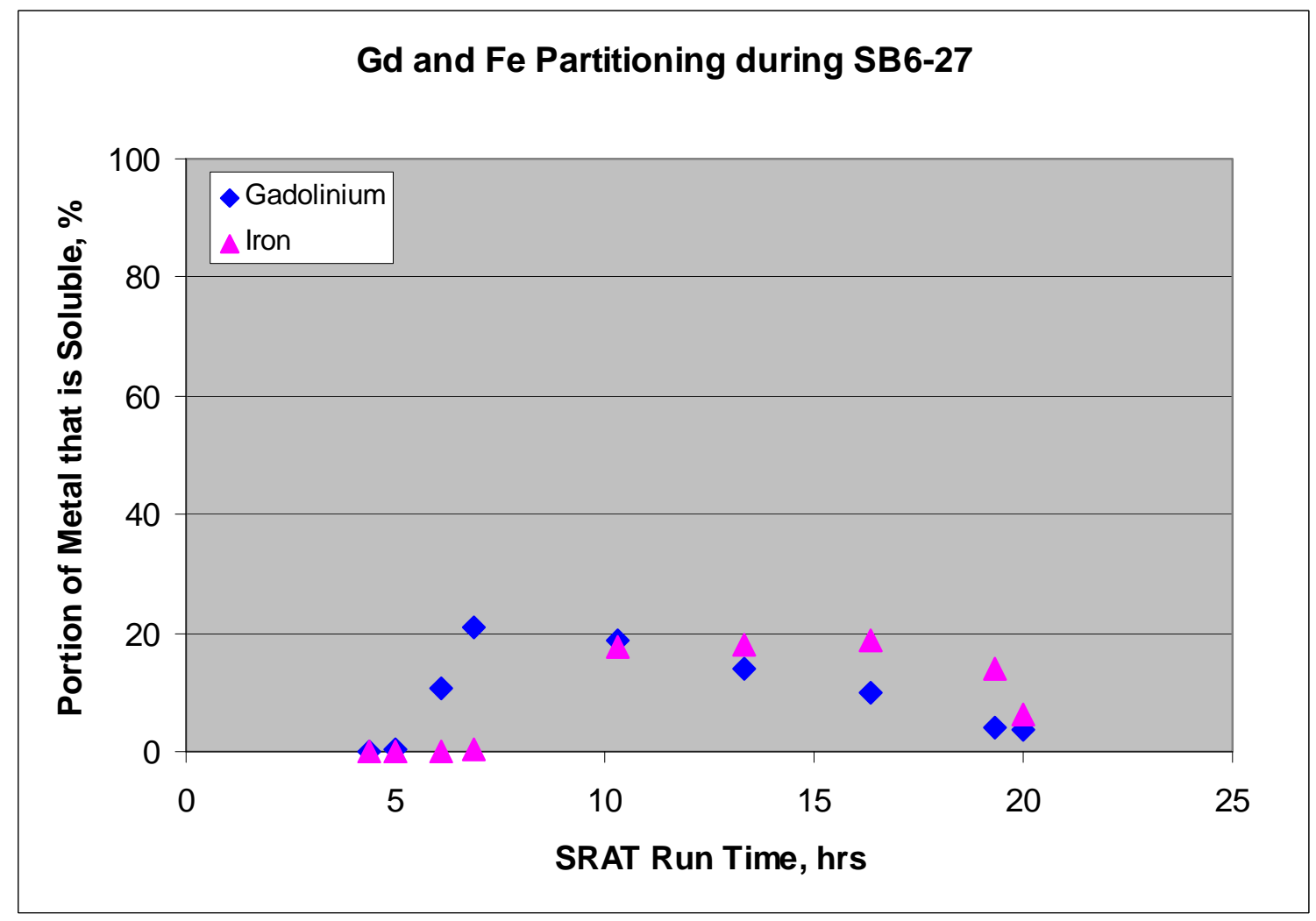

Figure 5-11. SB6-27: Gd and Fe Partitioning 
As shown in Figure 5-9, the acid additions of SB6-27 reduced the slurry pH to a minimum value of 3.6, which occurred about seven hours into the SRAT simulation. Approximately 2.5 hours earlier $(\mathrm{t}=4.4 \mathrm{hrs})$, the $\mathrm{pH}$ was 6.0 , and by the end of the simulation $(\mathrm{t}=20.0 \mathrm{hrs})$, the $\mathrm{pH}$ had risen from 3.6 to 5.2 .

Over the time period from $t=4.4$ hours until the end of the simulation, the liquid-phase gadolinium concentrations varied by a factor of $\sim 600$ and the liquid-phase iron concentrations varied by a factor of $\sim 1000$ (see Figure 5-10). Specifically, the gadolinium concentrations ranged from $\sim 0.3$ to $\sim 180 \mathrm{mg} / \mathrm{L}$, with the minimum observed at $\mathrm{t}=4.4$ hours and the maximum observed at $\mathrm{t}=10.3$ hours. In contrast, the iron concentrations ranged from $\sim 5$ to $\sim 5000 \mathrm{mg} / \mathrm{L}$, with the minimum observed at $\mathrm{t}=4.4$ hours and the maximum observed at $t=13.3$ hours.

The corresponding portions of gadolinium and iron partitioning to the liquid-phase ranged from $\sim 0.04 \%$ to $\sim 21 \%$ and $\sim 0.03 \%$ to $\sim 19 \%$, respectively (see Figure $5-11$ ). Despite the higher relative iron concentrations, the partitioning behaviors of the gadolinium and iron were very similar to one another. However, the partitioning of iron into the liquid-phase lagged several hours behind the partitioning of gadolinium. This can be seen in Figure 5-11, where the highest partitioning values for iron appear to the right of the highest partitioning values for gadolinium. This difference suggests that the dissolution of solid-phase iron was significantly slower than that of solid-phase gadolinium.

The liquid-phase sodium concentrations during SB6-27 ranged from $1.8 \mathrm{E}+4$ to $2.7 \mathrm{E}+4$ $\mathrm{mg} / \mathrm{L}$. These concentrations indicate that acid additions diluted the slurry by $\sim 10 \%$, and boiling/evaporation removed about one-third of the total water. The total solids content and the Fe:Gd ratio measurements of the SB6-27 SRAT product (22.8 wt\% and 28, respectively) are consistent with expectations (taking analytical uncertainties into account) and provide assurance that the SRAT simulation was executed properly. 
SB6-28 (Fe:Gd target of 25; $10 \%$ nitric acid, 90\% formic acid)

Liquid-phase constituent and $\mathrm{pH}$ data for SB6-28 are given in Table 5-13. Plots of the $\mathrm{pH}$ profile, $\mathrm{Gd}$ and $\mathrm{Fe}$ concentrations, and $\mathrm{Gd}$ and $\mathrm{Fe}$ partitioning behavior are given as functions of time in Figures 5-12, 5-13, and 5-14, respectively. SRAT product analyses indicated that the final total solids content was $22.8 \mathrm{wt} \%$ and the Fe:Gd ratio was 28.

Table 5-13. Liquid-Phase Concentrations, Partitioning, and pH during SB6-28

\begin{tabular}{|c|c|c|c|c|c|c|}
\hline \multirow{2}{*}{$\begin{array}{c}\text { Time, } \\
\text { hrs }\end{array}$} & \multirow{2}{*}{$\mathbf{p H}$} & \multicolumn{2}{|c|}{ Liquid-phase Concentration, mg/L } & \multicolumn{2}{c|}{ Soluble Portion of Constituent, \% } \\
\cline { 3 - 7 } & & Gadolinium & Iron & Sodium & Gadolinium & Iron \\
\hline \hline 3.7 & 6.0 & $5.8 \mathrm{E}-1$ & $8.8 \mathrm{E} 0$ & $1.8 \mathrm{E}+4$ & 0.082 & 0.048 \\
\hline 4.3 & 5.0 & $6.5 \mathrm{E} 0$ & $4.7 \mathrm{E} 0$ & $2.0 \mathrm{E}+4$ & 0.84 & 0.023 \\
\hline 6.1 & 4.0 & $1.2 \mathrm{E}+2$ & $6.2 \mathrm{E}+1$ & $1.9 \mathrm{E}+4$ & 17 & 0.32 \\
\hline 9.7 & 4.6 & $1.2 \mathrm{E}+2$ & $3.7 \mathrm{E}+3$ & $2.2 \mathrm{E}+4$ & 14 & 16 \\
\hline 12.7 & 4.9 & $9.4 \mathrm{E}+1$ & $5.1 \mathrm{E}+3$ & $2.6 \mathrm{E}+4$ & 9.1 & 19 \\
\hline 15.7 & 5.6 & $1.4 \mathrm{E}+1$ & $2.3 \mathrm{E}+3$ & $2.5 \mathrm{E}+4$ & 1.4 & 0.0 \\
\hline 18.7 & 6.1 & $3.9 \mathrm{E} 0$ & $2.4 \mathrm{E}+2$ & $2.7 \mathrm{E}+4$ & 0.37 & 0.0028 \\
\hline 19.0 & 6.3 & $1.6 \mathrm{E} 0$ & $7.9 \mathrm{E}-1$ & $2.7 \mathrm{E}+4$ & 0.15 & \\
\hline
\end{tabular}

$\mathrm{pH}$ as a Function of Time during SB6-28

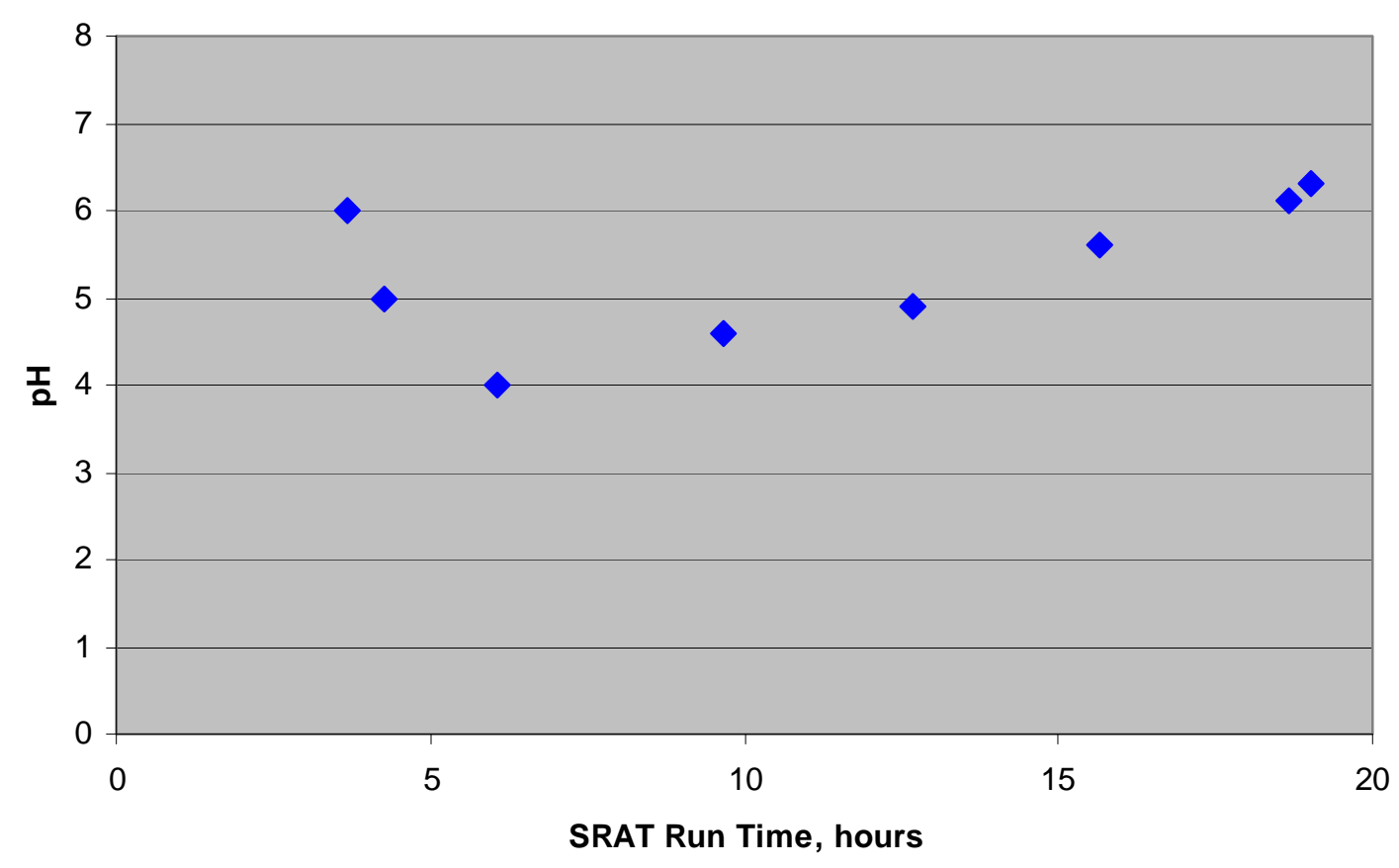

Figure 5-12. SB6-28: pH Profile 


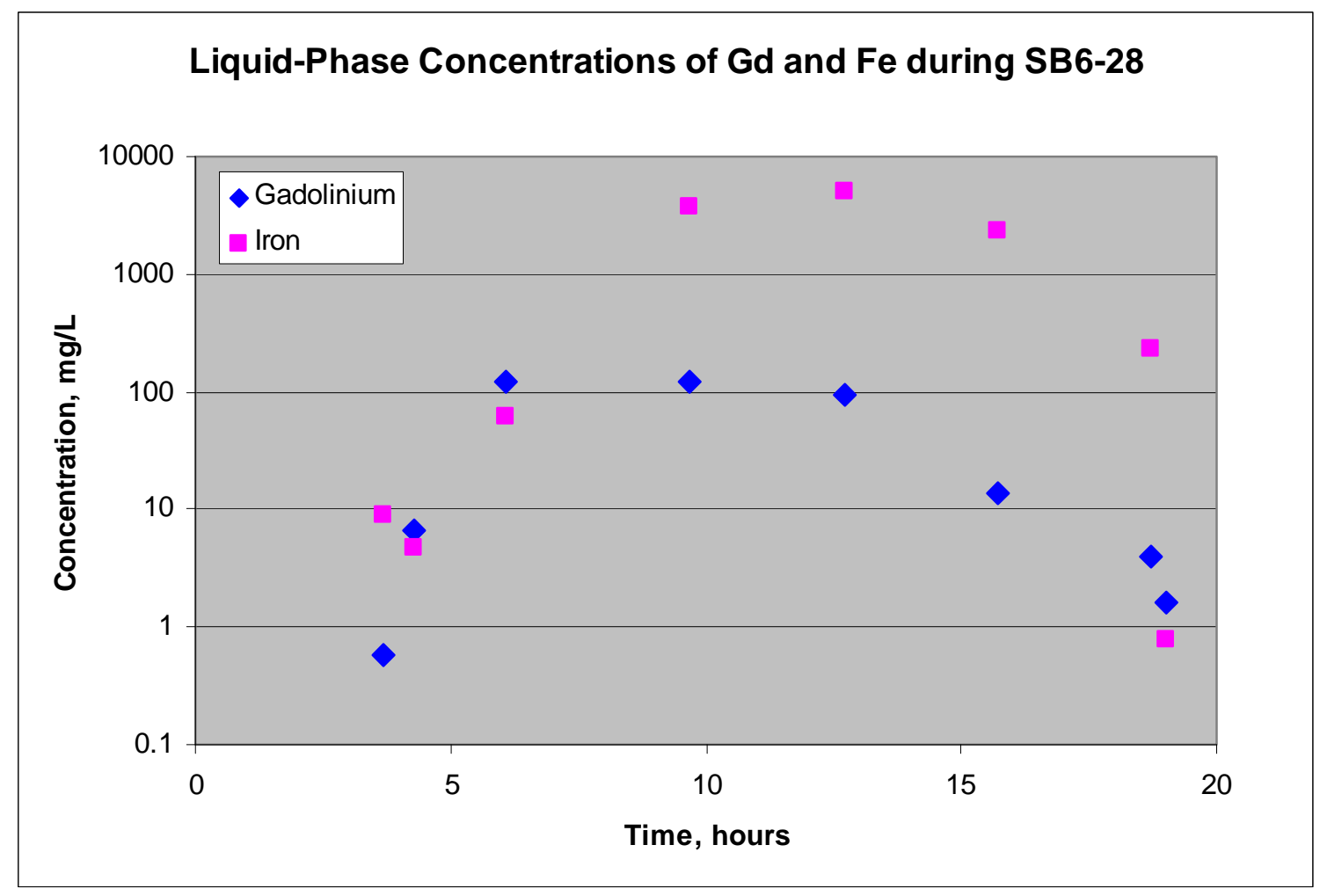

Figure 5-13. SB6-28: Gd and Fe Supernatant Concentrations

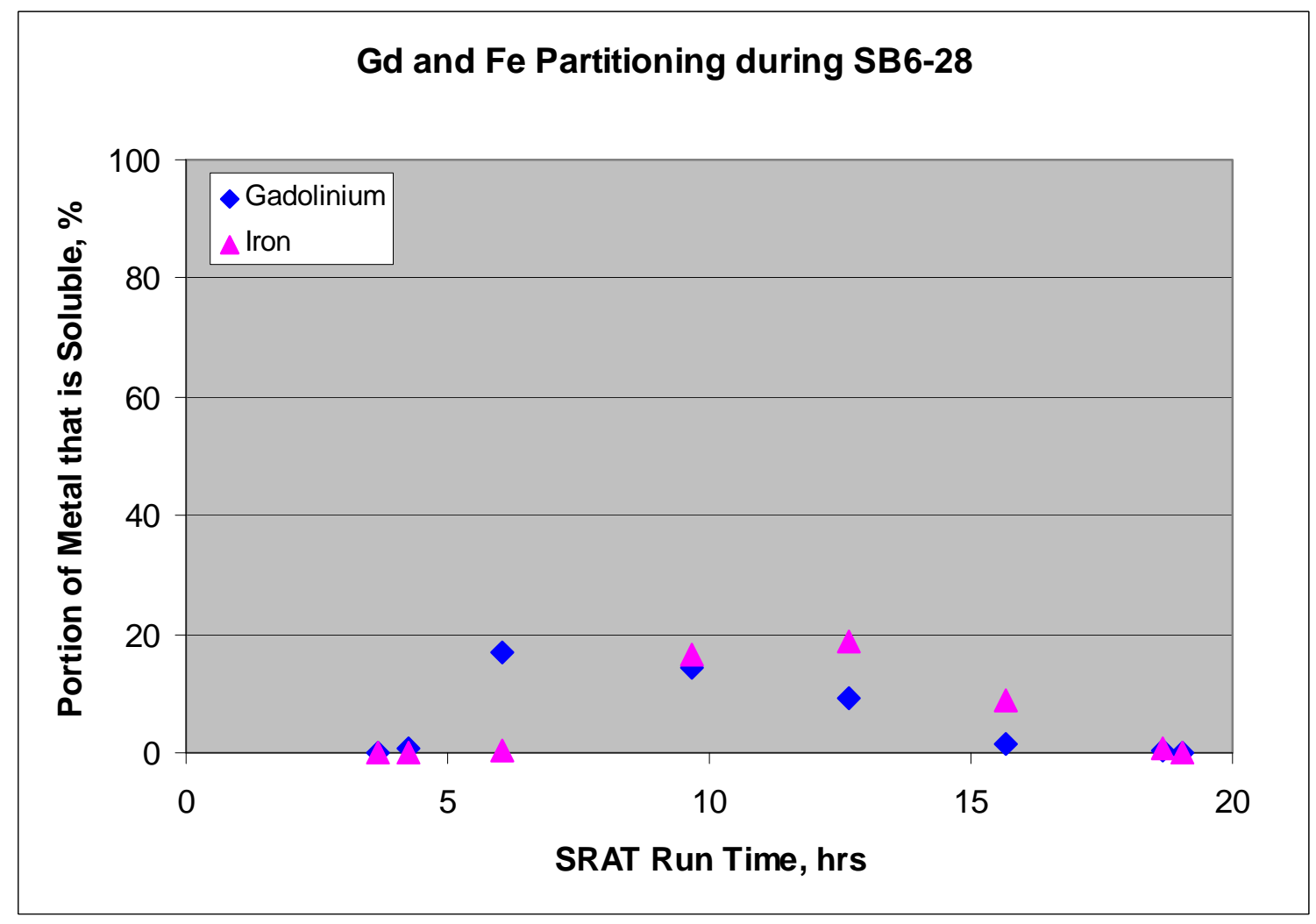

Figure 5-14. SB6-28: Gd and Fe Partitioning 
As shown in Figure 5-12, the acid additions of SB6-28 reduced the slurry pH to a minimum value of 4.0, which occurred about six hours into the SRAT simulation. Approximately 2.5 hours earlier $(\mathrm{t}=3.7 \mathrm{hrs})$, the $\mathrm{pH}$ was 6.0 , and by the end of the simulation $(\mathrm{t}=19.0 \mathrm{hrs})$, the $\mathrm{pH}$ had risen from 4.0 to 6.3 . Note that both the minimum and final $\mathrm{pH}$ values of SB6-28 were higher than those of SB6-27. These differences were attributed to the lower fraction of nitric acid utilized in the SB6-28 simulation (10\% nitric acid in SB6-28 versus 30\% nitric acid in SB6-27).

Over the time period from $t=3.7$ hours until the end of the simulation, the liquid-phase gadolinium concentrations varied by a factor of $\sim 200$ and the liquid-phase iron concentrations varied by a factor of $\sim 6500$ (see Figure 5-13). Specifically, the gadolinium concentrations ranged from $\sim 0.6$ to $\sim 120 \mathrm{mg} / \mathrm{L}$, with the minimum observed at $\mathrm{t}=3.7$ hours and the maximum observed between $\mathrm{t} \approx 6$ and $\mathrm{t} \approx 10$ hours. In contrast, the iron concentrations ranged from $\sim 0.8$ to $\sim 5000 \mathrm{mg} / \mathrm{L}$, with the minimum observed at the end of the simulation ( $\mathrm{t}=19.0$ hours) and the maximum observed at $\mathrm{t}=12.7$ hours.

The corresponding portions of gadolinium and iron partitioning to the liquid-phase ranged from $\sim 0.08 \%$ to $\sim 17 \%$ and $\sim 0.003 \%$ to $\sim 19 \%$, respectively (see Figure $5-14$ ). Clearly, the maximum portions of gadolinium and iron partitioning to the liquid phase were similar to one another, and consistent with the maximum portions identified in the previous SRAT simulation (SB6-27). Also consistent with the previous SRAT simulation was the lagging of iron dissolution behind gadolinium dissolution, by several hours.

The liquid-phase sodium concentrations during SB6-28 ranged from 1.8E+4 to $2.7 \mathrm{E}+4$ $\mathrm{mg} / \mathrm{L}$, the same as observed in SB6-27. The total solids content and the Fe:Gd ratio measurements of the SB6-28 SRAT product (22.8 $\mathrm{wt} \%$ and 28 , respectively) are consistent with expectations (taking analytical uncertainties into account) and provide assurance that the SRAT simulation was executed properly. 
SB6-29 (Fe:Gd target of 50; 30\% nitric acid, 70\% formic acid)

Liquid-phase constituent and $\mathrm{pH}$ data for SB6-29 are given in Table 5-14. Plots of the $\mathrm{pH}$ profile, $\mathrm{Gd}$ and $\mathrm{Fe}$ concentrations, and $\mathrm{Gd}$ and $\mathrm{Fe}$ partitioning behavior are given as functions of time in Figures 5-15, 5-16, and 5-17, respectively. SRAT product analyses indicated that the final total solids content was $21.4 \mathrm{wt} \%$ and the Fe:Gd ratio was 49.

Table 5-14. Liquid-Phase Concentrations, Partitioning, and pH during SB6-29

\begin{tabular}{|c|c|c|c|c|c|c|}
\hline Time, & \multirow{2}{*}{ pH } & \multicolumn{2}{|c|}{ Liquid-phase Concentration, mg/L } & \multicolumn{2}{c|}{ Soluble Portion of Constituent, \% } \\
\cline { 3 - 7 } & & Gadolinium & Iron & Sodium & Gadolinium & Iron \\
\hline \hline 3.8 & 6.0 & $2.0 \mathrm{E}-1$ & $3.8 \mathrm{E} 0$ & $1.8 \mathrm{E}+4$ & 0.049 & 0.021 \\
\hline 4.3 & 5.0 & $3.6 \mathrm{E}-1$ & $4.1 \mathrm{E} 0$ & $1.9 \mathrm{E}+4$ & 0.089 & 0.022 \\
\hline 5.2 & 4.0 & $1.7 \mathrm{E}+1$ & $2.6 \mathrm{E}+1$ & $1.7 \mathrm{E}+4$ & 4.5 & 0.16 \\
\hline 6.6 & 3.5 & $6.2 \mathrm{E}+1$ & $9.1 \mathrm{E}+1$ & $1.8 \mathrm{E}+4$ & 16 & 0.52 \\
\hline 9.9 & 4.1 & $7.8 \mathrm{E}+1$ & $4.5 \mathrm{E}+3$ & $2.1 \mathrm{E}+4$ & 17 & 21 \\
\hline 12.9 & 4.4 & $6.8 \mathrm{E}+1$ & $5.7 \mathrm{E}+3$ & $2.5 \mathrm{E}+4$ & 13 & 23 \\
\hline 15.9 & 4.7 & $4.0 \mathrm{E} 0$ & $5.1 \mathrm{E}+3$ & $2.4 \mathrm{E}+4$ & 7.6 & 22 \\
\hline 18.9 & 4.9 & $2.4 \mathrm{E}+1$ & $4.1 \mathrm{E}+3$ & $2.4 \mathrm{E}+4$ & 4.5 & 17 \\
\hline 21.8 & 5.3 & $1.1 \mathrm{E}+1$ & $4.0 \mathrm{E}+3$ & $2.6 \mathrm{E}+4$ & 2.0 & 16 \\
\hline
\end{tabular}

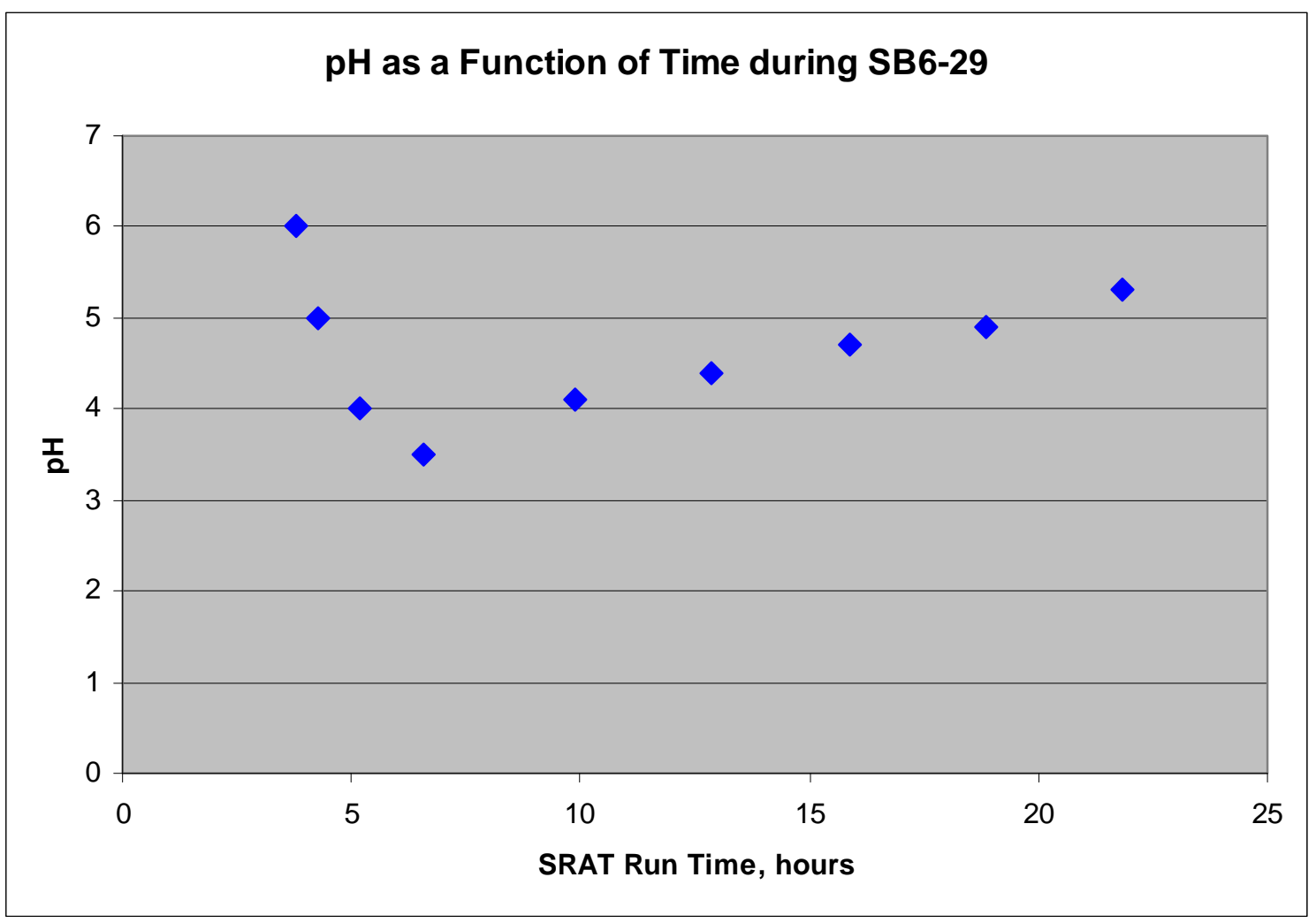

Figure 5-15. SB6-29: pH Profile 


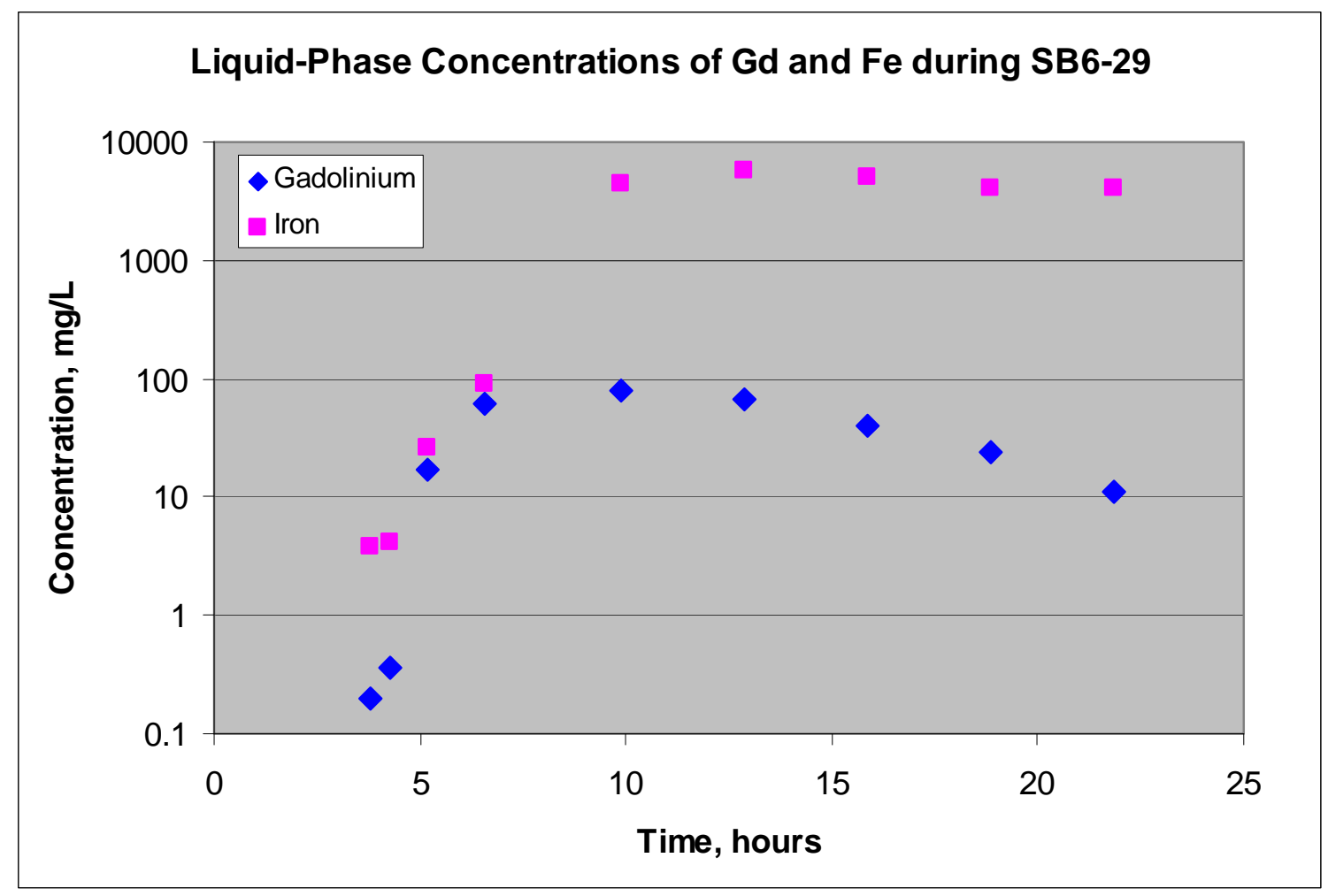

Figure 5-16. SB6-29: Gd and Fe Supernatant Concentrations

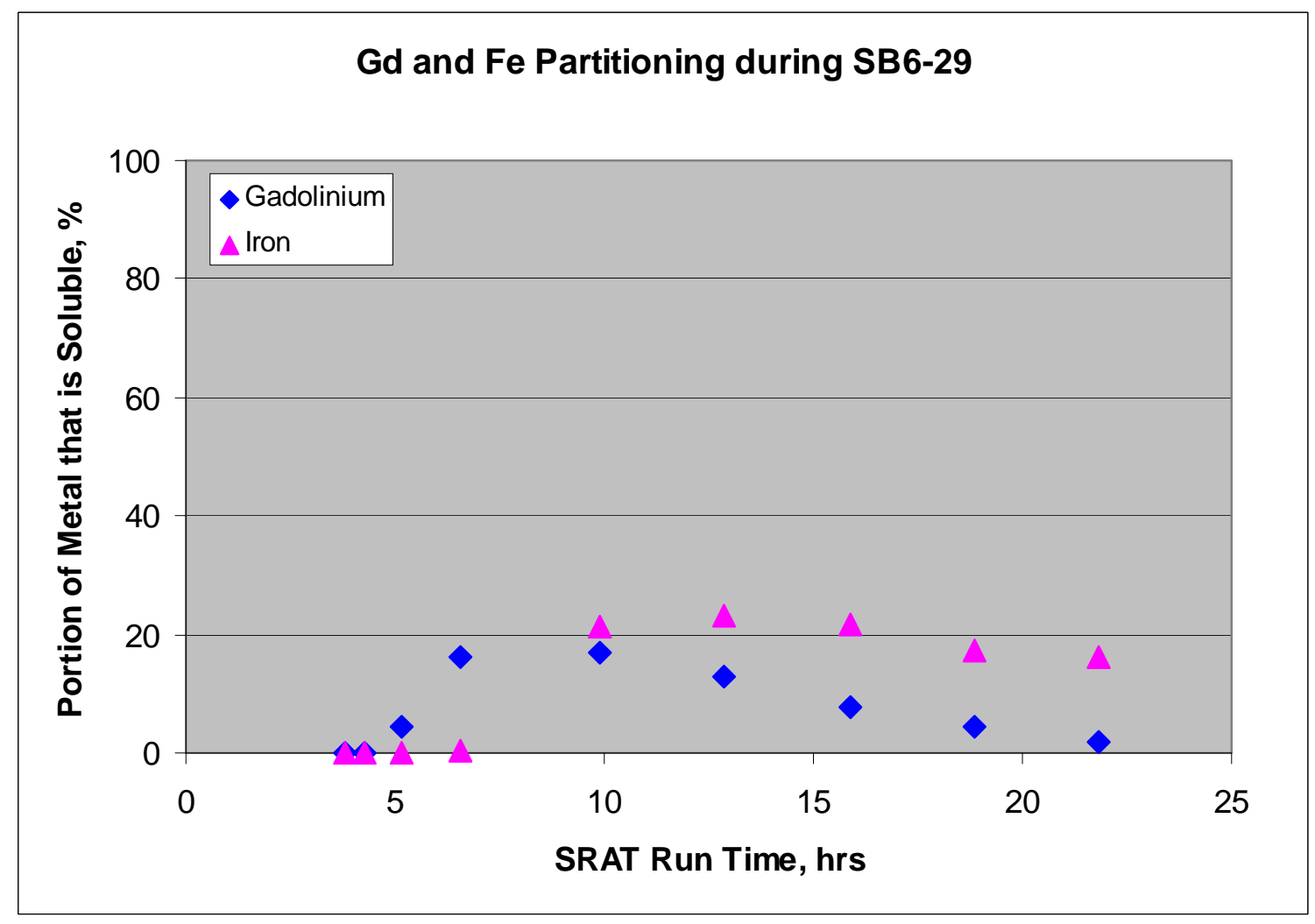

Figure 5-17. SB6-29: Gd and Fe Partitioning 
As shown in Figure 5-15, the acid additions of SB6-29 reduced the slurry pH to a minimum value of 3.5 , which occurred about seven hours into the SRAT simulation. Approximately three hours earlier $(\mathrm{t}=3.8 \mathrm{hrs})$, the $\mathrm{pH}$ was 6.0 , and by the end of the simulation ( $\mathrm{t}=21.8 \mathrm{hrs})$, the $\mathrm{pH}$ had risen from 3.5 to 5.3. The minimum and final $\mathrm{pH}$ values of SB6-29 were very similar to those of SB6-27. This similarity was expected, since SB6-27 and SB6-29 were both acidified identically (30\% nitric acid and 70\% formic acid).

Over the time period from $\mathrm{t}=3.8$ hours until the end of the simulation, the liquid-phase gadolinium concentrations varied by a factor of $\sim 400$ and the liquid-phase iron concentrations varied by a factor of $\sim 1500$ (see Figure 5-16). Specifically, the gadolinium concentrations ranged from $\sim 0.2$ to $\sim 80 \mathrm{mg} / \mathrm{L}$, with the minimum observed at $\mathrm{t}=3.8$ hours and the maximum observed at $\mathrm{t} \approx 10$ hours. In contrast, the iron concentrations ranged from $\sim 4$ to $\sim 5700 \mathrm{mg} / \mathrm{L}$, with the minimum observed at $\mathrm{t}=3.8$ hours and the maximum observed at $\mathrm{t}=12.9$ hours.

The maximum liquid-phase concentration of gadolinium in SB6-29 was about half that observed in SB6-27 (the other simulation with identical acid addition). These data support the hypothesis that gadolinium solubility decreases as the Fe:Gd ratio increases, since the only difference between the SB6-29 and SB6-27 simulations was that the SB629 slurry contained half the gadolinium of the SB6-27 slurry (50:1 Fe:Gd for SB6-29 and 25:1 Fe:Gd for SB6-27).

The corresponding portions of gadolinium and iron partitioning to the liquid-phase ranged from $\sim 0.05 \%$ to $\sim 17 \%$ and $\sim 0.02 \%$ to $\sim 23 \%$, respectively (see Figure $5-17$ ). As in the previous two SRAT simulations, the maximum portions of gadolinium and iron that were soluble during SB7-29 were the same order of magnitude $(\sim 20 \%)$, despite the significantly lower slurry gadolinium content of SB6-29 (half that of the SB6-27 and SB6-28 slurries). Also consistent with the previous SRAT simulations was the lagging of iron dissolution behind gadolinium dissolution by several hours.

The liquid-phase sodium concentrations during SB6-29 ranged from $1.8 \mathrm{E}+4$ to $2.6 \mathrm{E}+4$ $\mathrm{mg} / \mathrm{L}$. The similarity between these concentrations and the ones observed in SB6-27 and SB6-28 is not unexpected given the typical consistency of SRAT simulation operations. The total solids content and the Fe:Gd ratio measurements of the SB6-29 SRAT product (21.4 $\mathrm{wt} \%$ and 49, respectively) are consistent with expectations (taking analytical uncertainties into account) and provide assurance that the SRAT simulation was executed properly. 
SB6-30 (Fe:Gd target of 50; 10\% nitric acid, 90\% formic acid)

Note: SRAT run SB6-30 is considered anomalous since the quantity of insoluble solids was approximately $\mathbf{5 0 \%}$ lower than planned. This was apparently due to inadequate mixing of the slurry prior to transfer into the SRAT rig. As a result, the acid stoichiometry and $\mathrm{Fe}$ : Gd ratio were both significantly different from the targets. For this reason, the SB6-30 data should not be considered representative of data obtained under typical baseline conditions.

Liquid-phase constituent and $\mathrm{pH}$ data for SB6-30 are given in Table 5-15. Plots of the $\mathrm{pH}$ profile, $\mathrm{Gd}$ and $\mathrm{Fe}$ concentrations, and $\mathrm{Gd}$ and $\mathrm{Fe}$ partitioning behavior are given as functions of time in Figures 5-18, 5-19, and 5-20, respectively. SRAT product analyses indicated that the final total solids content was $17.1 \mathrm{wt} \%$ and the Fe:Gd ratio was 26.

Table 5-15. Liquid-Phase Concentrations, Partitioning, and pH during SB6-30

\begin{tabular}{|c|c|c|c|c|c|c|}
\hline $\begin{array}{c}\text { Time, } \\
\text { hrs }\end{array}$ & \multirow{2}{*}{$\mathbf{p H}$} & \multicolumn{2}{|c|}{ Liquid-phase Concentration, mg/L } & \multicolumn{2}{c|}{ Soluble Portion of Constituent, \% } \\
\cline { 3 - 7 } & Gadolinium & Iron & Sodium & Gadolinium & Iron \\
\hline \hline 3.1 & 6.0 & $2.7 \mathrm{E}-1$ & $5.3 \mathrm{E} 0$ & $1.6 \mathrm{E}+4$ & 0.088 & 0.065 \\
\hline 3.4 & 5.0 & $2.1 \mathrm{E} 0$ & $2.6 \mathrm{E} 0$ & $1.7 \mathrm{E}+4$ & 0.67 & 0.031 \\
\hline 5.1 & 4.0 & $5.9 \mathrm{E}+1$ & $3.5 \mathrm{E}+1$ & $1.7 \mathrm{E}+4$ & 18 & 0.40 \\
\hline 5.6 & 3.7 & $9.4 \mathrm{E}+1$ & $3.1 \mathrm{E}+2$ & $1.7 \mathrm{E}+4$ & 29 & 3.6 \\
\hline 9.1 & 4.1 & $2.4 \mathrm{E}+2$ & $6.1 \mathrm{E}+3$ & $2.4 \mathrm{E}+4$ & 53 & 51 \\
\hline 12.1 & 4.4 & $2.7 \mathrm{E}+2$ & $7.4 \mathrm{E}+3$ & $2.4 \mathrm{E}+4$ & 59 & 60 \\
\hline 15.2 & 4.8 & $2.2 \mathrm{E}+2$ & $9.0 \mathrm{E}+3$ & $2.5 \mathrm{E}+4$ & 46 & 72 \\
\hline 18.1 & 5.3 & $1.2 \mathrm{E}+2$ & $8.7 \mathrm{E}+3$ & $2.4 \mathrm{E}+4$ & 26 & 70 \\
\hline 18.6 & 5.4 & $4.9 \mathrm{E}+1$ & $3.9 \mathrm{E}+3$ & $2.6 \mathrm{E}+4$ & 9.7 & 30 \\
\hline
\end{tabular}




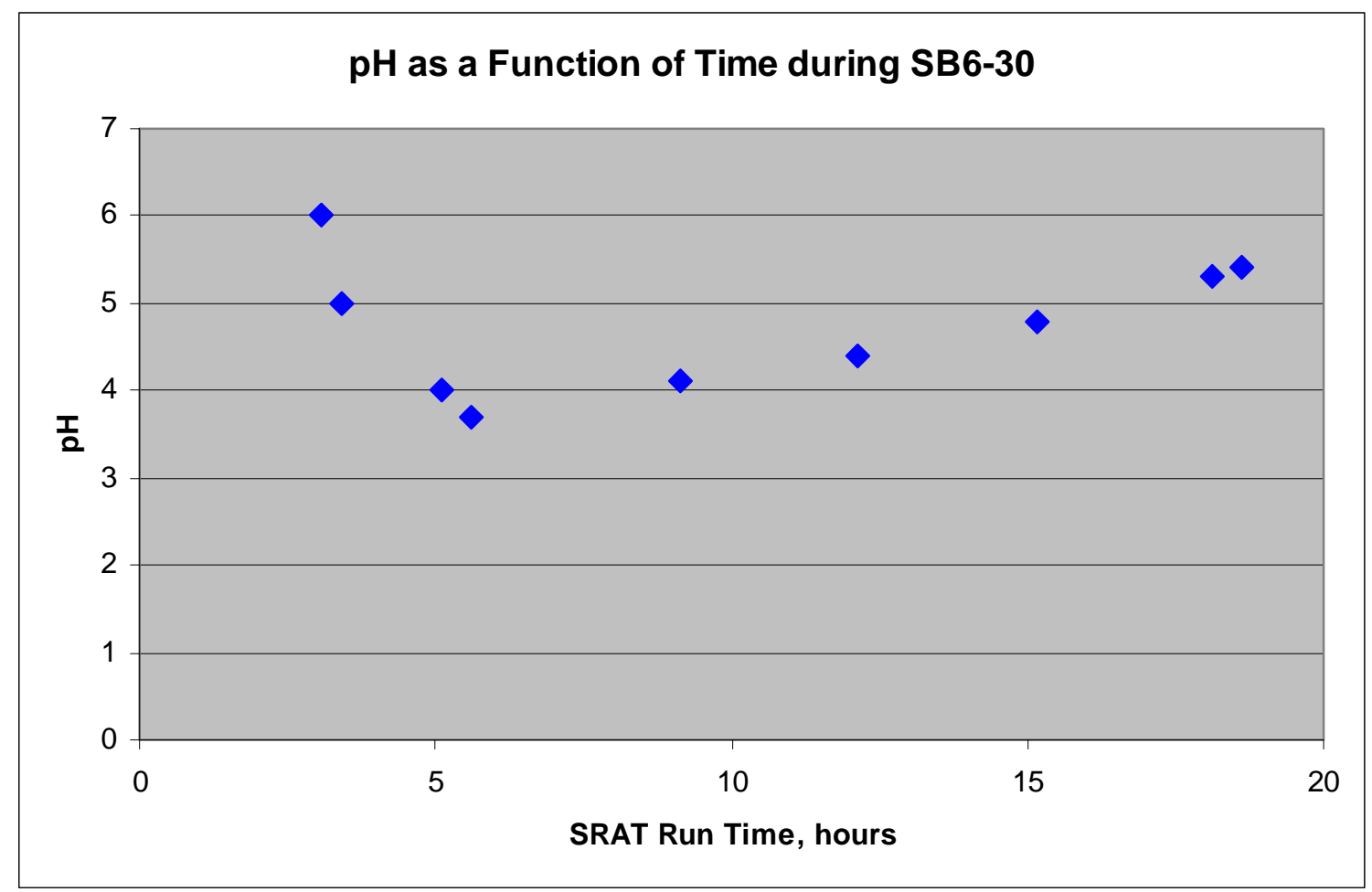

Figure 5-18. SB6-30: pH Profile

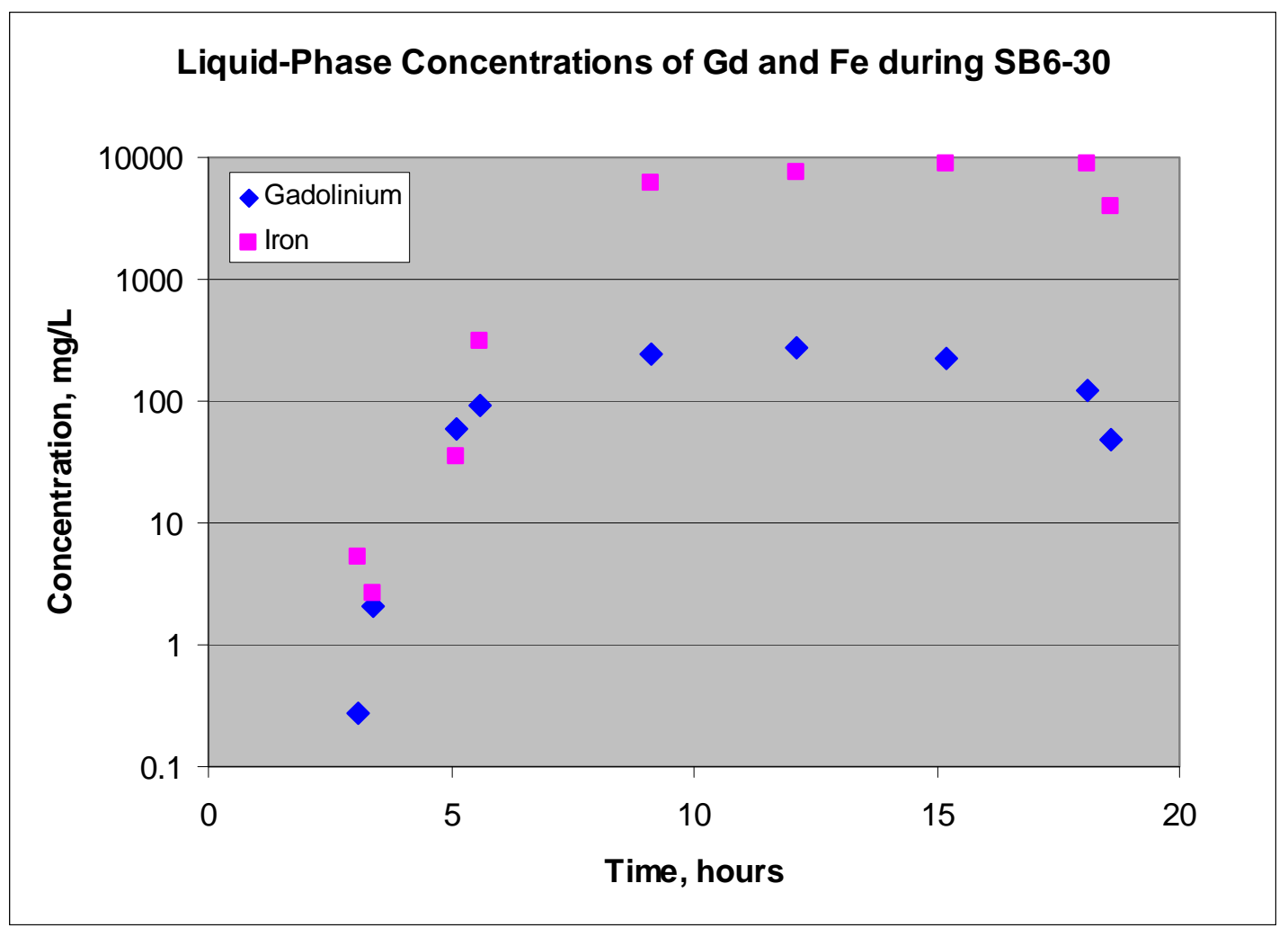

Figure 5-19. SB6-30: Gd and Fe Supernatant Concentrations 


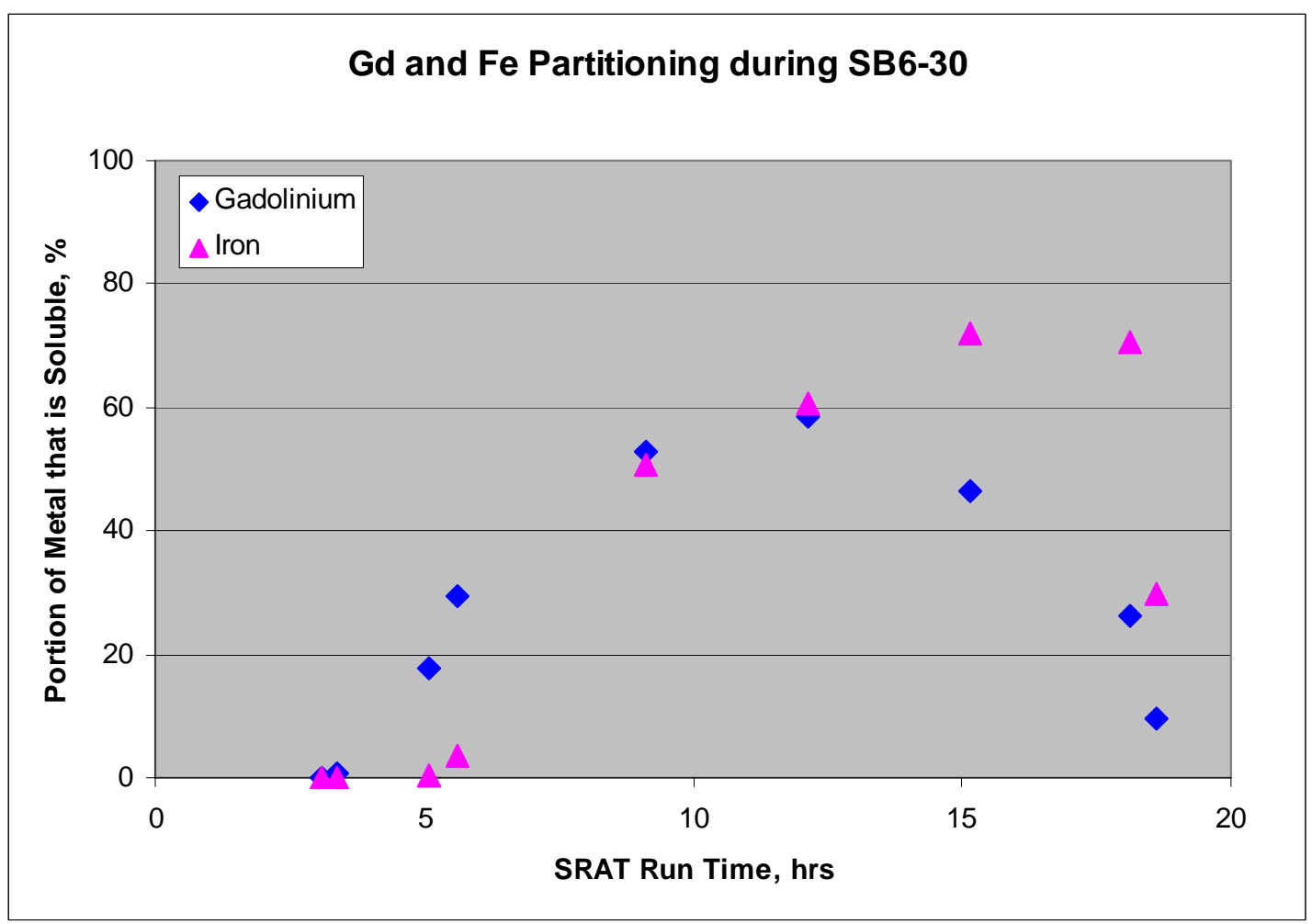

Figure 5-20. SB6-30: Gd and Fe Partitioning

As shown in Figure 5-18, the acid additions of SB6-30 reduced the slurry $\mathrm{pH}$ to a minimum value of 3.7, which occurred about six hours into the SRAT simulation. Approximately three hours earlier $(\mathrm{t}=3.1 \mathrm{hrs})$, the $\mathrm{pH}$ was 6.0 , and by the end of the simulation $(\mathrm{t}=18.6 \mathrm{hrs})$, the $\mathrm{pH}$ had risen from 3.7 to 5.4. The minimum and final $\mathrm{pH}$ values of SB6-30 were clearly lower than those of SB6-28 (4.0 and 6.3, respectively), which was initially surprising given that the targeted acidification protocols for SB6-30 and SB6-28 were the same (10\% nitric acid and 90\% formic acid). The reason for the $\mathrm{pH}$ difference became apparent after reviewing the relative solids contents of the SB6-28 and SB6-30 SRAT products (22.8 and $17.1 \mathrm{wt} \%$, respectively).

The solids content of the SB6-28 SRAT product (22.8 wt\%) agreed well with the final solids target identified in the acid calculation $(23.0 \mathrm{wt} \%)$. In contrast, the solids content of the SB6-30 SRAT product (17.1 wt $\%$ ) was significantly lower than the final solids target $(23.0 \mathrm{wt} \%)$ - by a factor of approximately $25 \%$. This low solids content was atypical and attributed to inadequate suspension of insoluble solids during transfer of the simulant slurry into the SRAT rig - which lessened the insoluble solids content of the test aliquot. The net effect was that the SB6-30 simulation was run under unintentionally anomalous conditions, with an acid stoichiometry that was very likely different from the $150 \%$ target. (Uncertainties in the initial solids distribution of the SB6-30 sludge prevented a reliable determination of the actual acid stoichiometry). Note that the depressed Fe:Gd ratio measured in the SRAT product (26, as opposed to the value of 50 
that was targeted) was reflective of the lower quantity of iron present, due to reduced insoluble solids content.

Over the time period from $t=3.1$ hours until the end of the simulation, the liquid-phase gadolinium concentrations varied by a factor of $\sim 1000$ and the liquid-phase iron concentrations varied by a factor of $\sim 3500$ (see Figure 5-19). Specifically, the gadolinium concentrations ranged from $\sim 0.3$ to $\sim 270 \mathrm{mg} / \mathrm{L}$, with the minimum observed at $\mathrm{t}=3.1$ hours and the maximum observed at $\mathrm{t}=12.1$ hours. In contrast, the iron concentrations ranged from $\sim 3$ to $9000 \mathrm{mg} / \mathrm{L}$, with the minimum observed at $\mathrm{t}=3.4$ hours and the maximum observed at $\mathrm{t}=15.2$ hours.

The maximum liquid-phase concentrations of gadolinium and iron in SB6-30 were about twice those observed in SB6-28. These differences were attributed to the lower solids concentrations, which consumed less acid, resulting in lower $\mathrm{pH}$ conditions and enhanced dissolution of available solid-phase metals.

The corresponding portions of gadolinium and iron partitioning to the liquid-phase ranged from $\sim 0.09 \%$ to $\sim 60 \%$ and $\sim 0.03 \%$ to $\sim 70 \%$, respectively (see Figure $5-20$ ). Based on these values, the maximum portions of gadolinium and iron that were soluble during SB6-30 were about 3-4 times those of the previous three SRAT simulations (SB6$27,-28$, and -29). The significant increase in liquid-phase partitioning during SB6-30 demonstrates the impact of a significantly lower initial insoluble solids concentration. Regardless of the higher relative acidity, the onset of iron dissolution in SB6-30 still lagged the onset of gadolinium dissolution gadolinium by several hours, just like in SB6$27,-28$, and -29 .

The liquid-phase sodium concentrations during SB6-30 ranged from 1.6E+4 to $2.6 \mathrm{E}+4$ $\mathrm{mg} / \mathrm{L}$. Note that the minimum sodium concentration was $\sim 10-15 \%$ less than the minimum sodium concentrations of SB6-27, -28, and -29. This difference may have been related to the atypically lower total solids content of the SB6-30 simulation and/or the analytical uncertainty. 
GF-13 (Fe:Gd target of 25; 49\% nitric acid, 10\% formic acid, 41\% glycolic acid)

Liquid-phase constituent and $\mathrm{pH}$ data for GF-13 are given in Table 5-16. Plots of the $\mathrm{pH}$ profile, Gd and Fe concentrations, and Gd and Fe partitioning behavior are given as functions of time in Figures 5-21, 5-22, and 5-23, respectively. SRAT product analyses indicated that the final total solids content was $25.7 \mathrm{wt} \%$ and the Fe:Gd ratio was 30.

Table 5-16. Liquid-Phase Concentrations, Partitioning, and pH during GF-13

\begin{tabular}{|c|c|c|c|c|c|}
\hline \multirow{2}{*}{$\begin{array}{c}\text { Time, } \\
\text { hrs }\end{array}$} & \multirow{2}{*}{$\mathbf{p H}$} & \multicolumn{2}{|c|}{ Concentration, mg/L } & \multicolumn{2}{c|}{ Soluble Portion of Constituent, \% } \\
\cline { 3 - 6 } & & Gadolinium & Iron & Gadolinium & Iron \\
\hline \hline 4.0 & 6.0 & $1.9 \mathrm{E}-1$ & $3.1 \mathrm{E} 0$ & 0.017 & 0.0094 \\
\hline 5.0 & 4.8 & $6.2 \mathrm{E}-1$ & $1.4 \mathrm{E} 0$ & 0.055 & 0.0042 \\
\hline 6.0 & 4.4 & $3.8 \mathrm{E}+2$ & $4.5 \mathrm{E}+1$ & 34 & 0.14 \\
\hline 7.0 & 4.0 & $3.0 \mathrm{E}+2$ & $3.5 \mathrm{E}+1$ & 27 & 0.11 \\
\hline 7.9 & 3.6 & $4.7 \mathrm{E}+2$ & $2.5 \mathrm{E}+2$ & 42 & 0.76 \\
\hline 11.5 & 3.7 & $7.2 \mathrm{E}+2$ & $3.6 \mathrm{E}+2$ & 64 & 1.1 \\
\hline 14.5 & 3.8 & $8.2 \mathrm{E}+2$ & $9.0 \mathrm{E}+2$ & 73 & 2.7 \\
\hline 17.5 & 3.9 & $7.9 \mathrm{E}+2$ & $1.1 \mathrm{E}+3$ & 70 & 3.3 \\
\hline 20.6 & 4.0 & $9.1 \mathrm{E}+2$ & $4.0 \mathrm{E}+2$ & 81 & 1.2 \\
\hline
\end{tabular}

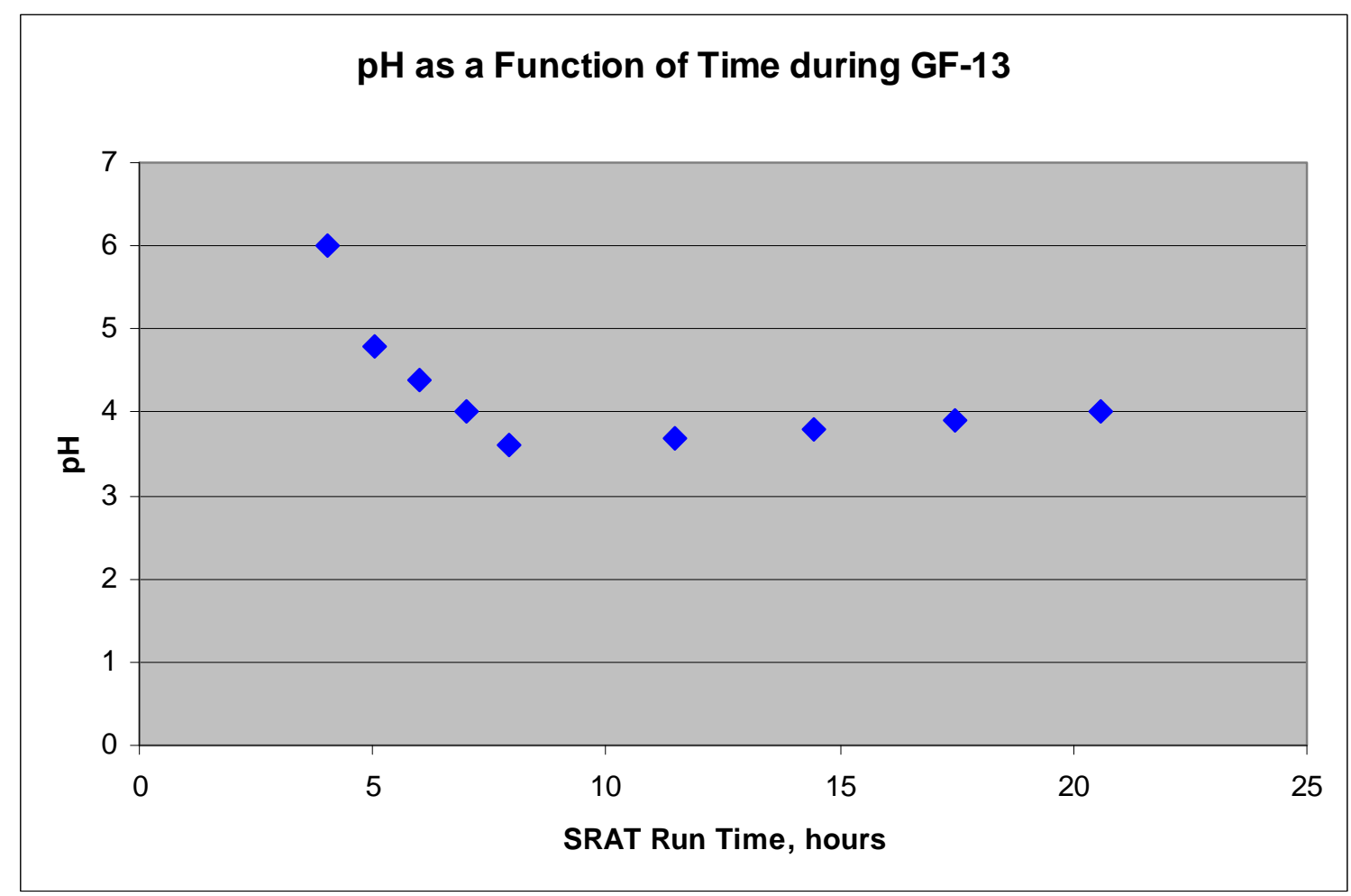

Figure 5-21. GF-13: pH Profile 


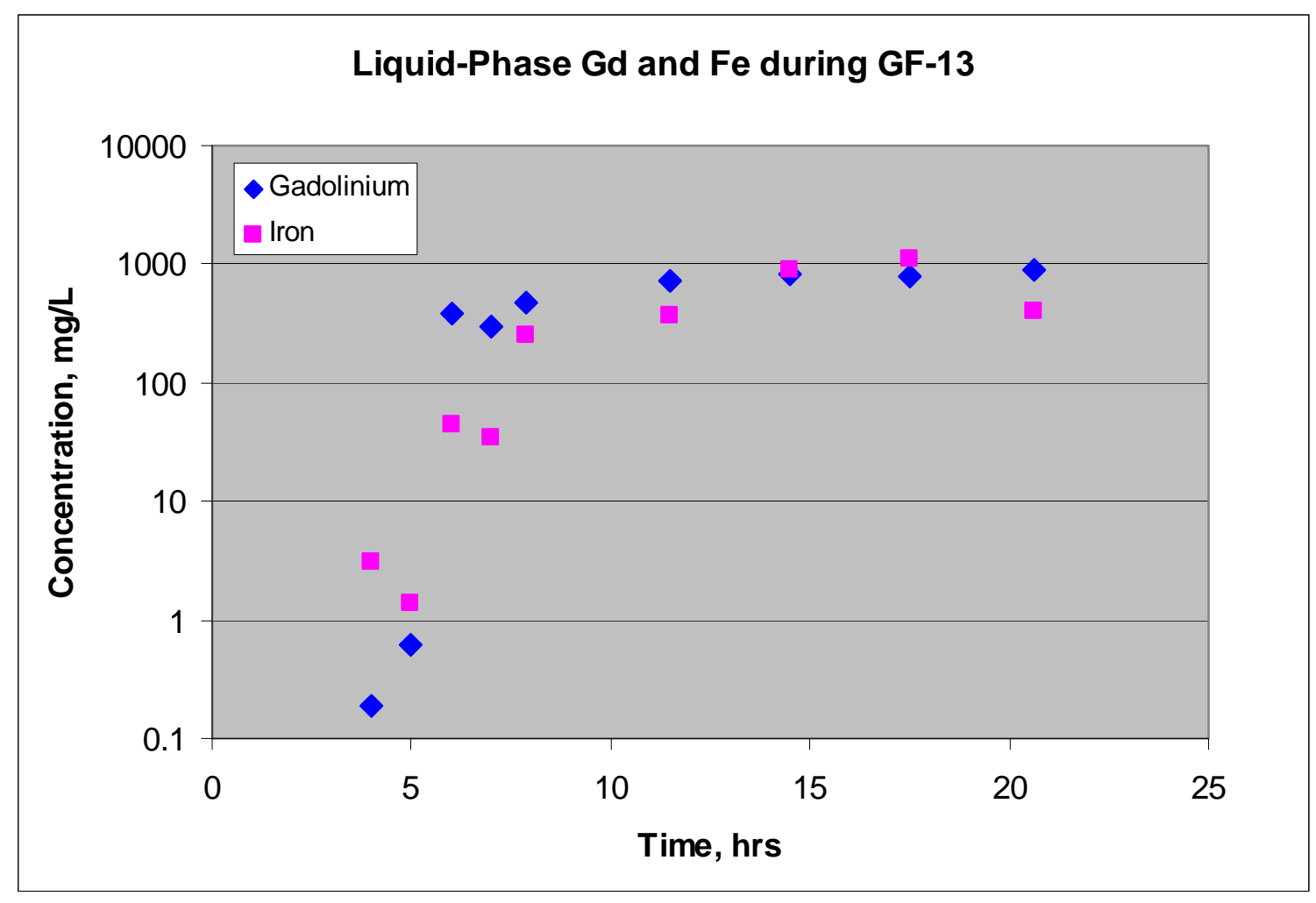

Figure 5-22. GF-13: Gd and Fe Supernatant Concentrations

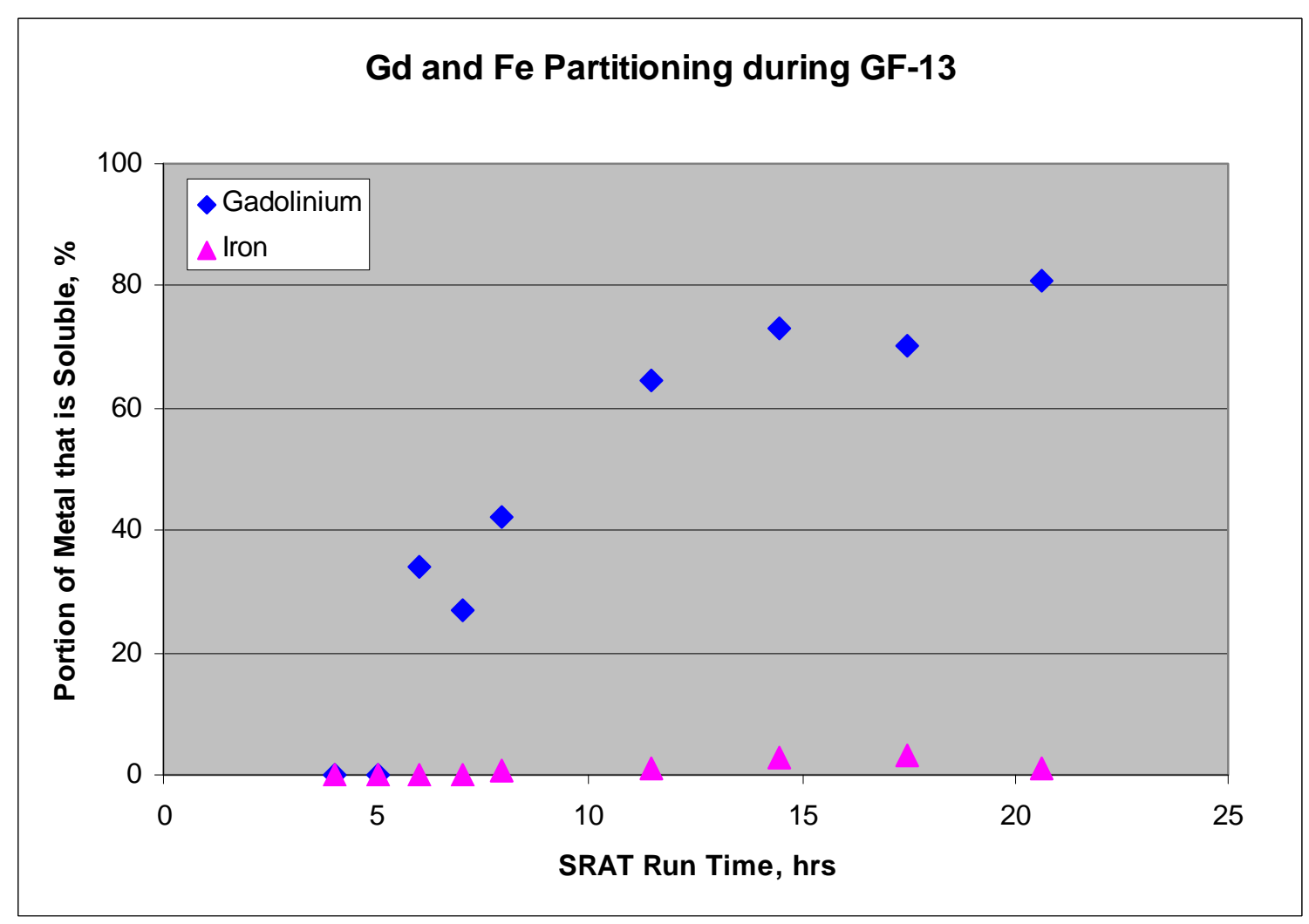

Figure 5-23. GF-13: Gd and Fe Partitioning 
As shown in Figure 5-21, the acid additions of GF-13 reduced the slurry $\mathrm{pH}$ to a minimum value of 3.6, which occurred about eight hours into the SRAT simulation. Approximately five hours earlier $(\mathrm{t}=4.0 \mathrm{hrs})$, the $\mathrm{pH}$ was 6.0 , and by the end of the simulation $(\mathrm{t}=20.6 \mathrm{hrs})$, the $\mathrm{pH}$ had risen from 3.6 to 4.0. As compared to the previous SRAT simulations (SB6-27, -28, -29, and -30), the increase in $\mathrm{pH}$ following acid addition was significantly less for the GF-13 simulation. This difference was attributed to the presence of glycolic acid, which was absent from the previous simulations.

Over the time period from $t=4.0$ hours until the end of the GF-13 simulation, the liquidphase gadolinium concentrations varied by a factor of $\sim 5000$ and the liquid-phase iron concentrations varied by a factor of $\sim 800$ (see Figure 5-22). Specifically, the gadolinium concentrations ranged from $\sim 0.2$ to $910 \mathrm{mg} / \mathrm{L}$, with the minimum observed at $\mathrm{t}=4.0$ hours and the maximum observed at $t=20.6$ hours (the end of the simulation). In contrast, the iron concentrations ranged from 1.4 to $1100 \mathrm{mg} / \mathrm{L}$, with the minimum observed at $t=5.0$ hours and the maximum observed at $t=17.5$ hours. The relatively high gadolinium and iron concentrations in the latter stages of the simulation reflect the relatively low $\mathrm{pH}$ conditions that endured following acid addition.

The maximum liquid-phase gadolinium concentrations in GF-13 were significantly higher (up to ten times higher) than those of the previous SRAT simulations. In contrast, the maximum iron concentrations in GF-13 were significantly lower (by a minimum factor of five) than those of the previous SRAT simulations. Additionally, the gadolinium and iron dissolution in GF-13 occurred nearly simultaneously (note the overlap of the concentration curves in Figure 5-22), as opposed to the previous simulations in which iron dissolution lagged considerably behind gadolinium dissolution. These differences were attributed to the presence of glycolic acid, which was utilized in GF-13, but absent from the previous simulations. Based on the results, it is conjectured that glycolic acid increases the gadolinium solubility, decreases the iron solubility, and raises the rate at which solid-phase iron dissolves.

The corresponding portions of gadolinium and iron partitioning to the liquid-phase in GF13 ranged from $\sim 0.02 \%$ to $\sim 80 \%$ and $\sim 0.01 \%$ to $\sim 3 \%$, respectively (see Figure $5-23$ ).

Clearly, the high proportion of gadolinium partitioned to the liquid phase at the end of the simulation ( $\sim 80 \%)$ left little gadolinium remaining in the solid phase. (Considering the impacts of normal experimental uncertainties and process fluctuations, the possibility of complete dissolution of gadolinium is real). In comparison, the very minor portion of iron that partitioned to solution provided confidence that the vast majority of iron remained intact in the solid phase.

The total solids content and the Fe:Gd ratio measurements of the GF-13 SRAT product (25.7 wt\% and 30, respectively) are consistent with expectations (taking analytical uncertainties into account) and provide assurance that the SRAT simulation was executed properly. 
GF-14 (Fe:Gd target of 25; 41\% nitric acid, 12\% formic acid, 47\% glycolic acid)

Liquid-phase constituent and $\mathrm{pH}$ data for GF-14 are given in Table 5-17. Plots of the $\mathrm{pH}$ profile, Gd and Fe concentrations, and Gd and Fe partitioning behavior are given as functions of time in Figures 5-24, 5-25, and 5-26, respectively. SRAT product analyses indicated that the final total solids content was $25.2 \mathrm{wt} \%$ and the Fe:Gd ratio was 30.

Table 5-17. Liquid-Phase Concentrations, Partitioning, and pH during GF-14

\begin{tabular}{|c|c|c|c|c|c|}
\hline $\begin{array}{c}\text { Time, } \\
\text { hrs }\end{array}$ & \multirow{2}{*}{$\mathbf{p H}$} & \multicolumn{2}{c|}{ Supernatant Concentration, mg/L } & \multicolumn{2}{c|}{ Soluble Portion of Constituent, \% } \\
\cline { 3 - 6 } & & Gadolinium & Iron & Gadolinium & Iron \\
\hline \hline 4.7 & 6.0 & $6.8 \mathrm{E}-1$ & $1.6 \mathrm{E}+1$ & 0.062 & 0.048 \\
\hline 5.7 & 5.1 & $3.0 \mathrm{E} 0$ & $2.1 \mathrm{E} 0$ & 0.27 & 0.0062 \\
\hline 6.7 & 4.7 & $4.7 \mathrm{E}+1$ & $3.4 \mathrm{E} 0$ & 4.3 & 0.010 \\
\hline 7.7 & 4.3 & $3.3 \mathrm{E}+2$ & $9.8 \mathrm{E}+1$ & 30 & 0.29 \\
\hline 8.3 & 4.0 & $4.4 \mathrm{E}+2$ & $2.4 \mathrm{E}+2$ & 40 & 0.72 \\
\hline 11.3 & 4.4 & $6.1 \mathrm{E}+2$ & $1.2 \mathrm{E}+3$ & 56 & 3.7 \\
\hline 14.3 & 4.6 & $4.3 \mathrm{E}+2$ & $1.4 \mathrm{E}+3$ & 39 & 4.3 \\
\hline 17.3 & 4.7 & $3.2 \mathrm{E}+2$ & $1.7 \mathrm{E}+3$ & 29 & 5.0 \\
\hline 21.0 & 4.8 & $5.0 \mathrm{E}+2$ & $3.0 \mathrm{E}+2$ & 45 & 0.91 \\
\hline
\end{tabular}

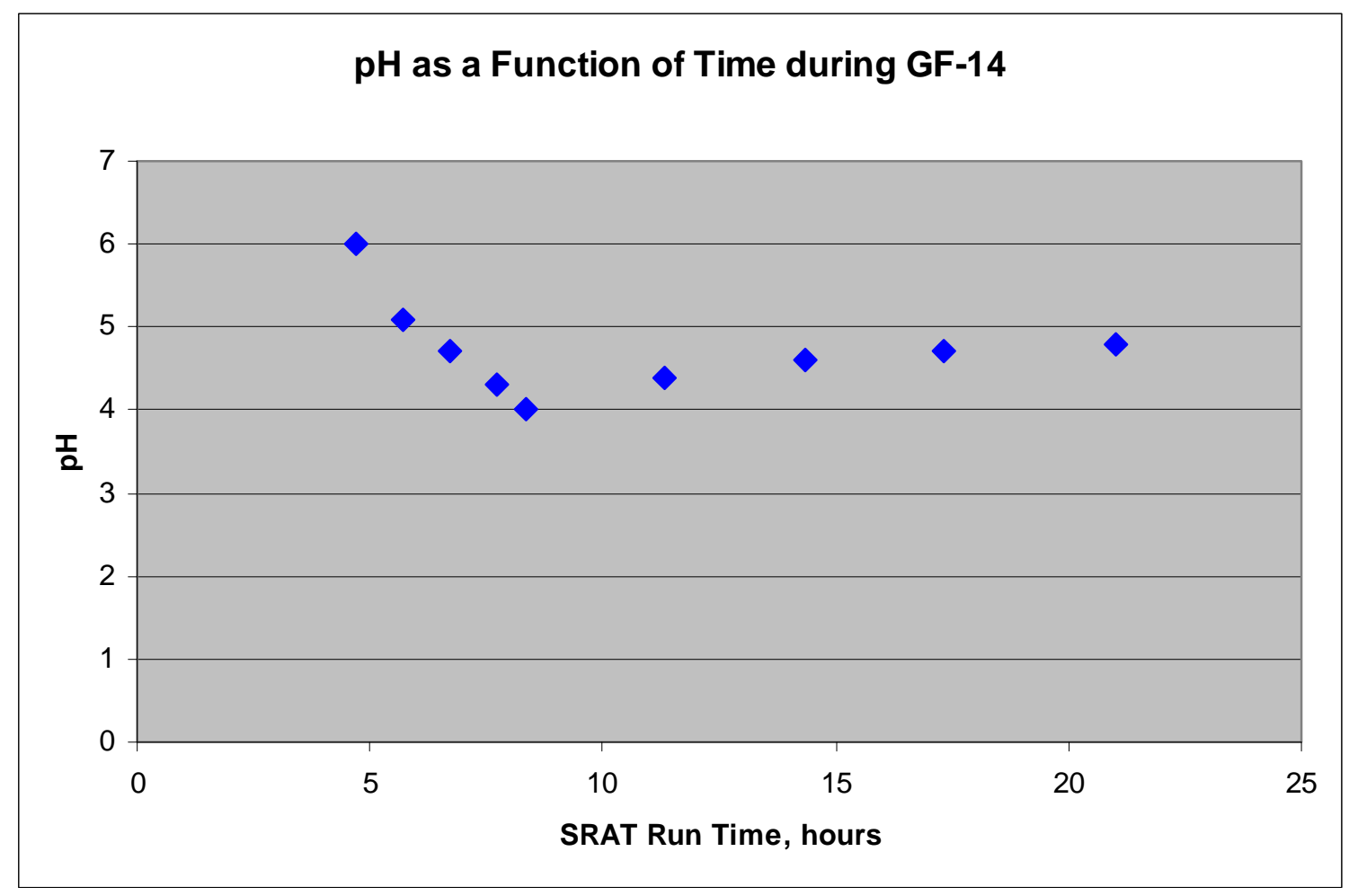

Figure 5-24. GF-14: pH Profile 


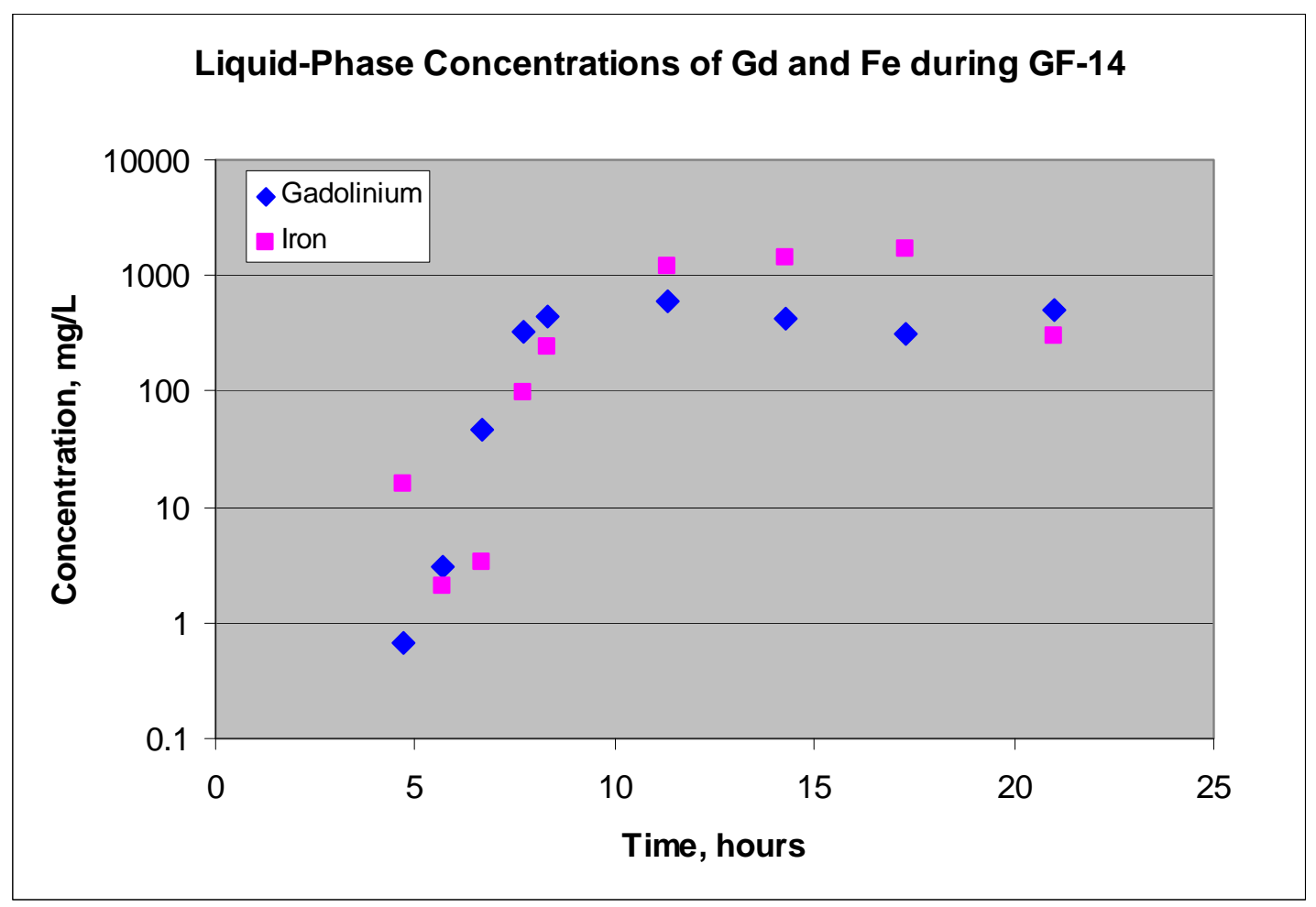

Figure 5-25. GF-14: Gd and Fe Supernatant Concentrations

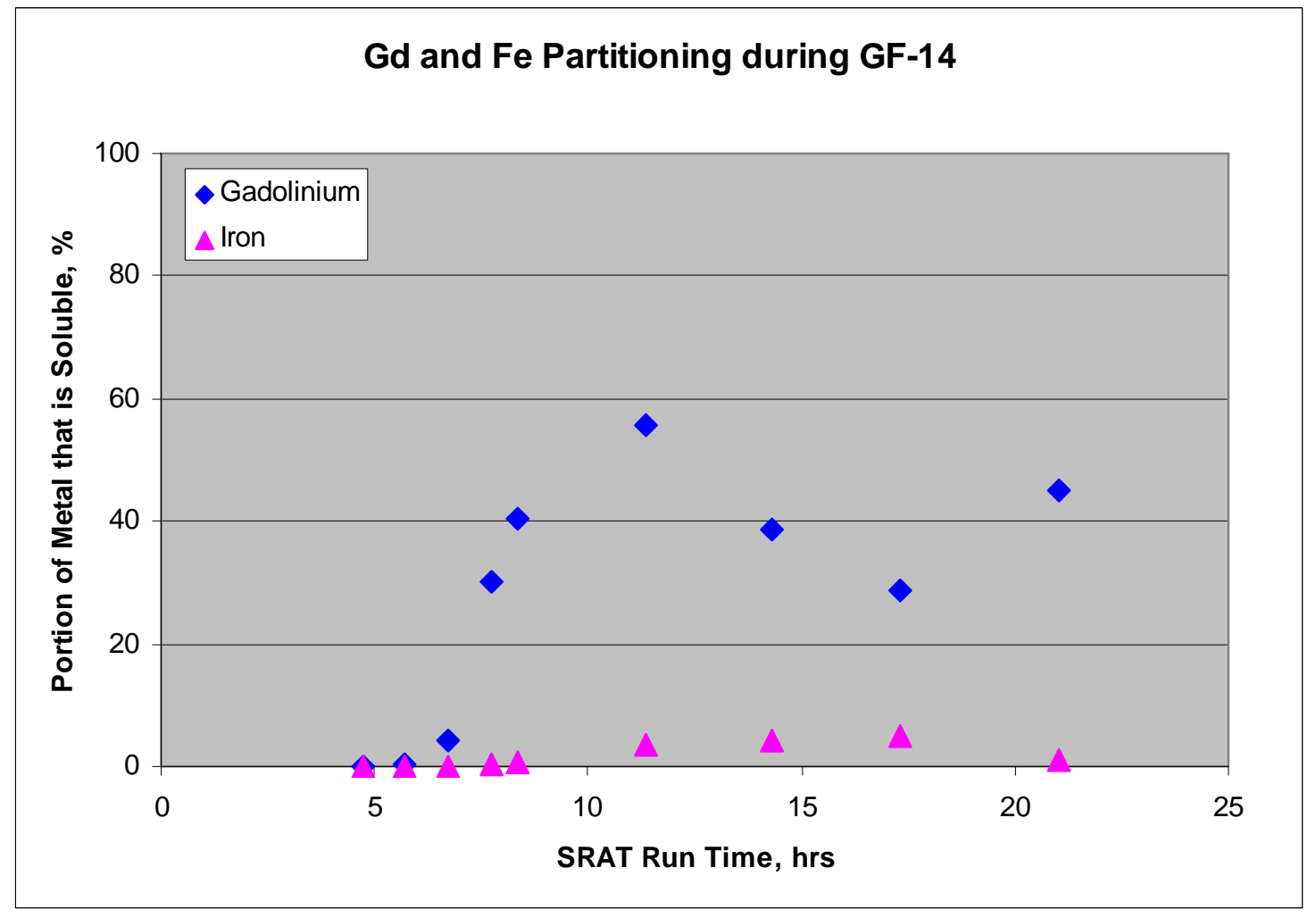

Figure 5-26. GF-14: Gd and Fe Partitioning 
As shown in Figure 5-24, the acid additions of GF-14 reduced the slurry $\mathrm{pH}$ to a minimum value of 4.0, which occurred about eight hours into the SRAT simulation. Approximately three and a half hours earlier $(\mathrm{t}=4.7 \mathrm{hrs})$, the $\mathrm{pH}$ was 6.0 , and by the end of the simulation $(\mathrm{t}=21.0 \mathrm{hrs})$, the $\mathrm{pH}$ had risen from 4.0 to 4.8 . Note that the minimum and final $\mathrm{pH}$ values of GF-14 were higher than those of GF-13 (3.6 and 4.0, respectively). These $\mathrm{pH}$ differences were attributed to the lower fraction of nitric acid utilized in the GF-14 simulation.

Over the time period from $t=4.7$ hours until the end of the GF-14 simulation, the liquidphase gadolinium concentrations varied by a factor of $\sim 900$ and the liquid-phase iron concentrations varied by a factor of $\sim 800$ (see Figure 5-25). Specifically, the gadolinium concentrations ranged from $\sim 0.7$ to $610 \mathrm{mg} / \mathrm{L}$, with the minimum observed at $\mathrm{t}=4.7$ hours and the maximum observed at $t=11.3$ hours. In contrast, the iron concentrations ranged from $\sim 2$ to $1700 \mathrm{mg} / \mathrm{L}$, with the minimum observed at $\mathrm{t}=5.7$ hours and the maximum observed at $t=17.3$ hours. The relatively high gadolinium and iron concentrations in the latter stages of the simulation reflect the relatively modest increase in $\mathrm{pH}$ that occurred following the acid addition.

The maximum liquid-phase gadolinium concentration in GF-14 was about 30\% lower than that in GF-13. In contrast, the maximum liquid-phase iron concentration in GF-14 was about $50 \%$ higher than that in GF-13. Whether these differences can be attributed to the higher formic acid content (12\% in GF-14 versus $10 \%$ in GF-13) and/or the higher glycolic acid content (47\% in GF-14 versus $41 \%$ in GF-13) is not clear.

As in the case of GF-13, gadolinium and iron dissolution in GF-14 occurred nearly simultaneously, as opposed to the SB6-27 to SB6-30 simulations in which iron dissolution lagged significantly behind gadolinium dissolution. This observation provides additional support that the presence of glycolic acid raises the rate at which solid-phase iron dissolves.

The corresponding portions of gadolinium and iron partitioning to the liquid-phase in GF14 ranged from $\sim 0.06 \%$ to $\sim 60 \%$ and $\sim 0.006 \%$ to $\sim 5 \%$, respectively (see Figure $5-26$ ). Although the maximum portion of gadolinium in the liquid-phase was somewhat lower than in GF-13 ( 80\%), it was still high, leaving a minority of gadolinium in the solid phase. In contrast, the maximum portion of iron in the liquid-phase was still relatively small, leaving the vast majority of iron intact in the solid phase.

The total solids content and the Fe:Gd ratio measurements of the SRAT product $(25.2$ $\mathrm{wt} \%$ and 30 , respectively) are consistent with expectations (taking analytical uncertainties into account) and provide assurance that the SRAT simulation was executed properly. 


\section{Summary of Gd and Fe Partitioning in SRAT Simulations}

In the SRAT simulations performed in the absence of glycolic acid (SB6-27, -28, 29, -30), the minimum $\mathrm{pH}$ values ranged from 3.5-4.0, and the maximum portions of gadolinium partitioning to the liquid-phase were approximately equal to or less than the corresponding portions of iron. In the first three simulations (SB6-27, -28, and -29), the maximum portions of soluble gadolinium and iron were all about $20 \%$. Note that these three simulations included two cases in which the Fe:Gd ratio was 25 (SB6-27 and -28) and one case in which the Fe:Gd ratio was 50 (SB6-29). The similar extent of gadolinium partitioning in the SB6-29 simulation despite the significantly lower gadolinium content is an indication of the complexity of solubilization mechanisms in sludge.

In the fourth simulation (SB6-30), the maximum portions of gadolinium and iron partitioning to the liquid-phase were significantly larger, $\sim 60 \%$ and $\sim 70 \%$, respectively. These larger portions were attributed to the unintended low solids concentrations, which consumed less acid, making more acid available for dissolution of solid-phase metals.

In the SRAT simulations performed in the presence of glycolic acid (GF-13 and -14), the range of minimum $\mathrm{pH}$ values (3.6-4.0) was about the same as in the SB6- series of simulations - however, the maximum portions of gadolinium partitioning to the liquid phase were significantly higher, while the maximum portions of iron partitioning to the liquid phase were significantly lower. Specifically, the maximum portions of gadolinium in solution were about $80 \%$ and $60 \%$, while the maximum portions of iron were about $3 \%$ and $5 \%$, respectively. These results suggested that use of glycolic acid facilitated gadolinium solubilization and impeded iron solubilization.

The rates that gadolinium partitioned to solution during and after the acid additions were clearly higher than those of iron, as evidenced by the lag between the times of the maximum liquid-phase gadolinium concentration and the times of the maximum liquidphase iron concentration. Specifically, the maximum supernatant iron concentrations were found to occur about 3-6 hours after the maximum supernatant gadolinium concentrations. Based on this timeframe, the supernatant concentrations observed in the 30-minute beaker tests should not be considered representative of equilibrium conditions.

The tracking of gadolinium partitioning in additional SRAT simulation testing would be helpful to better define the impacts of process parameters. Of most usefulness would be SRAT simulation testing focusing on gadolinium under conditions of: 1) a wider range of acid addition scenarios; 2) a wider range of sludge compositions; and 3) one or more real-waste sludge matrices. The additional SRAT simulation testing should address anticipated sludge batch conditions applicable to excess plutonium disposition scenarios.

Although the potential application of gadolinium as a supplemental neutron poison is clear, future evaluations should also address the possibility of crediting other neutronabsorbing constituents, particularly those constituents that are already present in the 
waste. The ability to credit such pre-existing constituents may be beneficial under conditions where adequate poisoning by iron and/or gadolinium alone is impractical.

\subsection{CONCLUSIONS}

1) Measurable liquid-phase gadolinium partitioning is to be expected in the Chemical Processing Cell, particularly as the $\mathrm{pH}$ drops to 4.0 or less. In SRAT simulations utilizing nitric and formic acids at 150\% acid stoichiometry, the maximum fractions of gadolinium and iron partitioning into solution were comparable, both at $\sim 20 \%$. In contrast, in a SRAT simulation utilizing nitric and formic acids under anomalously low solids concentrations, the maximum fractions of gadolinium and iron partitioning into solution ranged from $60-70 \%$. Glycolic acid used in combination with nitric and formic acids appears to significantly increase the fraction of gadolinium partitioning into solution, while reducing the fraction of iron partitioning into solution. Specifically, in SRAT simulations utilizing nitric, formic, and glycolic acid at 100\% acid stoichiometry, the maximum fractions of gadolinium partitioning into solution were $\sim 60-80 \%$, while the maximum fractions of iron partitioning into solution were only $\sim 3-5 \%$. Conditions that reduce the $\mathrm{pH}$ significantly below 4.0 will also result in high gadolinium dissolution. Although the Fe:Gd ratio appears to impact partitioning, the exact relationship is not clear. Regardless, a conservatively large gadolinium content (with respect to the neutron poisoning demand) is advantageous from the perspective of having a reserve of excess gadolinium in the solid phase.

2) The equilibration times for gadolinium and iron partitioning were typically longer than the durations of the beaker tests (particularly for iron, which partitioned to solution considerably slower than gadolinium). As a consequence, the results obtained from the beaker tests were thought to underestimate liquid-phase partitioning in many cases. Nonetheless, the beaker tests demonstrated that the vast majority of gadolinium partitioned to the liquid phase at $\mathrm{pH}$ 2, regardless of the other conditions (Fe:Gd ratio, slurry matrix, temperature, and oxalate concentration).

3) The impacts of temperature on the liquid-phase gadolinium concentrations appear to be modest at best. Typically, the concentrations observed at elevated temperatures $(\sim 93$ $\left.{ }^{\circ} \mathrm{C}\right)$ were about $25 \%$ higher than at room temperatures $\left(\sim 22{ }^{\circ} \mathrm{C}\right)$. However, in some instances, the concentrations at elevated temperature were less than those at room temperature. These differences suggest that the uncertainties of the measured concentrations were of the same order as the concentration differences.

4) The presence of oxalate had an immeasurable effect on the liquid-phase gadolinium concentrations, although it did raise the liquid-phase iron concentrations. This difference provides an advantage for using gadolinium as a neutron poison when processing high oxalate content waste.

5) Additional SRAT simulation tests addressing gadolinium partitioning over a wider range of alternate conditions would provide a stronger basis for gauging the adequacy of 
gadolinium as a neutron poison in the CPC. Of greatest usefulness would be SRAT simulations focusing on a larger range of acid addition scenarios and other sludge compositions, particularly those specific to future sludge batches where excess plutonium disposition is being considered.

6) Crediting other constituents in waste as potential neutron poisons may be beneficial in cases where adequate poisoning by iron and/or gadolinium alone is impractical.

\subsection{RECOMMENDATION}

Perform additional SRAT simulation testing with gadolinium partitioning monitored under conditions of: a) alternate acid addition scenarios; b) alternate sludge simulant matrices; and c) real-waste sludge. The specific conditions of the testing should be chosen to target the conditions anticipated for future sludge batches into which excess plutonium additions are planned. 


\subsection{REFERENCES}

1 Reboul, S. H. Gadolinium Solubility and Volatility During DWPF Processing, WSRC-STI-2008-00051, January 2008.

2 Reboul, S. H. Task Technical and Quality Assurance Plan for Quantifying the Partitioning of Gadolinium in the Chemical Processing Cell, Savannah River National Laboratory, Aiken, SC, SRNL-RP-2010-00931, June 7, 2010.

3 Reboul, S. H. Laboratory Notebook: Partitioning of Gadolinium in the Chemical Processing Cell, Savannah River National Laboratory, Aiken, SC, SRNL-NB2010-00102, Date Opened: July 9, 2010.

4 Stone, M. E. SRS HLW Sludge Simulant Preparation, Savannah River National Laboratory, Aiken, SC, L29 Manual, Procedure ITS-00124, Rev. 2, April 2008.

5 Reboul, S. H., D. R. Click, and D. P. Lambert. Sludge Batch 7 (SB7) Washing Demonstration to Determine Sulfate/Oxalate Removal Efficiency and Settling Behavior, Savannah River National Laboratory, Aiken, SC, SRNL-STI-201000697, December 2010.

6 Stone, M. E. Laboratory Scale Chemical Process Cell Simulations, Savannah River National Laboratory, Aiken, SC, L29 Manual, Procedure ITS-0094, Rev. 4, March 2010.

7 Stone, M. E. Lab-Scale CPC Equipment Set-up, Savannah River National Laboratory, Aiken, SC, SRNL-PSE-2006-00074, Rev. 2, February 2010. 


\section{APPENDIX A: RUN PARAMETERS FOR SRAT RUN \#SB6-27}

\section{L CPC Run Parameters SB6-E Qualification Support Run SB6-27}

Equipment Set-up and Sludge Batching

Initial MWWT Mass $(\mathrm{g})$ GC File Name

60.8 GC Start Time

$\frac{\text { SB627- }}{6: 10}$

Leak Checks

Pre-Leak Check

Flow Input $\quad 90.0 \mathrm{sccm}$

Sludge and Trim Chemical Target Addition Masses

\begin{tabular}{|c|c|c|}
\hline & Target $(\mathrm{g})$ & Actual (g) \\
\hline \multirow{2}{*}{$\begin{array}{l}\text { Sludge Simulant } \\
\qquad \mathrm{AgNO}_{3}\end{array}$} & $3,500.00$ & 3500.05 \\
\hline & 0.1178 & 0.1199 \\
\hline $\mathrm{HgO}$ (yellow) & 10.4037 & 10.4494 \\
\hline $\mathrm{Pd}\left(\mathrm{NO}_{3}\right)_{2}{ }^{*} \mathrm{H}_{2} \mathrm{O}$ sol'n & 0.2286 & 0.2298 \\
\hline $\mathrm{CaCO}_{3}$ & 6.6080 & 6.6091 \\
\hline
\end{tabular}

GC Pre-Calibration Gas 41544446

pH Probe Calibration/Checks prior to acid addition and after run Pre-Run Probe Calibration
pH 4 Buffer
4.00

Post-Run Probe Check

pH 4 Buffer

4.07

Flow Output $84.4 \mathrm{sccm}$

SB6E simulant

\begin{tabular}{|c|c|c|}
\hline \multirow[b]{2}{*}{$\mathrm{Rh}\left(\mathrm{NO}_{3}\right)_{3}{ }^{*} 2 \mathrm{H}_{2} \mathrm{O}$ sol'n } & Target & Actual (g) \\
\hline & 2.4236 & 2.419 \\
\hline $\mathrm{RuCl}_{3}$ & 1.4152 & 1.4059 \\
\hline Flush Water & 100.00 & 100.049 \\
\hline $\mathrm{Gd}(\mathrm{NO} 3) 3^{*} 6 \mathrm{H} 2 \mathrm{O}$ & 7.5200 & 7.5153 \\
\hline Initial Sample & 0.00 & \\
\hline
\end{tabular}

pH 10 Buffer

10.00

pH 10 Buffer
9.97
pH 7 check 7.11

pH 7 buffer 7.13 
SRAT Cycle Parameters

SRAT Air purge (slm)

Nafion Dryer pure (slm)

SRAT He purge (sccm)

4.64

Run \#

SB6-27

Initial sludge $\mathrm{pH}$

SRAT Start Time

$6: 42$ (power to mantle)

Initial Antifoam Addition

200 ppm antifoam target, g initial

100 ppm antifoam target, g emergency Additional antifoam needed $(\mathrm{g})$

Nitric Acid Addition

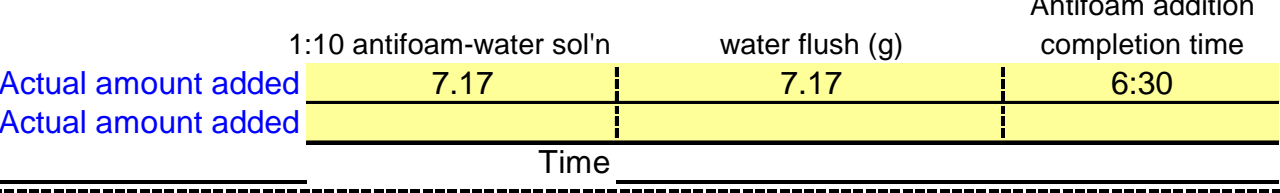
Acid Molarity (M)

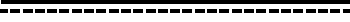

Time

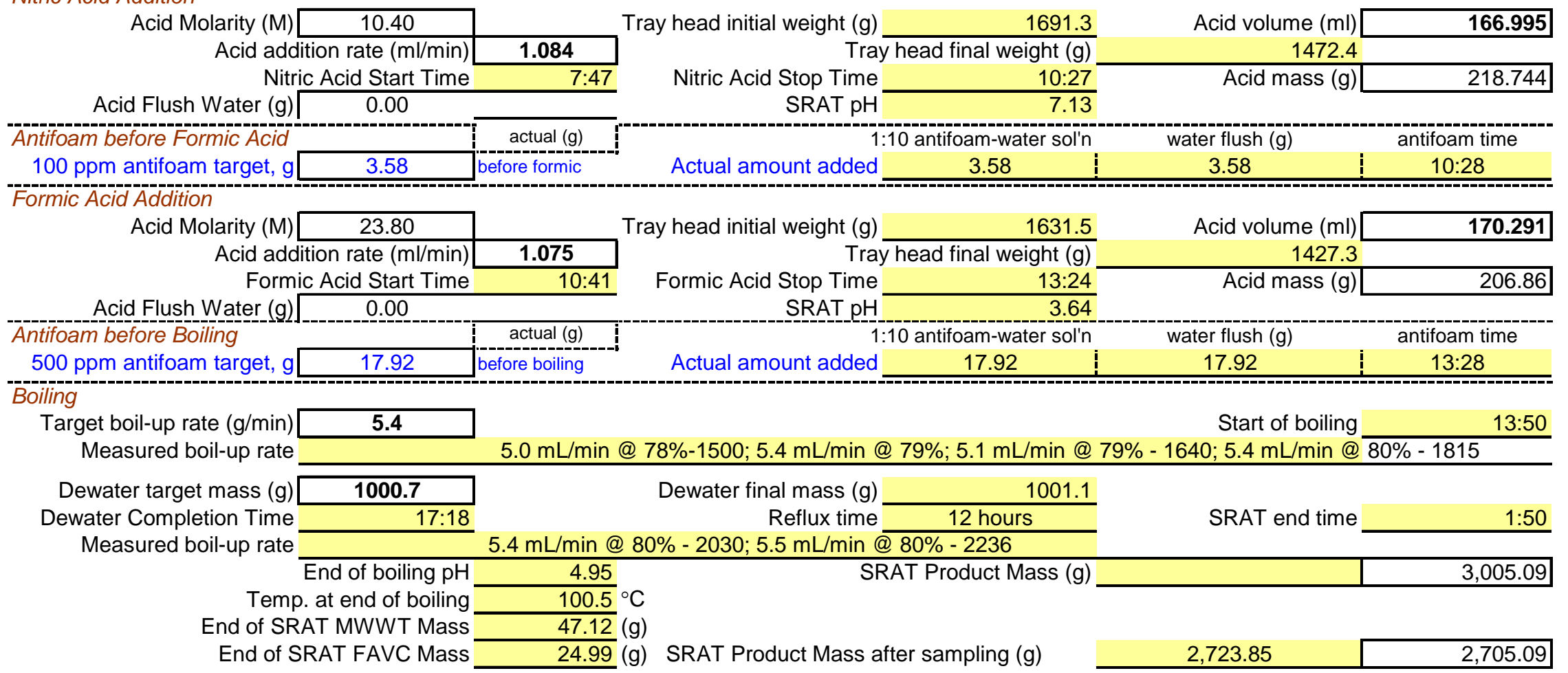




\section{APPENDIX B: RUN PARAMETERS FOR SRAT RUN \#SB6-28}

\section{L CPC Run Parameters SB6-E Qualification Support Run SB6-28}

Equipment Set-up and Sludge Batching

Initial MWWT Mass (g) GC File Name

$\frac{51.54}{\text { SB628- }}$

Leak Checks

Pre-Leak Check

$$
\text { Flow Input } \quad 90.0 \mathrm{sccm}
$$

Sludge and Trim Chemical Target Addition Masses

\begin{tabular}{r|cr} 
& Target $(\mathrm{g})$ & \multicolumn{1}{c}{ Actual $(\mathrm{g})$} \\
\cline { 2 - 2 } Sludge Simulant & $\mathbf{3 , 5 0 0 . 0 0}$ & 3500.05 \\
\cline { 2 - 2 } $\mathrm{AgNO}_{3}$ & $\mathbf{0 . 1 1 7 8}$ & 0.1182 \\
\cline { 2 - 3 } $\mathrm{HgO}$ (yellow) & $\mathbf{1 0 . 4 0 3 7}$ & 10.4061 \\
\cline { 2 - 3 } $\mathrm{Pd}\left(\mathrm{NO}_{3}\right)_{2}{ }^{*} \mathrm{H}_{2} \mathrm{O} \mathrm{sol}^{\prime} \mathrm{n}$ & $\mathbf{0 . 2 2 8 6}$ & 0.2250 \\
\cline { 2 - 3 } $\mathrm{CaCO}_{3}$ & $\mathbf{6 . 6 0 8 0}$ & 6.6098 \\
& &
\end{tabular}

$\mathrm{pH}$ Probe Calibration/Checks prior to acid addition and after run Pre-Run Probe Calibration

$$
\text { pH } 4 \text { Buffer } \quad 4.01
$$

Post-Run Probe Check

pH 4 Buffer 4.09
GC Pre-Calibration Gas

41544464

Flow Output $98.7 \mathrm{sccm}$

SB6E simulant

\begin{tabular}{r|c|r} 
& Target & \multicolumn{1}{c}{ Actual $(\mathrm{g})$} \\
\cline { 2 - 3 } $\mathrm{Rh}\left(\mathrm{NO}_{3}\right)_{3} * 2 \mathrm{H}_{2} \mathrm{O}$ sol'n & $\mathbf{2 . 4 2 3 6}$ & 2.4293 \\
\cline { 2 - 3 } $\mathrm{RuCl}_{3}$ & $\mathbf{1 . 4 1 5 2}$ & 1.4186 \\
\cline { 2 - 3 } Flush Water & $\mathbf{1 0 0 . 0 0}$ & 100.034 \\
\cline { 2 - 3 } $\mathrm{Gd}(\mathrm{NO} 3) 3 * 6 \mathrm{H} 2 \mathrm{O}$ & $\mathbf{7 . 5 2 0 0}$ & 7.5346 \\
\cline { 2 - 3 } Initial Sample & 0.00 & \\
\cline { 2 - 3 } & &
\end{tabular}

pH 10 Buffer

10.02

$\mathrm{pH} 7$ check 7.13

$\mathrm{pH} 10$ Buffer 10.31 
SRAT Cycle Parameters

SRAT Air purge (slm)

Nafion Dryer pure (slm)

SRAT He purge (sccm)

4.64

Run \#

SB6-28

Initial sludge $\mathrm{pH}$

SRAT Start Time

$6: 39$ (power to mantle)

Initial Antifoam Addition

200 ppm antifoam target, g initial

100 ppm antifoam target, g emergency Additional antifoam needed $(\mathrm{g})$

Nitric Acid Addition

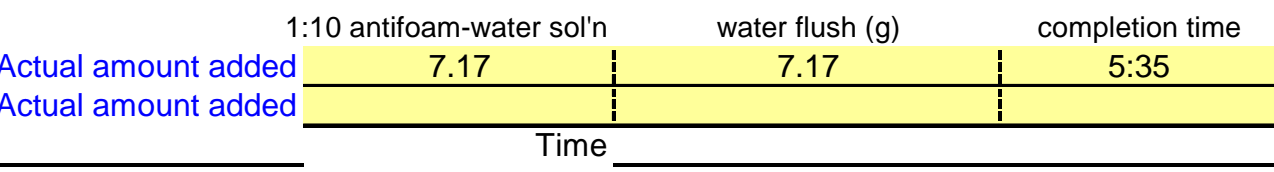

Time Acid Molarity (M) $10.40 \quad$ Tray head initial weight \begin{tabular}{ll} 
Acid addition rate $(\mathrm{ml} / \mathrm{min})$ & $\mathbf{1 . 0 8 4}$ \\
\hline
\end{tabular} Nitric Acid Start Time $\quad 7: 43$

Acid Flush Water (g)

\begin{tabular}{|c|c|c|}
\hline Acid Flush Water (g) & 0.00 & \\
\hline Antifoam before Formic Acid & & actual $(g)$ \\
\hline 100 ppm antifoam target, g & 3.58 & before formic \\
\hline
\end{tabular}
Tray head final weight $(\mathrm{g})$
Nitric Acid Stop Time Nitric Acid Stop Time SRAT $\mathrm{pH}$

Acid volume $(\mathrm{ml})$ 1260.9 100 ppm antifoam target, $\mathrm{g} \quad 3.58$ 1:10 antifoam-water sol'n

Acid mass (g)

55.665 Formic Acid Addition

Acid Molarity (M) $23.60 \quad$ Tray head initial weight Actual amount added 3.58 .54

72.915
Acid addition rate $(\mathrm{ml} / \mathrm{min}) \quad \mathbf{1 . 0 7 5}$ Formic Acid Start Time Acid Flush Water $(g) \quad 0.00$ $8: 53$ Tray head initial weight $(\mathrm{g})$ Tray head final weic water flush (g) 3.58 antifoam time

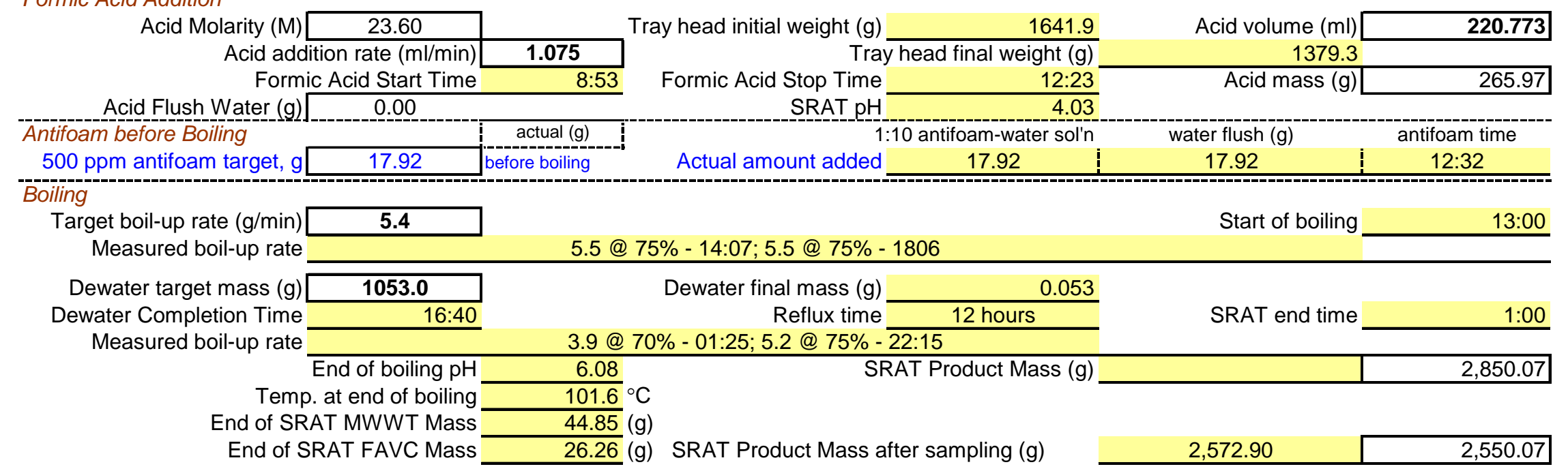




\section{APPENDIX C: RUN PARAMETERS FOR SRAT RUN \#SB6-29}

\section{L CPC Run Parameters SB6-E Qualification Support Run SB6-29}

Equipment Set-up and Sludge Batching

Initial MWWT Mass $(\mathrm{g})$

$$
\text { GC File Name }
$$

GC Start Time

43.26

Leak Checks

Pre-Leak Check

Flow Input

$90.0 \mathrm{sccm}$

Sludge and Trim Chemical Target Addition Masses

\begin{tabular}{r|cr} 
& Target $(\mathrm{g})$ & \multicolumn{1}{c}{ Actual $(\mathrm{g})$} \\
\cline { 2 - 2 } Sludge Simulant & $\mathbf{3 , 5 0 0 . 0 0}$ & 3500.00 \\
\cline { 2 - 2 } $\mathrm{AgNO}_{3}$ & $\mathbf{0 . 1 1 7 8}$ & 0.1178 \\
\cline { 2 - 3 } $\mathrm{HgO}$ (yellow) & $\mathbf{1 0 . 4 0 3 7}$ & 10.4037 \\
\cline { 2 - 3 } $\mathrm{Pd}\left(\mathrm{NO}_{3}\right)_{2}{ }^{*} \mathrm{H}_{2} \mathrm{O} \mathrm{sol'n}$ & $\mathbf{0 . 2 2 8 6}$ & 0.2286 \\
\cline { 2 - 3 } $\mathrm{CaCO}_{3}$ & $\mathbf{6 . 6 0 8 0}$ & 6.608 \\
& &
\end{tabular}

GC Pre-Calibration Gas

41544464

3.52

Flow Output $97.6 \mathrm{sccm}$

SB6E simulant

\begin{tabular}{r|c|r} 
& Target & \multicolumn{1}{c}{ Actual $(\mathrm{g})$} \\
\cline { 3 - 3 } $\mathrm{Rh}\left(\mathrm{NO}_{3}\right)_{3}{ }^{*} \mathrm{H}_{2} \mathrm{O}$ sol'n & $\mathbf{2 . 4 2 3 6}$ & 2.4236 \\
\cline { 3 - 3 } $\mathrm{RuCl}$ & $\mathbf{1 . 4 1 5 2}$ & 1.4152 \\
\cline { 2 - 3 } Flush Water & $\mathbf{1 0 0 . 0 0}$ & 100.0 \\
\cline { 2 - 3 } $\mathrm{Gd}(\mathrm{NO} 3) 3 * 6 \mathrm{H} 2 \mathrm{O}$ & $\mathbf{3 . 7 6 0 0}$ & 3.7600 \\
\cline { 2 - 3 } Initial Sample & 0.00 & \\
\cline { 2 - 3 } & &
\end{tabular}

pH Probe Calibration/Checks prior to acid addition and after run Pre-Run Probe Calibration

$$
\mathrm{pH} 4 \text { Buffer } \quad 4.00
$$

Post-Run Probe Check

$\mathrm{pH} 4$ Buffer

3.98

pH 10 Buffer

10.00

pH 10 Buffe

9.91
pH 7 check 7.03

$\mathrm{pH} 7$ buffer 6.94 
SRAT Cycle Parameters

SRAT Air purge (slm)

Nafion Dryer pure (slm)

SRAT He purge (sccm)

4.64

Run \#

SB6-29

nitial sludge $\mathrm{pH}$

SRAT Start Time

7:03 (power to mantle)

Initial Antifoam Addition

\begin{tabular}{ll|l}
200 ppm antifoam target, g & 7.17 \\
100 ppm antial & emergency
\end{tabular}

Additional antifoam needed $(\mathrm{g})$

Nitric Acid Addition

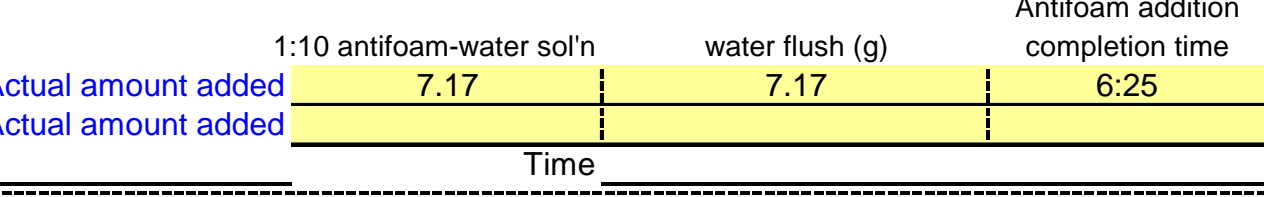

Acid Molarity (M) 10.40

Time

Tray head final weight

Acid volume $(\mathrm{ml}) \quad 166.995$ \begin{tabular}{ll} 
Acid addition rate $(\mathrm{ml} / \mathrm{min})$ & $\mathbf{1 . 0 8 4}$ \\
\hline
\end{tabular}

Acid Flush Water (g) Nitric Acid Start Time

Nitric Acid Stop Time SRAT $\mathrm{pH}$ 1446.2

\begin{tabular}{c} 
Acid Flush Water $(\mathrm{g})$ \\
\cline { 1 - 2 }
\end{tabular}
Formic Acid Addition

Acid Molarity (M) $23.60 \quad$ Tray head initial weight $(\mathrm{g})$

Tray head final weigh

Acid volume $(\mathrm{ml})$

171.712 Acid addition rate $(\mathrm{ml} / \mathrm{min})$ Formic Acid Start Time Acid Flush Water $(g)$ 10:55 Formic Acid Stop Time SRAT $\mathrm{pH}$

Antifoam before Boiling \begin{tabular}{lll} 
& & \\
\hline & & actual (g) \\
\hdashline 00 ppm antifoam target, $g$ & 17.92 & before boling
\end{tabular} Acid mass (g) 206.86 Boiling

Target boil-up rate $(\mathrm{g} / \mathrm{min})$ Measured boil-up rate 5.4 ctual amount added $1: 10$ antifoam-water sol'n water flush (g) 17.92 17.92

Start of boiling $13: 48$ $5.4 @ 80 \%-1445 ; 5.5 @ 80 \%$ - 1538; $5.7 @ 80 \%$ - 1628

Dewater target mass $(\mathrm{g}) \quad \mathbf{1 0 0 0 . 7}$ Dewater Completion Time Measured boil-up rate

$17: 00$

ewater final mass $(\mathrm{g})$

Reflux time

$5.2 @ 78 \%$ End of boiling $\mathrm{pH}$ Temp. at end of boiling End of SRAT MWWT Mass End of SRAT FAVC Mass 4.88 $101.9^{\circ} \mathrm{C}$ $47.0778(\mathrm{~g})$ 32.9672 (g) SRAT Product Mass after sampling (g) 1000.7 12 hours $-2430$ SRAT end time 14:02

\section{g)} N/A $3,005.09$ SRAT Product Mass (g)

$2,677.50$
$2,705.09$ 


\section{APPENDIX D: RUN PARAMETERS FOR SRAT RUN \#SB6-30}

\section{L CPC Run Parameters SB6-E Qualification Support Run SB6-30}

Equipment Set-up and Sludge Batching

Initial MWWT Mass $(\mathrm{g})$

GC File Name 47.12 GC Start Time

SB630$3: 52$

Leak Checks

Pre-Leak Check

$$
\text { Flow Input }
$$
$90.0 \mathrm{sccm}$

Sludge and Trim Chemical Target Addition Masses

\begin{tabular}{|c|c|c|}
\hline \multirow{3}{*}{$\begin{array}{r}\text { Sludge Simulant } \\
\qquad \mathrm{AgNO}_{3}\end{array}$} & Target (g) & \multirow{2}{*}{$\begin{array}{l}\text { Actual (g) } \\
3500\end{array}$} \\
\hline & $3,500.00$ & \\
\hline & 0.1178 & 0.1178 \\
\hline HgO (yellow) & 10.4037 & 10.4037 \\
\hline $\mathrm{Pd}\left(\mathrm{NO}_{3}\right)_{2}{ }^{*} \mathrm{H}_{2} \mathrm{O}$ sol'n & 0.2286 & 0.2286 \\
\hline $\mathrm{CaCO}_{3}$ & 6.6080 & 6.6080 \\
\hline
\end{tabular}

pH Probe Calibration/Checks prior to acid addition and after run Pre-Run Probe Calibration

$$
\text { pH } 4 \text { Buffer } \quad 4.00
$$

Post-Run Probe Check
$\mathrm{pH} 4$ Buffer 4.13

pH 10 Buffer 10.00

pH 10 Buffer 10.05
Target

\begin{tabular}{r|c|r} 
& Target & \multicolumn{1}{c}{ Actual (g) } \\
\cline { 2 - 3 } $\mathrm{Rh}\left(\mathrm{NO}_{3}\right)_{3}{ }^{*} 2 \mathrm{H}_{2} \mathrm{O} \mathrm{sol} n$ & $\mathbf{2 . 4 2 3 6}$ & 0.4236 \\
\cline { 2 - 3 } $\mathrm{RuCl}_{3}$ & $\mathbf{1 . 4 1 5 2}$ & 1.4152 \\
\cline { 2 - 3 } Flush Water & $\mathbf{1 0 0 . 0 0}$ & 100.0 \\
\cline { 2 - 3 } $\mathrm{Gd}(\mathrm{NO} 3) 3 * 6 \mathrm{H} 2 \mathrm{O}$ & $\mathbf{3 . 7 6 0 0}$ & 3.7600 \\
\cline { 2 - 3 } Initial Sample & 0.00 & \\
\cline { 2 - 3 } & &
\end{tabular}

SB6E simulant
41544464

\author{
$81.3 \mathrm{sccm}$
}


SRAT Cycle Parameters

SRAT Air purge (slm)

Nafion Dryer pure (slm)

SRAT He purge (sccm)

4.64

Run \#

SB6-30

Initial sludge $\mathrm{pH}$

SRAT Start Time

7:03 (power to mantle)

Initial Antifoam Addition

\begin{tabular}{ll|l}
200 ppm antifoam target, g & 7.17 \\
100 ppm antial & emergency
\end{tabular}

Additional antifoam needed (g)

Nitric Acid Addition

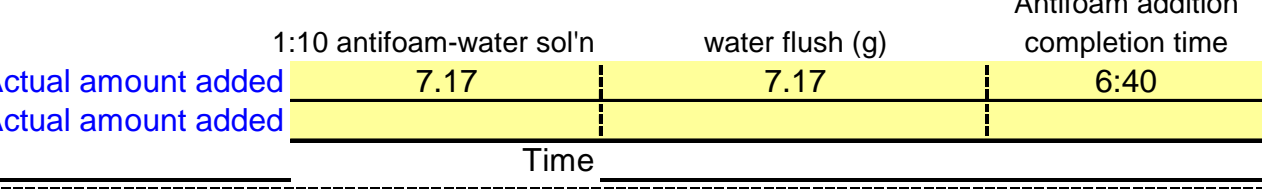

Acid Molarity (M) 10.40

Acid addition rate $(\mathrm{ml} / \mathrm{min}) \quad \mathbf{1 . 0 8 4}$ Nitric Acid Start Time

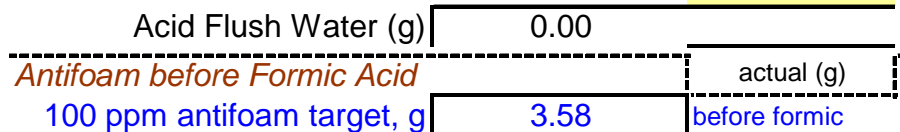

8:14

Tray head final weight $(\mathrm{g})$

$\begin{array}{rrr} & & 1593.4 \\ \text { Nitric Acid Stop Time } & 9: 07 & \text { Acid mass (g) }\end{array}$

666.7

Acid volume $(\mathrm{ml})$ 1593.4

55.665 SRAT $\mathrm { pH } \longdiv { 1 0 . 6 4 }$ 1:10 antifoam-water sol'n water flush (g)

72.915

100 ppm antifoam target, Formic Acid Addition

Acid Molarity (M) Acid addition rate $(\mathrm{ml} / \mathrm{min})$ Formic Acid Start Time Acid Flush Water (g) (g) 0.00

Antifoam before Boiling $\begin{array}{r}\text { actual }(\mathrm{g}) \\ \hline 17.92\end{array}$ Actual amount added 3.58 3.58 antifoam time

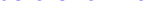
Tray head initial weight $(\mathrm{g})$ Acid volume (ml) 9:27 Boiling

Target boil-up rate $(\mathrm{g} / \mathrm{min})$ Measured boil-up rate 5.4

1.082 (9:26 Tray head final weight (g) Acid mass (g)

220.773

9:26
Formic Acid Stop Time SRAT $\mathrm{pH}$

$12: 54$ 1352.4 g) 265.97

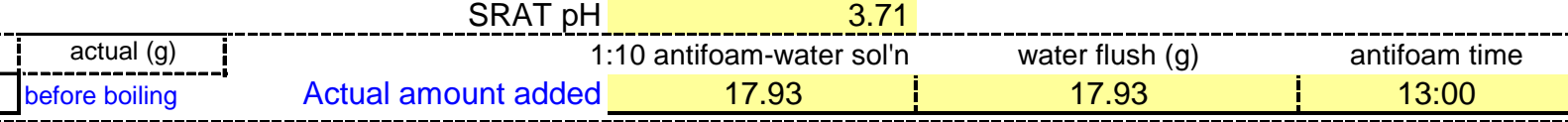

Start of boiling 13:23

Dewater target mass $(\mathrm{g}) \quad \mathbf{1 0 5 3 . 0}$ Dewater Completion Time Measured boil-up rate $16: 46$ End of boiling $\mathrm{pH}$ Temp. at end of boiling End of SRAT MWWT Mass End of SRAT FAVC Mass $5.42 @ 82 \%$ - 1440; $5.5 @ 82 \%$ - 1510; $5.6 @ 82 \%$ - 1709; $5.7 @ 82 \%$ - 2040

Reflux time 12 hours $\quad$ SRAT end time $1: 23$ Dewater final mass $(\mathrm{g}) \quad 1054.1$ Reflux time $2,850.07$ $100.5^{\circ}$ SRAT Product Mass (g) N/A

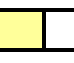




\section{APPENDIX E: RUN PARAMETERS FOR SRAT RUN \#GF-13}

\section{L CPC Run Parameters SB6-H flowsheet development Run GF-13}

Equipment Set-up and Sludge Batching

Initial MWWT Mass $(\mathrm{g})$ GC File Name GC Start Time 44.8 8:05

Leak Checks

Pre-Leak Check

$$
\text { Flow Input }
$$
$90.0 \mathrm{sccm}$

Sludge and Trim Chemical Target Addition Masses

\begin{tabular}{r|c|r} 
& Target & Actual $(\mathrm{g})$ \\
\cline { 2 - 2 } Sludge Simulant & $\mathbf{2 , 8 5 0 . 0 0}$ & $\mathbf{2 8 5 0 . 0 0}$ \\
\cline { 2 - 2 } AgNO3 & $\mathbf{0 . 1 0 7 7}$ & 0.1125 \\
\cline { 2 - 2 } HgO & $\mathbf{8 . 4 3 6 4}$ & 8.4350 \\
\cline { 2 - 2 } Pd(NO3)2 solution & $\mathbf{0 . 6 3 9 6}$ & 0.6402 \\
\cline { 2 - 2 } RuCl3 & $\mathbf{2 . 5 3 8 7}$ & 2.5399
\end{tabular}

pH Probe Calibration/Checks prior to acid addition and after run Pre-Run Probe Calibration

$$
\mathrm{pH} 4 \text { Buffer }
$$

Post-Run Probe Check

$$
\mathrm{pH} 4 \text { Buffer }
$$

GC Pre-Calibration Gas

41544464

Flow Output $84.2 \mathrm{sccm}$

\begin{tabular}{r|c|} 
& Target \\
\cline { 2 - 2 } Rh(NO3)3 solution & $\mathbf{3 . 7 6 4 0}$ \\
\cline { 2 - 2 } $\mathrm{BaO}$ & $\mathbf{0 . 5 3 2 7}$ \\
\cline { 2 - 2 } $\mathrm{Cd} 2 \mathrm{O} 3$ & $\mathbf{0 . 4 1 9 2}$ \\
\cline { 2 - 2 } & $\mathbf{0 . 6 0 6 1}$ \\
\cline { 2 - 2 } Gd(NO3)3*6H 20 & $\mathbf{7 . 5 0 0 0}$ \\
\hline
\end{tabular}
Actual (g) 3.7632

0.5331

0.4185

0.6070

flush water

pH 10 Buffer 10.00

pH 7 check 7.12

pH 10 Buffer 9.91 
SRAT Cycle Parameters

SRAT Air purge (sIm)

Initial sludge $\mathrm{pH}$

0.768

13.23

Initial Antifoam Addition

200 ppm antifoam target,

100 ppm antifoam target, g Additional antifoam needed $(\mathrm{g})$

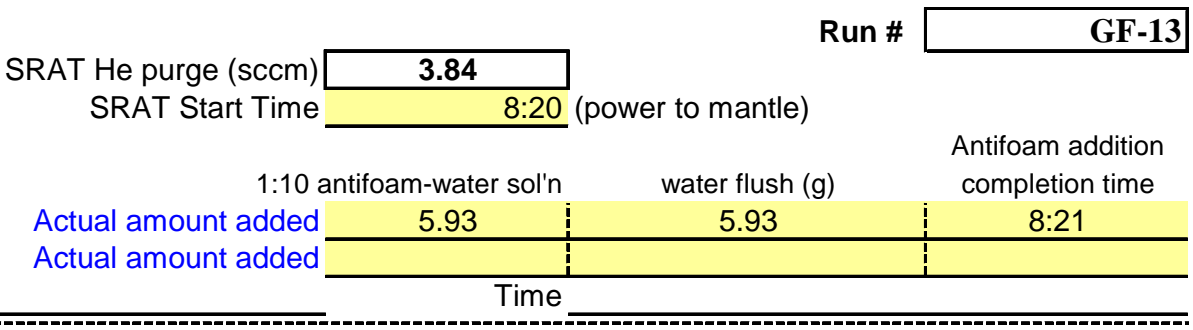

Nitric Acid Addition Acid Molarity $(\mathrm{M})$

\begin{tabular}{rc|} 
Acid addition rate $(\mathrm{ml} / \mathrm{min})$ & $\mathbf{0 . 9 0}$ \\
\hline Nitric Acid Start Time & $9: 31$ \\
\hline
\end{tabular}

Acid Flush Water $(\mathrm{g}) \quad 0.00$ itric Acid Start Time

Tray head initial weight $(\mathrm{g})$

Tray head final weight (g)

Acid volume $(\mathrm{ml})$

174.689 Nitric Acid Stop Time SRAT pH

\begin{tabular}{|c|c|c|c|c|c|c|}
\hline Antifoam before Formic/Glyco & & actual (g) & $1: 10 \mathrm{a}$ & 1-wate & water flush ( $g$ & antifoam time \\
\hline 100 ppm antifoam target, g & 2.97 & between acid & Actual amount added & 2.97 & & 12.57 \\
\hline
\end{tabular}
Formic/Glycolic Ac-od Addition Acid Molarity (M) $\mathrm{n} / \mathrm{a}$

Tray head initial weight $(\mathrm{g})$

Acid volume (ml)

144.287

$\begin{array}{ll}\text { Acid addition rate }(\mathrm{ml} / \mathrm{min}) & \mathbf{0 . 8 9}\end{array}$

Formic/Glycolic Acid Start Time 13:15

Acid Flush Water (g)

0.00 Acid Stop Time 1494.6

Antifoam before Boiling

500 ppm antifoam target, g 14.83

$$
\text { Acid mass (g) }
$$

$-\cdots$ 1:10 antifoam-water sol Boiling

Target boil-up rate $(\mathrm{g} / \mathrm{min})$ Measured boil-up rate

Dewater target mass (g) Dewater Completion Time Measured boil-up rate $\frac{\text { End of boiling } \mathrm{pH}}{\text { Temp. at end of boiling }}$

$\begin{array}{r}4.5 \\ \hline 966.6 \\ 20 \\ \hline\end{array}$
Actual amount added 14.83 water flush (g) 14.83 $16: 13$

Actual amount added $\quad 14.83 \quad$\begin{tabular}{c|c|c} 
antifoam \\
\hline
\end{tabular}

----.

Start of boiling $16: 30$ Temp. at end of boiling End of SRAT MWWT Mass End of SRAT FAVC Mass Reflux Time, hrs 12hrs 0min 977.7 Dewater final mass $(\mathrm{g})$ Reflux time SRAT end time $4: 30$ SRAT Product Mass (g) $2,411.35$ $2,550.19$ 3.97 $100.7^{\circ} \mathrm{C}$ $\frac{100.7}{47.978(\mathrm{~g})}$ 21.246 (g) SRAT Product Mass after sampling (g) $2,058.40$ $2,400.19$

GC Finish Time GC Post Calibration Gas

Post-Leak Check

Flow Input $90.0 \mathrm{sccm}$

Flow Output $82.6 \mathrm{sccm}$ 


\section{APPENDIX F: RUN PARAMETERS FOR SRAT RUN \#GF-14}

\section{L CPC Run Parameters SB6-H flowsheet development Run GF-14}

Equipment Set-up and Sludge Batching

Initial MWWT Mass $(\mathrm{g})$ GC File Name GC Start Time 47.8 GFS14-

Leak Checks

Pre-Leak Check

$$
\text { Flow Input }
$$
$90.0 \mathrm{sccm}$

Sludge and Trim Chemical Target Addition Masses

\begin{tabular}{r|c|r} 
& Target & Actual $(\mathrm{g})$ \\
\cline { 2 - 2 } Sludge Simulant & $\mathbf{2 , 8 5 0 . 0 0}$ & $\mathbf{2 8 5 0 . 0 0}$ \\
\cline { 2 - 2 } AgNO3 & $\mathbf{0 . 1 0 7 7}$ & 0.1078 \\
\cline { 2 - 2 } HgO & $\mathbf{8 . 4 3 6 4}$ & 8.4391 \\
\cline { 2 - 2 } Pd(NO3)2 solution & $\mathbf{0 . 6 3 9 6}$ & 0.6406 \\
\cline { 2 - 2 } RuCl3 & $\mathbf{2 . 5 3 8 7}$ & 2.5392
\end{tabular}

pH Probe Calibration/Checks prior to acid addition and after run Pre-Run Probe Calibration

$$
\mathrm{pH} 4 \text { Buffer }
$$

Post-Run Probe Check

$$
\text { pH } 4 \text { Buffer }
$$

GC Pre-Calibration Gas

41544464

Flow Output $99.4 \mathrm{sccm}$

\begin{tabular}{r|c|} 
& Target \\
\cline { 2 - 2 } Rh(NO3)3 solution & $\mathbf{3 . 7 6 4 0}$ \\
\cline { 2 - 2 } $\mathrm{BaO}$ & $\mathbf{0 . 5 3 2 7}$ \\
\cline { 2 - 2 } $\mathrm{C} 2 \mathrm{O} 3$ & $\mathbf{0 . 4 1 9 2}$ \\
\cline { 2 - 2 } & $\mathbf{0 . 6 0 6 1}$ \\
\cline { 2 - 2 } $\mathrm{Gd}(\mathrm{NO} 3) 3 * 6 \mathrm{H} 20$ & $\mathbf{7 . 5 0 0 0}$ \\
\cline { 2 - 2 }
\end{tabular}
Actual (g) 3.7636

0.5332

0.4192

0.6073

flush water

pH 10 Buffer 10.00

pH 7 check 7.01

pH 10 Buffer 9.9 
SRAT Cycle Parameters SRAT Air purge (sIm) Initial sludge $\mathrm{pH}$

0.768 13.02

Initial Antifoam Addition

200 ppm antifoam target,

100 ppm antifoam target, $\mathrm{g}$ Additional antifoam needed

Nitric Acid Addition Acid Molarity $(\mathrm{M})$ Acid addition rate $(\mathrm{ml} / \mathrm{min})$
Nitric Acid Start Time

Acid Flush Water (g)

0.90

0.00

$9: 40$

Antifoam before Formic/Glycolic Acid

100 ppm antifoam target,

2.97

actual (g)

SRAT He purge (sccm) SRAT Start Time

Run \#

GF-14

Formic/Glycolic Acid Addition Acid Molarity (M) $\mathrm{n} / \mathrm{a}$ between acid

9:08 (power to mantle)

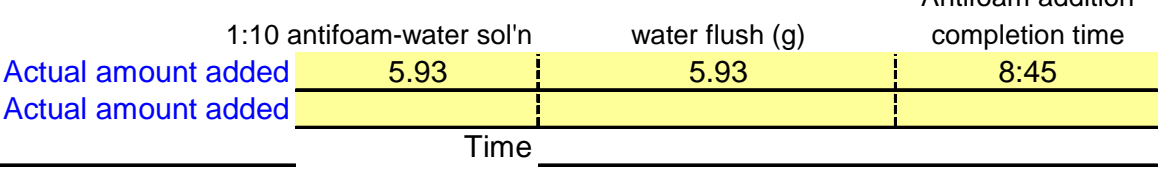

Time

ray head initial weight $(\mathrm{g})$

Tray head final weight $(\mathrm{g})$

Acid volume (ml)

146.198 Nitric Acid Stop Time Acid mass (g) 191.502

\begin{tabular}{|c|c|c|c|c|c|c|}
\hline Acid Molarity (M) & $\mathrm{n} / \mathrm{a}$ & & Tray head initial weight (g) & 1656.2 & Acid volume $(\mathrm{ml})$ & 167.076 \\
\hline Acid addi & lition rate $(\mathrm{ml} / \mathrm{min})$ & 0.89 & Tray hea & final weight $(\mathrm{g})$ & 1447 & \\
\hline Formic/Glycolic & ic Acid Start Time & $13: 12$ & Acid Stop Time & $16: 24$ & Acid mass (g) & 209.96 \\
\hline Acid Flush Water $(\mathrm{g})$ & 0.00 & & SRAT pH & 4.03 & & \\
\hline Antifoam before Boiling & & actual $(g)$ & $1: 10 \mathrm{a}$ & ifoam-water sol'n & water flush (g) & antifoam time \\
\hline $500 \mathrm{ppm}$ antifoam target, g & 14.83 & before boiling & Actual amount added & 14.83 & 14.83 & $16: 30$ \\
\hline Boiling & & & & & & \\
\hline Target boil-up rate $(\mathrm{g} / \mathrm{min})$ & 4.5 & & Reflux Time, hrs & $12 \mathrm{hrs} 0 \mathrm{~min}$ & Start of boiling & 17:00 \\
\hline Measured boil-up rate & & & & & & \\
\hline Dewater target mass $(\mathrm{g})$ & 957.3 & & Dewater final mass $(\mathrm{g})$ & 908.2 & & \\
\hline Dewater Completion Time & $20: 27$ & & Reflux time & & SRAT end time & 5:00 \\
\hline Measured boil-up & & & & & & \\
\hline & End of boiling $\mathrm{pH}$ & 4.8 & SRAT & roduct Mass (g) & $2,434.70$ & $2,546.54$ \\
\hline Temp & . at end of boiling & 102.0 & ${ }^{\circ} \mathrm{C}$ & & & \\
\hline End of SR & AT MWWT Mass & 56.9691 & & & & \\
\hline End of $\mathrm{S}$ & RAT FAVC Mass & 24.2678 & SRAT Product Mass af & r sampling (g) & $2,031.40$ & $2,396.54$ \\
\hline
\end{tabular}

GC Finish Time $7: 12$

GC Post Calibration Gas

Post-Leak Check

Flow Input $90.0 \mathrm{sccm}$

Flow Output $90.1 \mathrm{sccm}$ 


\section{Distribution:}

B. N. Attaway, 773-A

C. J. Bannochie, 773-42A

A. B. Barnes, 999-W

M. H. Barnett, 766-H

M. H. Beasley, 773-A

D. R. Best, 999-W

P. L. Bovan, 704-27S

J. M. Bricker, 704-27S

T. O. Burckhalter, 999-1W

P. U. Burkhalter, 773-A

M. C. Chandler, 703-H

M. C. Clark, 704-27S

D. R. Click, 773-A

D. A. Crowley, 773-43A

J. W. DuVall, 999-1W

H. H. Elder, 704-24S

A. P. Fellinger, 773-41A

T. L. Fellinger, 704-26S

A. I. Fernandez, 999-W

S. D. Fink, 773-A

B. J. Giddings, 786-5A

K. D. Gilbreath, 766-H

J. M. Gillam, 766-H

B. A. Hamm, 766-H

E. K. Hansen, 999-W

C. C. Herman, 999-W

E. W. Holtzscheiter, 704-15S

J. F. Iaukea, 704-30S

P. R. Jackson, 703-46A

L. C. Johnson, 773-A

M. A. Jones, 773-A
D. P. Lambert, 999-W

M. T. Keefer, 766-H

D. C. Koopman, 999-W

S. L. Marra, 773-A

J. B. McCord, 766-H

J. E. Occhipinti, 704-S

J. M. Pareizs, 773-A

D. K. Peeler, 999-W

F. M. Pennebaker, 773-42A

S. G. Phillips, 704-15S

B. R. Pickenheim, 704-28S

H. M. Pittman, 704-27S

J. W. Ray, 704-S

S. H. Reboul, 773-A

J. M. Ridley, 704-S

T. A. Reilly, CCC-3

W. T. Riley, 999-W

A. R. Shafer, 704-27S

H. B. Shah, 766-H

D. C. Sherburne, 704-S

P. T. Simmons, 999-1W

A. V. Staub, 704-27S

M. E. Stone, 999-W

D. J. Wheeler, 773-A

V. J. Williams, 999-1W

B. J. Wiedenman, 773-A

A. W. Wiggins, $704-60 \mathrm{H}$

W. R. Wilmarth, 773-A

R. J. Workman, 999-1W

G. L. Smith, DOE/HQ-EM

J. D. Vienna, PNNL 